\title{
10. Anatomical adaptations to temporarily changed environmental conditions
}

Two principal capacities characterize seed plants. Primarily, cell formation pathways determine the basic structure of plant bodies, and the formation of different cell types. This is shown in the following figure.
Node (1) determines the formation of fusiform mother cells, vessels and axial parenchyma mother cells.

Node (2) determines the formation of fibers, tracheids and vessels. Node (3) determines the formation of parenchyma cells or vessels. Node (4) guides living parenchyma cells in various directions.

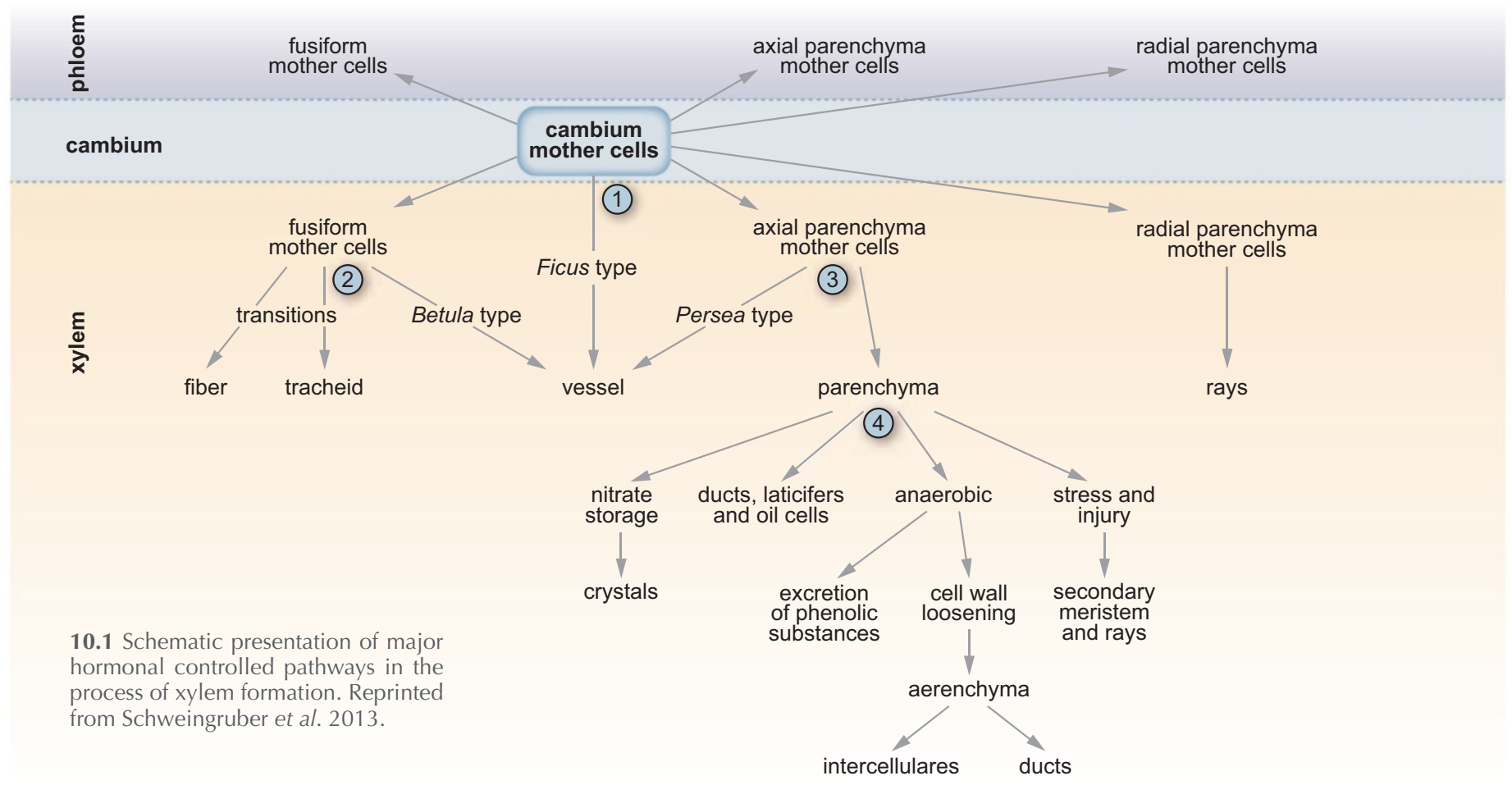

Secondarily, the cambium and cells are able to react to shortterm environmental changes with a reduction or an enhancement of their activity. This is described in detail in Larson 1994, Timell 1986, Schweingruber 2007 and Fromm 2013. In the following chapter the anatomical reactions to various environmental influences are demonstrated in a condensed form.

Two basic processes determine temporal anatomical reactions in all growth forms-from herbs over shrubs to trees-in all climatic zones and sites:

- Xylem mother cells in the cambial zone produce different amounts of fibers, vessels and axial and radial (ray) parenchyma. The consequence of intensive stress is structural change.

- Cambial cells and living parenchyma cells react to minor environmental influences with cell-wall expansion, secondary-cell-wall formation and lignification, and to intensive stress with the formation of callus tissue or ducts, and the excretion of various substances.

Short-term environmental conditions determine the anatomy of the xylem. However, the structures greatly vary because modifications occur based on genetic, taxon-specific information, and based on the location of the environmental impact (tropism). Cambial and cellular reactions are mostly combined. Reactions to the impact occur immediately or with a time lag. Anatomical reactions are mostly not unique to specific environmental influences.

In the following pages, the full range of variability has to be limited to showing a few examples for conifers and deciduous trees. 


\subsection{Anatomical effect of short-term environmental changes during the vegetation period}

\subsubsection{Individual small and large annual rings and missing rings}

"Large" and "small" are relative terms, and are always related to the mean values of width within a ring sequence. Extremely small or large rings express cambial reactions to short-term events in the leaf or root area of plants. A few extremely small rings can be the consequence of extreme droughts, cold days, short vegetation periods, or crown damage by insects. These are negative pointer years.
If environmental conditions are too extreme, annual rings can be missing completely; cambial and cellular activities are interrupted for at least one vegetation period. Missing rings can only be detected by cross-dating with other samples.

In contrast, above-average precipitation or warm days can lead to the formation of a few extremely large rings. These are positive pointer years.
Negative pointer years

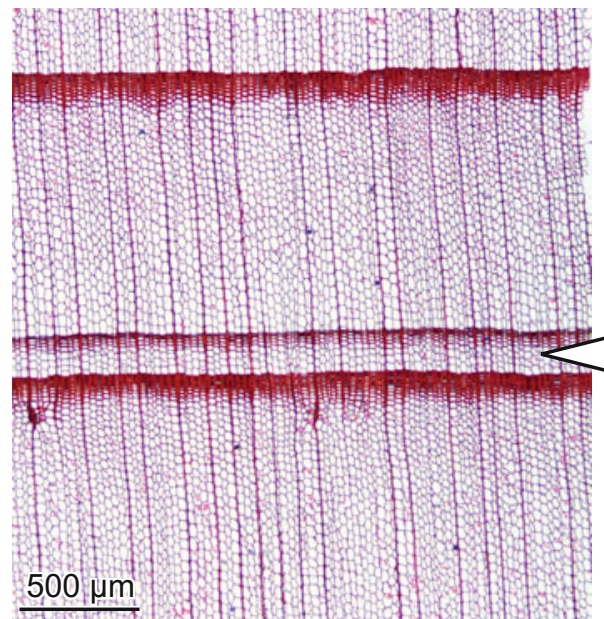

10.2 Extremely small ring with very few earlywood tracheids in the conifer Metasequoia glyptostroboides. A severe summer drought reduced the cambial activity mainly at the beginning of the growing season.

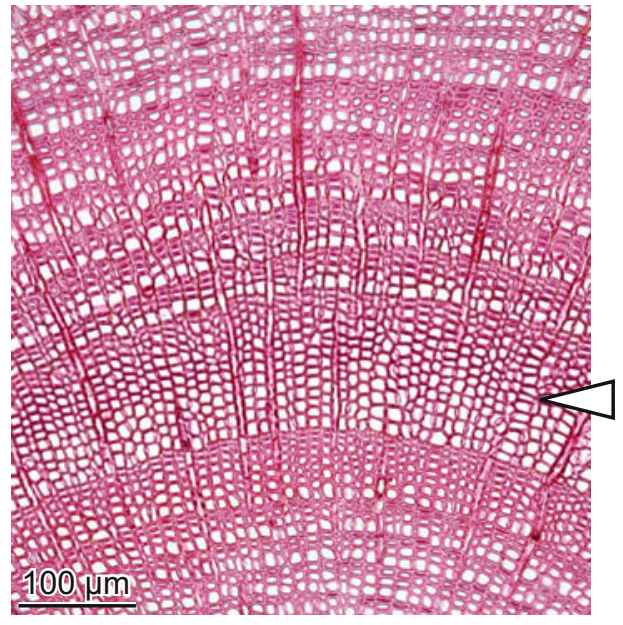

10.5 Extremely large ring in the conifer Larix dahurica. An unusually rainy and warm period probably induced accelerated growth at the northern timberline in eastern Siberia.

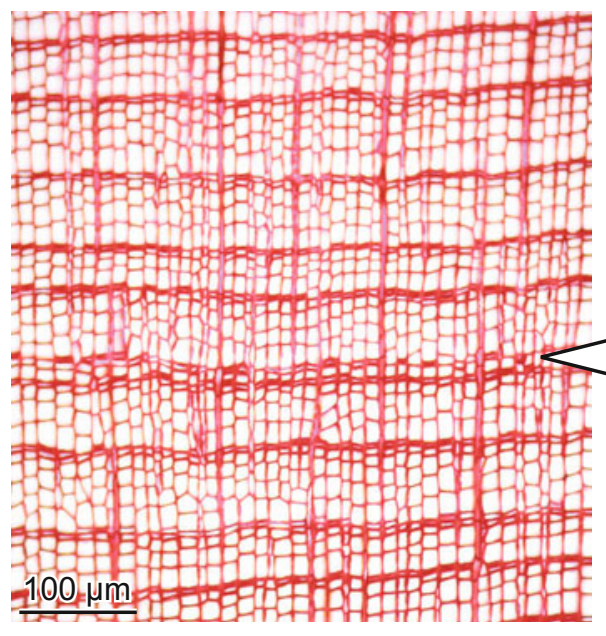

10.3 Extremely small ring with one earlywood tracheid in the conifer Juniperus communis. A very short and cold vegetation period in the subarctic environment reduced the cambial activity at the beginning of the growing season.

\section{Positive pointer years}

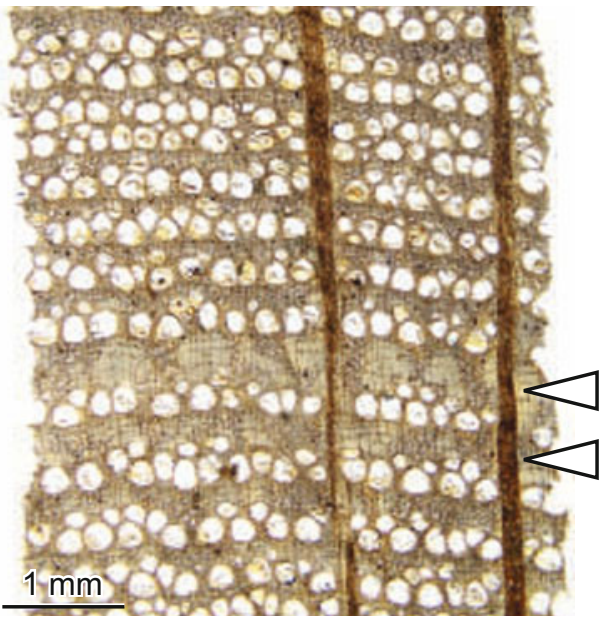

10.6 Two rings with large latewood zones in a sequence of smaller rings in a subfossil Quercus sp. from a bog with usually high water table in northern Germany. Larger rings may be the result of a larger aerobic root zone in drier years.

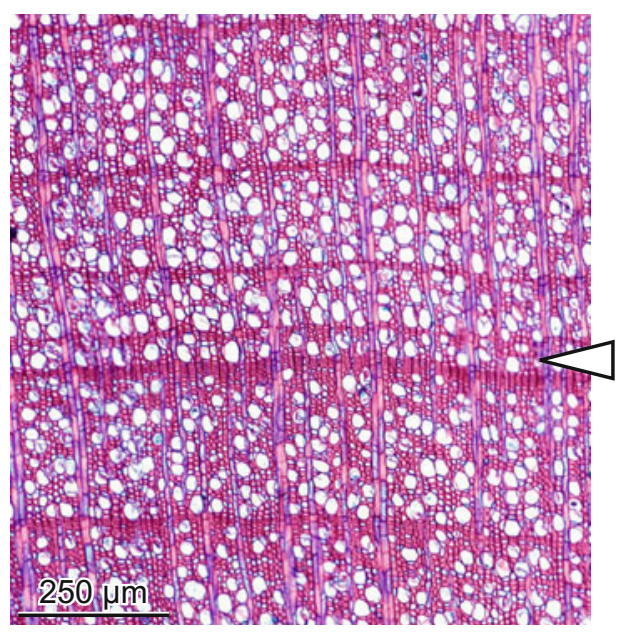

10.4 Extremely small ring in the deciduous tree Pyrus pyraster. The reason for this growth reduction is unknown.

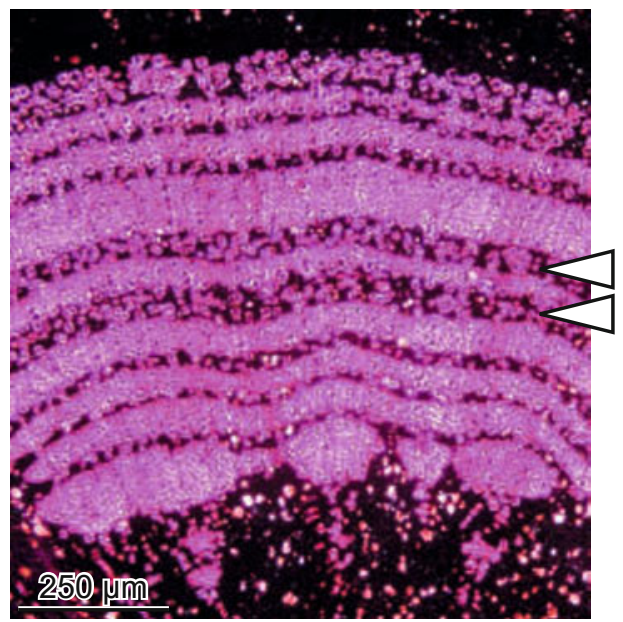

10.7 Two rings with large earlywood zones in the root collar of the herb Silene vulgaris in a meadow of the temperate zone, polarized light. 


\subsubsection{Discontinuous growth - Wedging rings}

The presence of wedging rings is an indication of a principal plant physiological law. Each cambial cell and each living differentiated cell reacts autonomously to external mechanical stresses. This capacity permits an optimal reaction to internal and external influencing factors and consequently, the physiological optimization of plants (Schweingruber 2007).
Wedging rings in increment cores or discs only provide a limited insight into the actual presence of rings within the whole plant. Nogler 1981 demonstrated that wedging or missing rings are only locally missing in stems. Ring wedging occurs in all growth forms and taxonomic units with secondary growth. Individual or several rings wedge out in short or long periods of suffering from stress, after position changes, or just in relation to the formation of fluted stems.

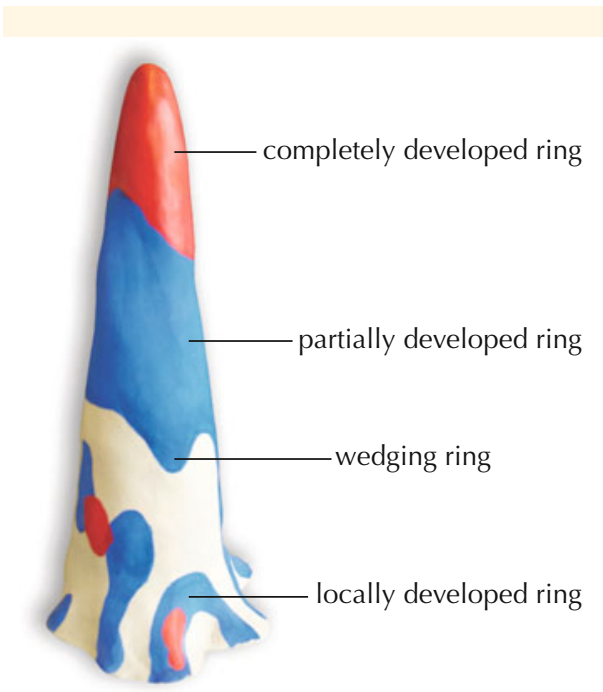

10.8 Schematic diagram of a locally absent, wedging or missing annual ring. Model: Nogler 1981.

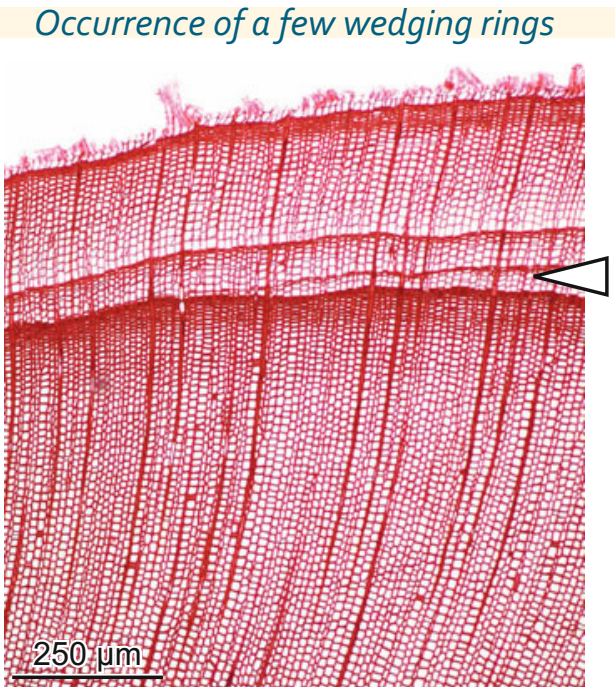

10.9 Individual wedging ring in the conifer Juniperus nana.

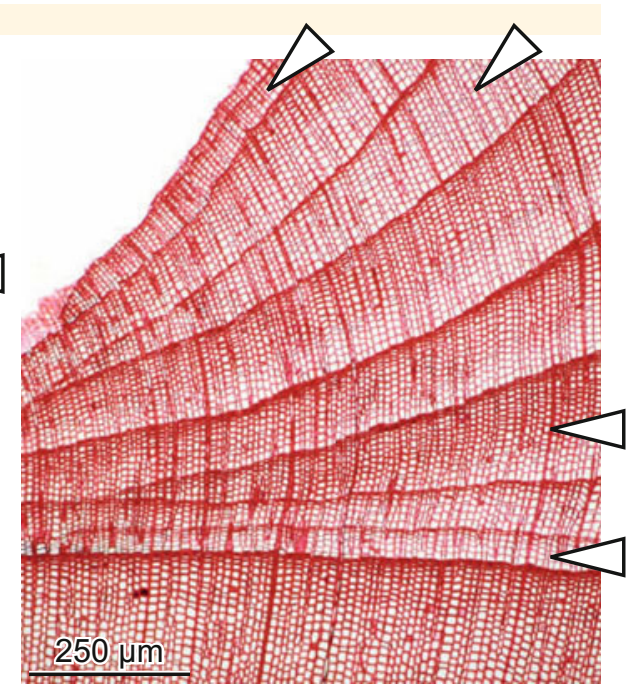

10.10 Many wedging rings in a zone of fluting of the stem of the conifer Juniperus nana.

\section{Occurrence of wedging ring zones}

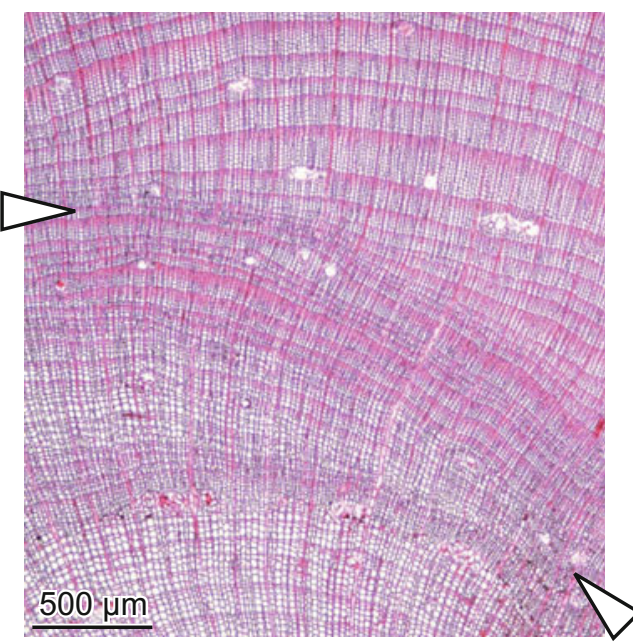

10.11 Wedging areas in a branch of Pinus mugo which changed its position after rock fall events.

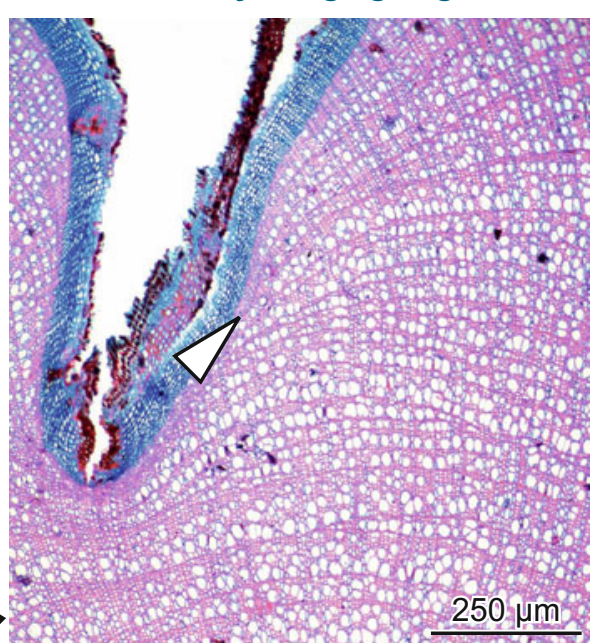

10.12 Wedging rings in a zone of fluting of the dwarf shrub Empetrum nigrum.

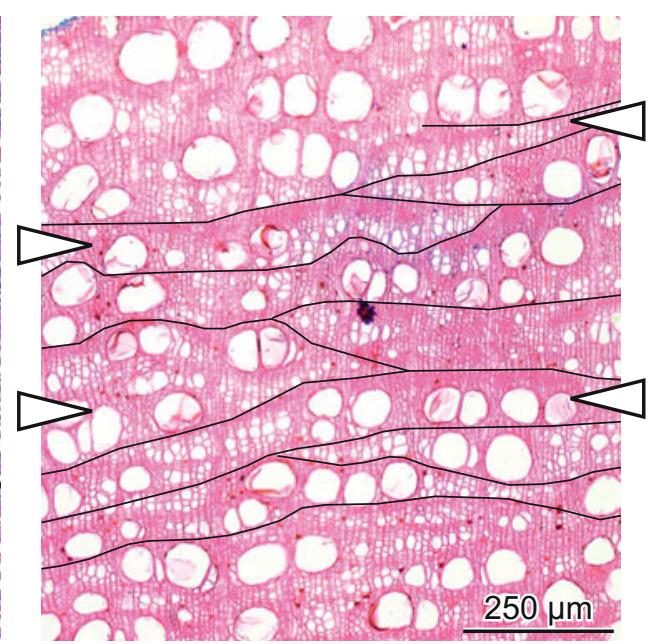

10.13 Multiple wedging rings in the ring-porous wood of Ulmus glabra after intensive browsing. 


\subsubsection{Individual small and large latewood zones and latewood zones with thin- or thick-walled tracheids}

Noticeable latewood zones in conifers are related to reduced or enhanced cambial activity or cell-wall formation activity of living tracheids. If the cell walls remain small they are called light years (low density; Kaennel \& Schweingruber 1995). Reduced cell wall growth is a result of low temperatures, insufficient water supply in the late summer or a lack of photosynthetic products after crown or root damages. Reduced cambial and cell activity often occurs together.

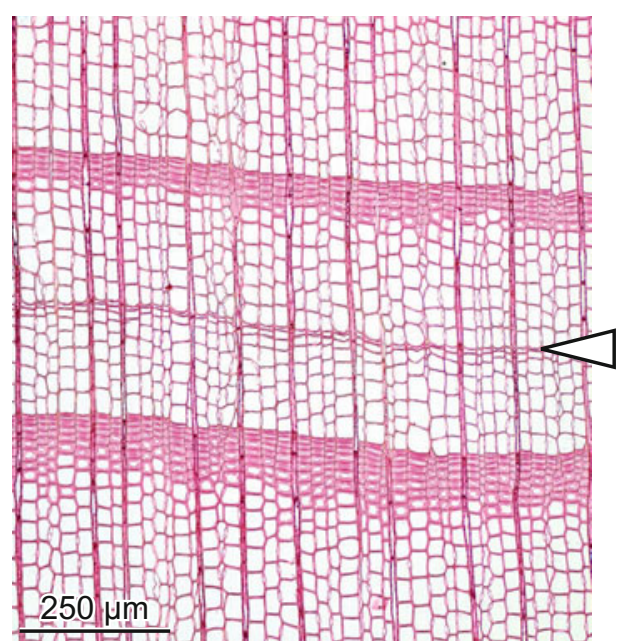

10.14 Individual ring with small latewood consisting of thin-walled tracheids in Larix decidua.

\section{Extremely light or dense latewood zones}

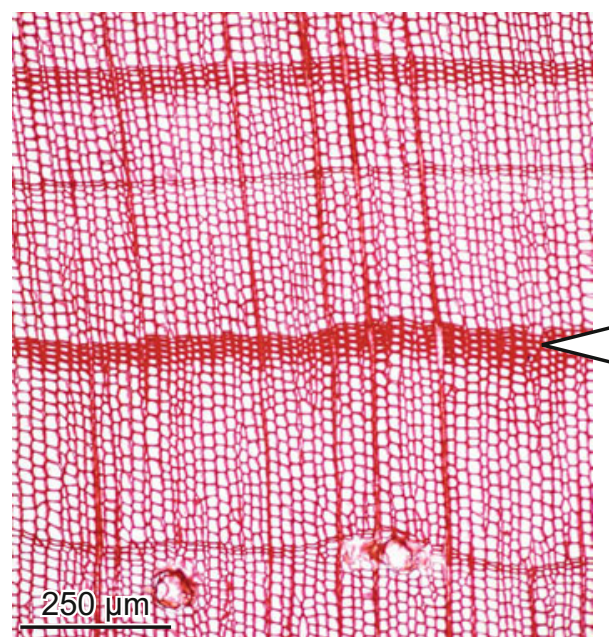

10.15 Individual ring with large latewood consisting of thick-walled tracheids in Pinus sylvestris.

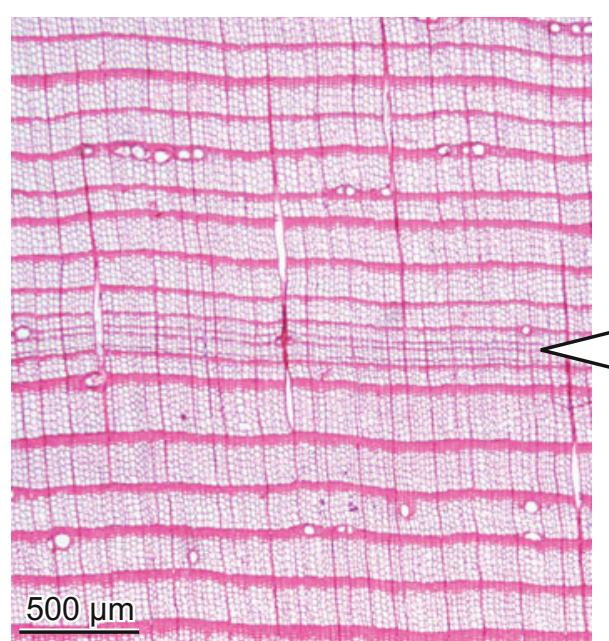

10.16 Sequence of small rings with small latewood zones consisting of thin-walled tracheids in Larix decidua.

\subsubsection{Individual, not fully lignified latewood zones ("blue rings")}

Lignification is the last step in the process of cell formation. If this process is interrupted, and the cells are not fully lignified, they appear blue in slides stained with Astrablue/Safranin.
These so-called "blue rings" were found exclusively in conifers of the northern high latitudes. It is believed that low temperatures in fall induce this feature. See Piermattei et al. 2015.

\section{Blue rings in conifers}

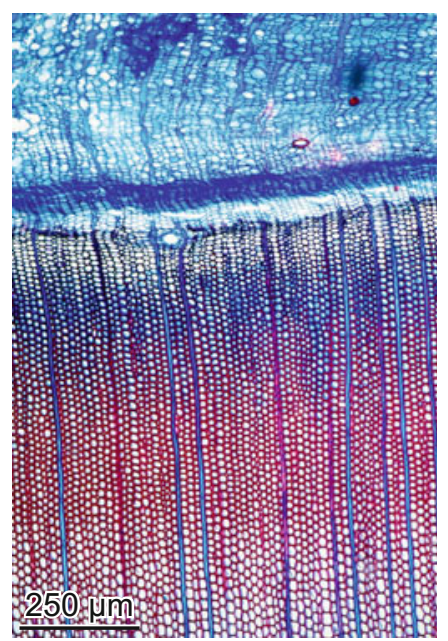

10.17 Latewood in a ring of Larix decidua growing at the treeline. The last section of the latewood tracheids is still in formation and the unlignified cells appear unstained or blue.

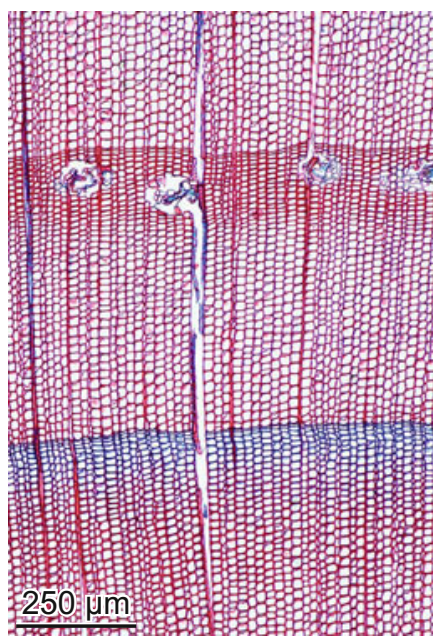

10.18 Unlignified latewood zone in Pinus sylvestris growing at the northern tree line.

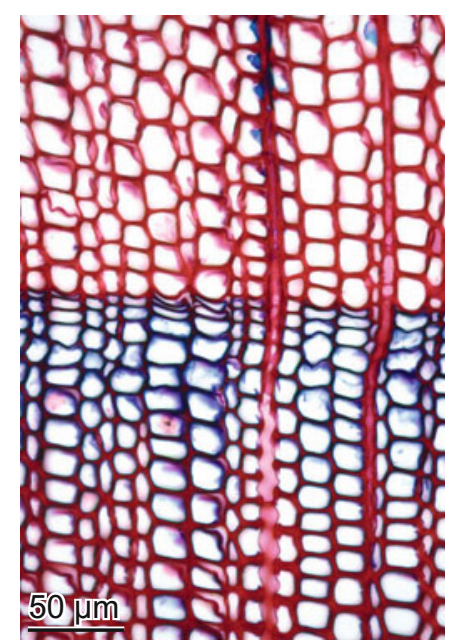

10.19 Completely formed latewood zone in Pinus sylvestris growing at the northern tree line. Primary walls are lignified (red), secondary walls are unlignified (blue).

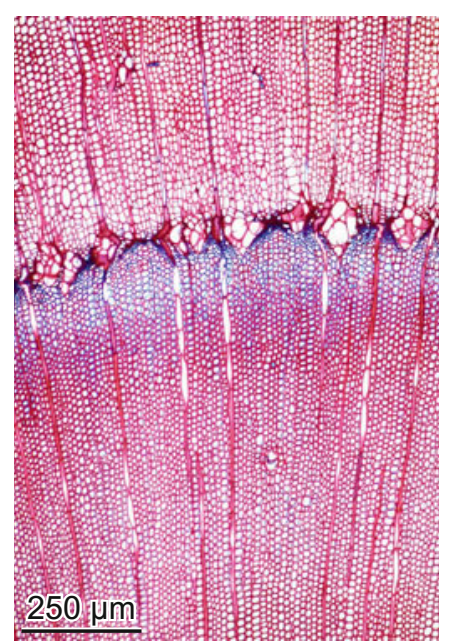

10.20 Frost ring and "blue ring" in the latewood of Larix decidua growing at the tree line. Extreme frost in early fall damaged the cambium cells and interrupted cell-wall formation. Callus tissue is formed and the secondary walls remain unlignified. 


\subsubsection{False rings and density variations}

False rings are normally formed rings with distinct latewood borders and cannot be anatomically distinguished from true annual rings. Their intra-annual occurrence can be identified only by cross-dating. The term density variation is based on $\mathrm{x}$-ray analysis of conifers and indicates intra-annual structural variations without distinct tangential borders. The difference between the two types is gradual.

False rings look like normal rings, containing a latewood zone with an abrupt transition from late- to earlywood. They occur mainly in Mediterranean and arid regions and are primarily triggered by short, intensive summer droughts.

Density variations of conifers are characterized by intra-annual tangential zones of thicker-walled and often smaller tracheids in relation to previous and following zones. They occur from the tropics to the temperate zone and are almost absent in boreal and arctic zones. Intra-annual density variations are triggered by short-term climatic events such as cold or dry periods during the growing season or slight damage to crown or roots. The susceptibility varies within the conifers. Cupressaceae are more, Pinaceae are less susceptible.

Intra-annual tangential structural changes of some deciduous plants are based on rhythmic formation of different cell types such as fibers/parenchyma, fibers/vessels or parenchyma/vessels. Theses changes generally occur in fast-growing stems of trees, shrubs and herbs from the tropics to the temperate zone. Such structural changes are triggered by genetic characteristics as well as short-term climatic events.
False rings

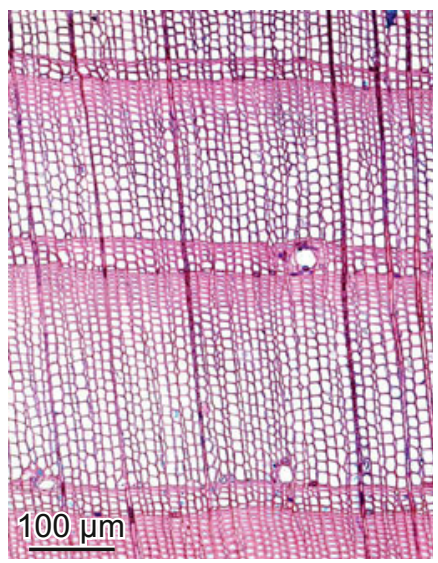

10.21 False rings in Pseudotsuga menziesii growing in Arizona, USA, an area with monsoon rains. There are two rings within a growing season, with the first ring interrupted from the second by a severe summer drought.

\section{Multiple density variations}

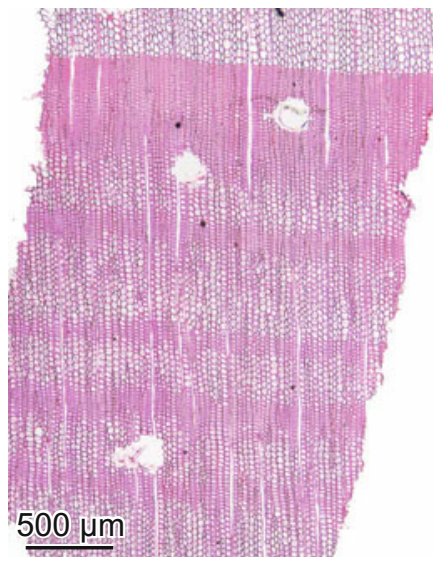

10.25 Multiple density variations in Pinus elliottii in tropical Tahiti.

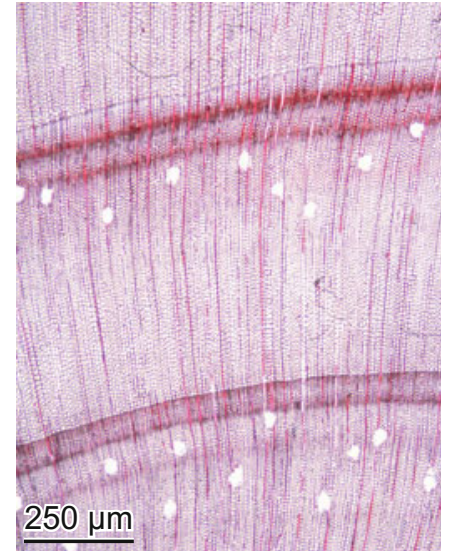

10.22 Large rings with two density variations in the latewood of Pinus sylvestris growing on shallow soil in Valais, Switzerland. Late summer drought triggered irregular latewood growth.

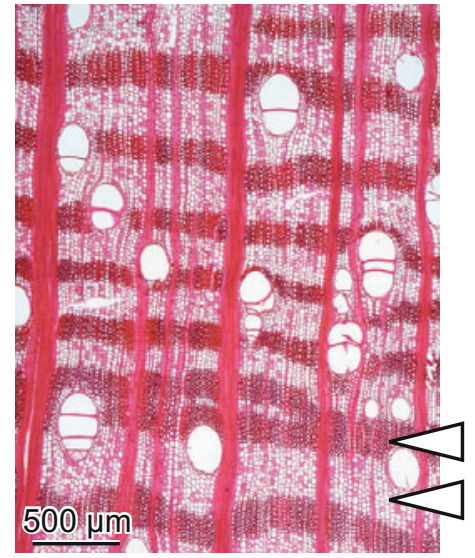

10.26 Tangential bands of fibers alternate with bands of parenchyma in Ficus sycomorus, Egypt. This is characteristic for many tropical species.

Few density variations in conifers

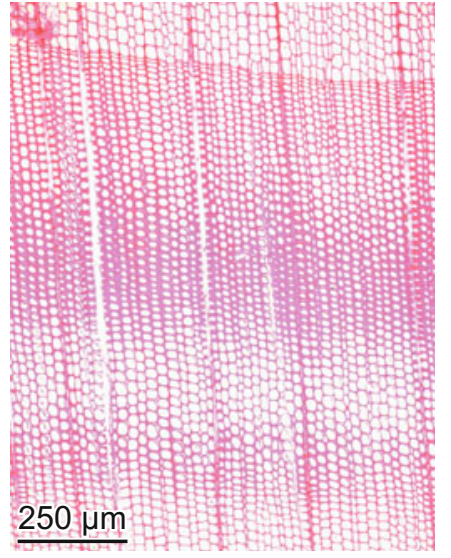

10.23 Large rings with two density variations in the latewood of Pinus sylvestris growing on sand dunes in Germany. Zones of smaller and larger, and thin- and thick-walled tracheids indicate variable water availability.

Intra-annual structural changes

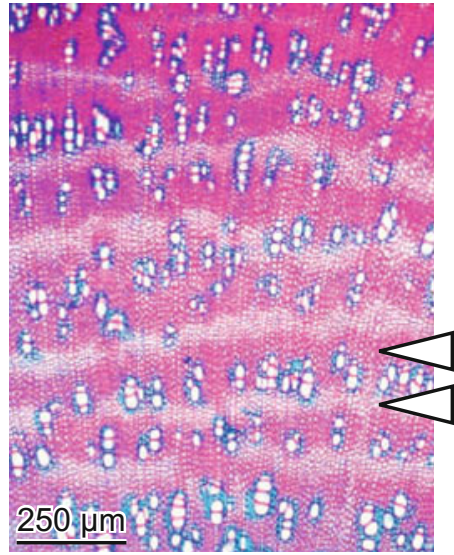

10.27 Tangential bands of thick- and thin-walled fibers alternate irregularly in a shoot of a $40 \mathrm{~cm}$-tall annual herb Lepidium campestre in the temperate zone in Davos, Switzerland.

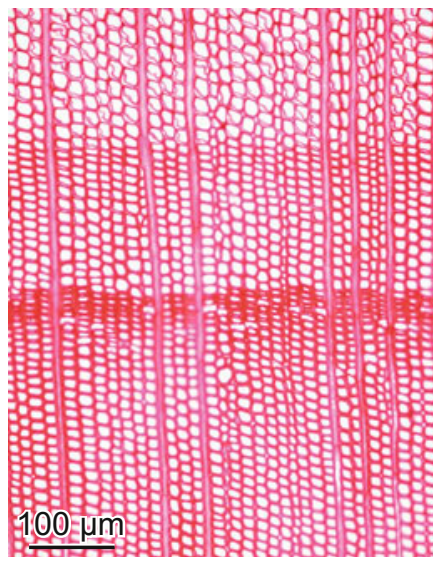

10.24 Two density variations in Cupressus sempervirens. The more intensive variation is characterized by a few rows of small, thick-walled tracheids. The weaker variation is expressed just by smaller tracheids.

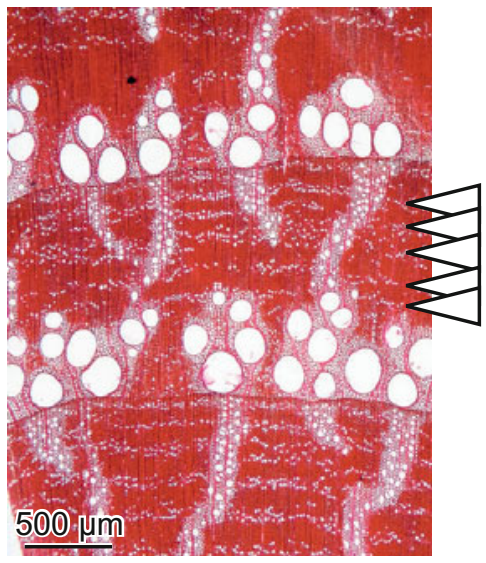

10.28 Tangentially arranged parenchyma cells in the latewood of the ring-porous Quercus robur of the temperate zone in Switzerland. 


\subsubsection{Tissue and fiber cracks}

All cracks are the result of short-term events.

Radial cracks in living conifer trees occur just in the earlywood of individual years, or along rays over many rings. Due to insufficient water flow in summer, the thin-walled earlywood cells contract laterally and split along the weakest zone-the rays. Tangential rows of radial splits can be dendrochronologically dated. Radial cracks in dry logs are a result of anisotropic tissue contractions. Extreme shrinkage of degraded, subfossil wood produces cogwheel-like stem sections. If splits in the xylem reach the cambial zone they induce traumatic reactions. Therefore cracks can be overgrown by accelerated cell production. Radial cracks in bark are the result of enlarged stem circumferences.

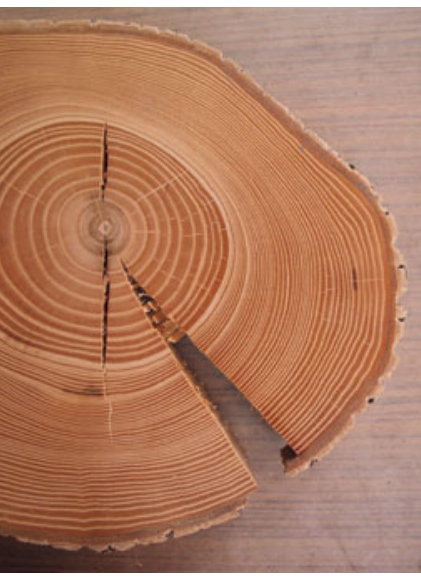

10.29 Radial cracks in a disc of Fraxinus excelsior are a result of intensive tangential shrinkage.

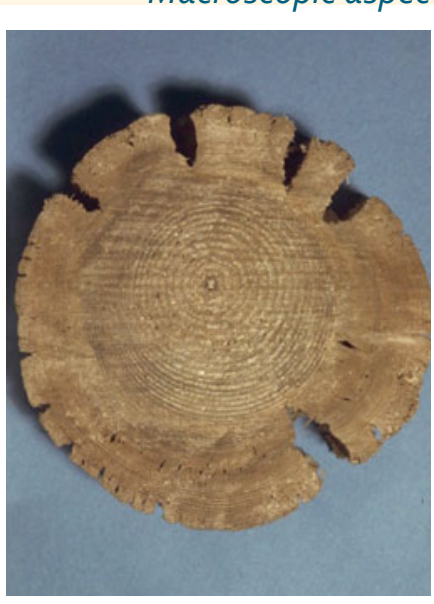

10.30 Large radial cracks in the anaerobically degraded peripheral zone of a Neolithic, waterlogged post of Abies alba.

\section{Microscopic aspect of radial cracks}

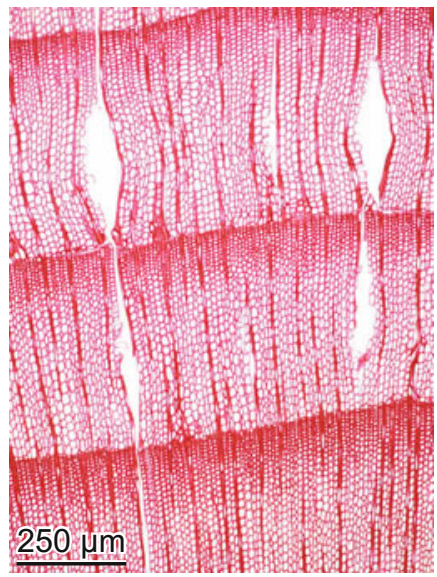

10.33 Intra-annual radial cracks along rays in the earlywood of Larix dahurica.

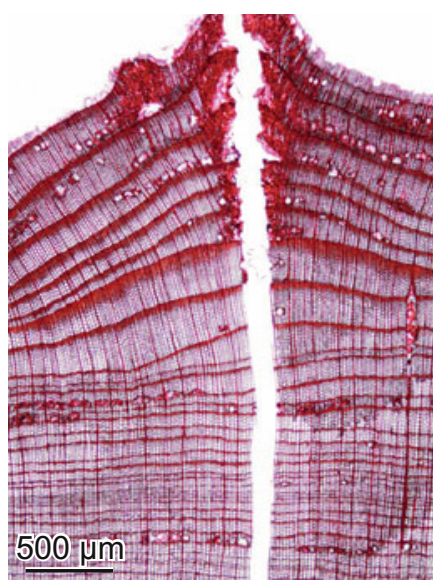

10.34 Frost split in Larix sibirica. The split opened and triggered accelerated radial growth and induced the formation of traumatic resin ducts.
Tangential cracks (ring shake) are a result of mechanical stress and occur along anatomically weak zones in various species. Genetic predisposition or extreme wind events are the most frequent causes of ring shake and resin pockets. Stems of the ring-porous chestnuts split along the earlywood vessels, those of spruces along the thin-walled earlywood tracheids. Resin pockets occur mainly in stems of conifers in windy mountainous regions. Extreme tangential splitting is characteristic for a few alpine herbs, e.g. Saxifraga sp. and Androsace sp.

Micro-cracks mainly occur in cell walls of conifer tracheids. Extremely intense, very short events of tension or pressure due to rock fall, wind storms or avalanches can break tracheids irreversibly. The stability of wood with broken tracheid walls is probably not much reduced. The abnormalities can be detected by microscopy with polarized light.

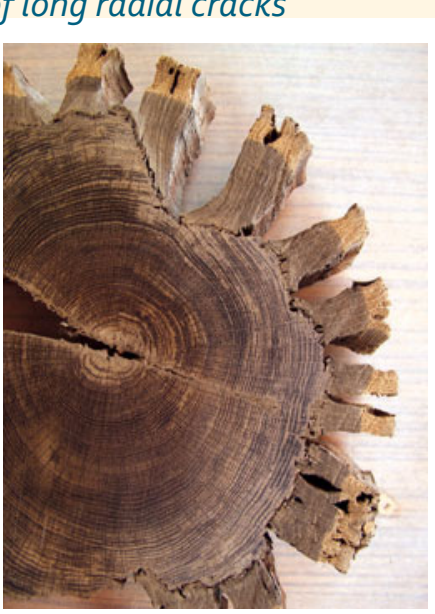

10.31 Extremely large radial cracks in the degraded, light-colored sapwood and the dark heartwood of a Neolithic, waterlogged post of Quercus sp.

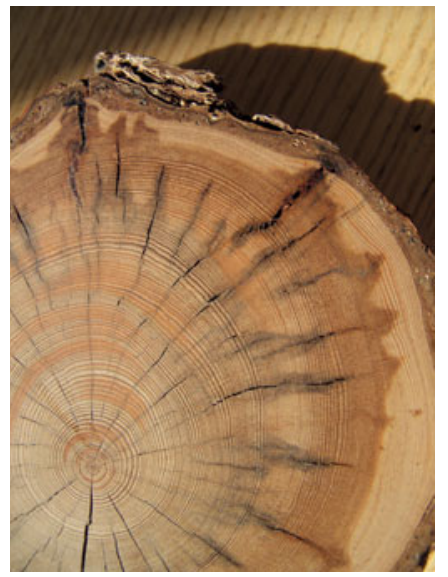

10.32 Many radial frost cracks in the heartwood of Larix laricina in the boreal zone. Material: Y. Begin.

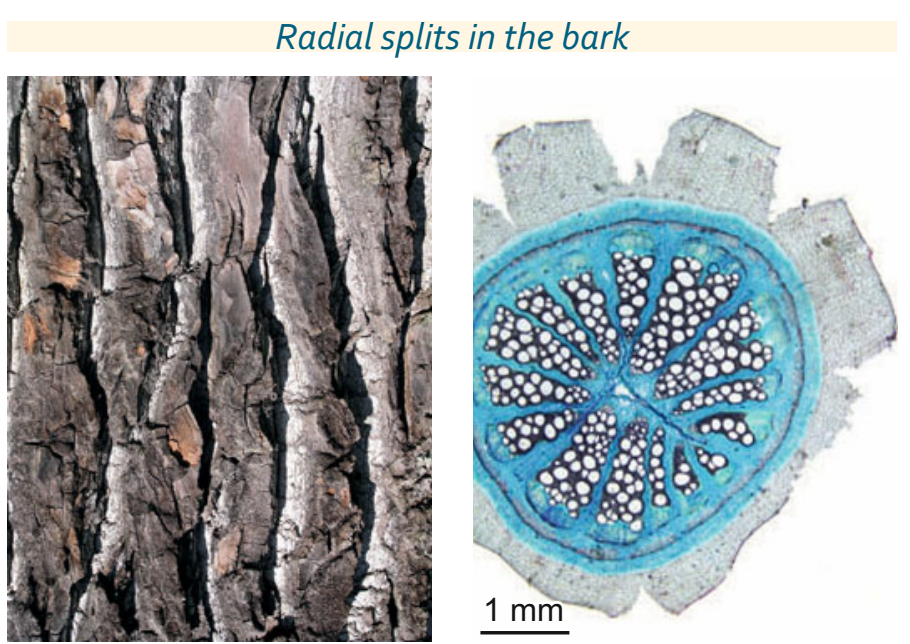

10.35 Radial splits in the bark of Populus nigra are a result of stem expansion.
10.36 Radial splits in the bark of Aristolochia macrophylla are a result of stem expansion. 


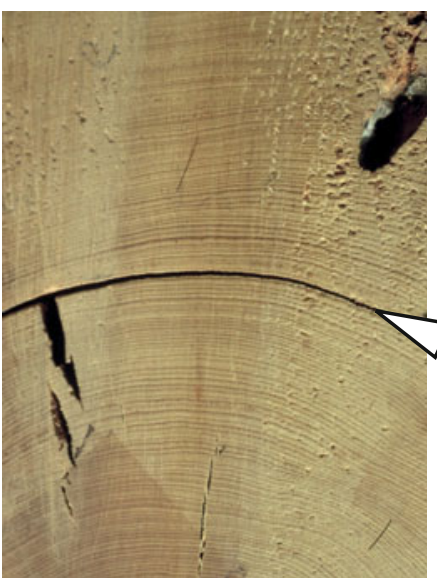

10.37 Tangential split in Picea glauca, indicating a thin-walled latewood after a volcanic event. Material: G. Jacoby.

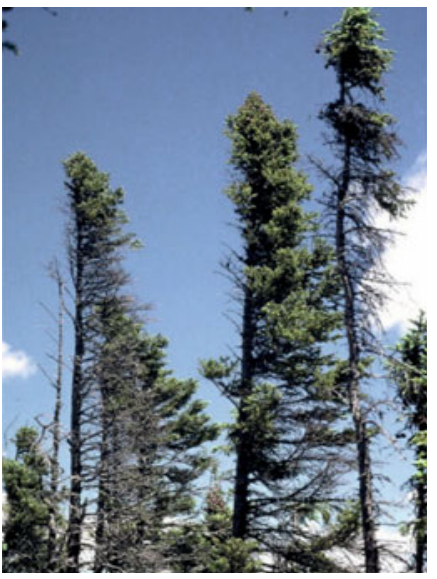

10.40 Picea engelmannii with onesided branches in a windy area.

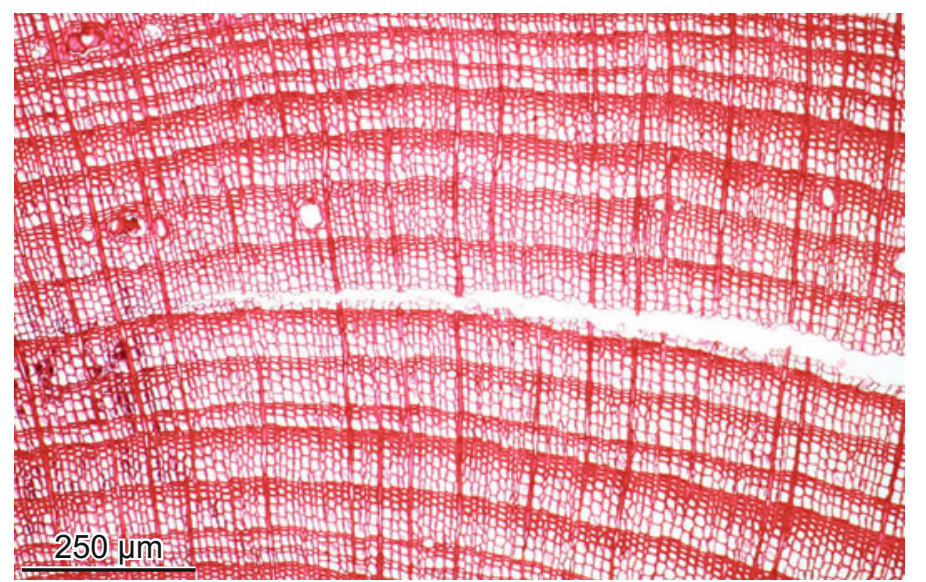

10.38 Tangential split along a thin-walled earlywood zone in Larix dahurica.

Wind-induced tangential cracks

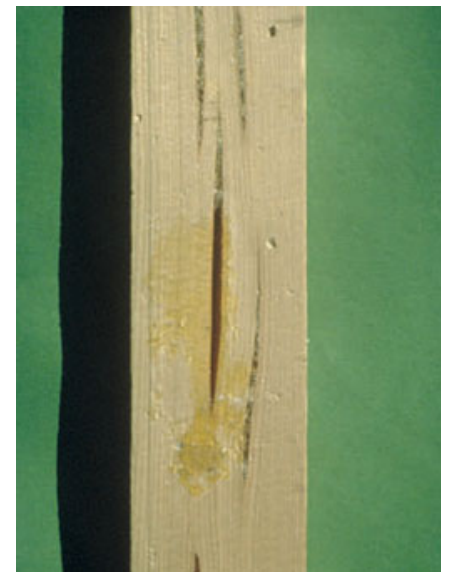

10.41 Longitudinal section trough resin pockets of Picea abies in an alpine region.

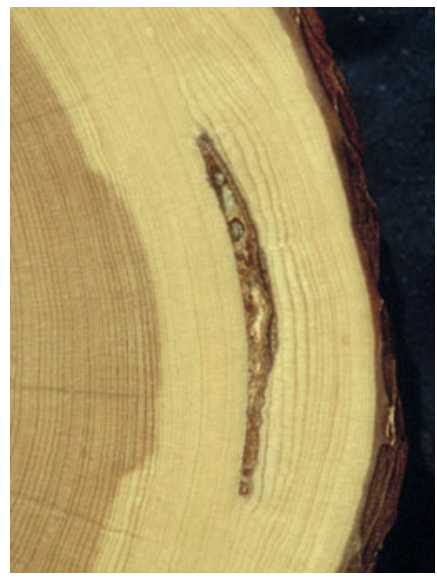

10.42 Macroscopic aspect of a resin pocket in Pinus sylvestris in an alpine region.

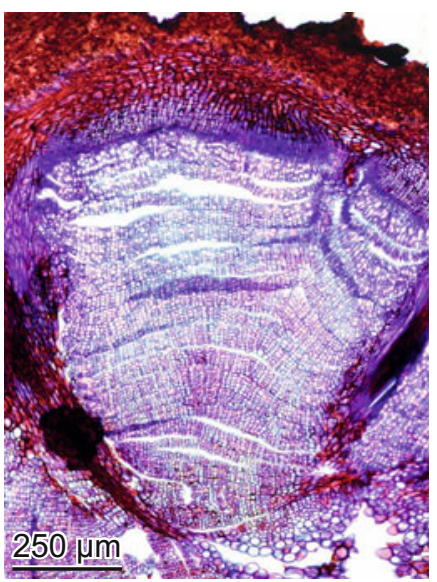

10.39 Tangential splits in a ray-less stem of the perennial herb Saxifraga muscoides.

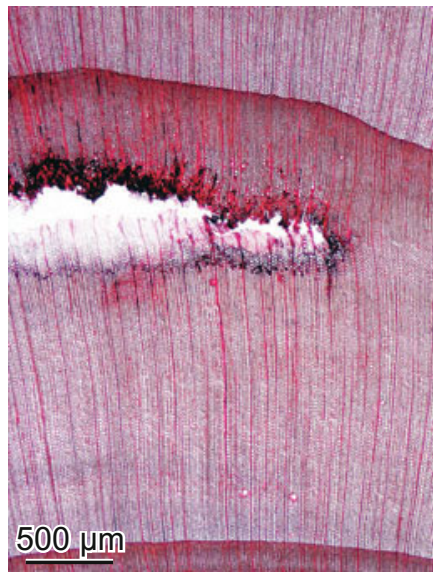

10.43 Microscopic aspect of a resin pocket in Picea abies. The crack borders are surrounded by callus tissues.

Shock-induced cracks in axial tracheid walls

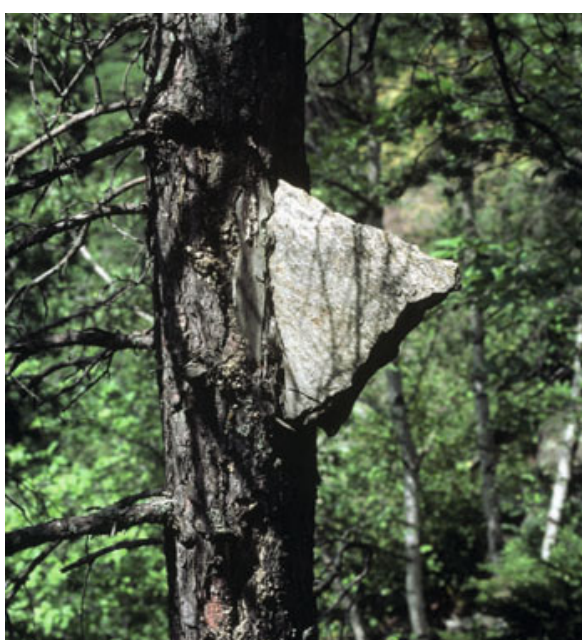

10.44 A stone hit a the stem of Pinus sylvestris in a rock fall.

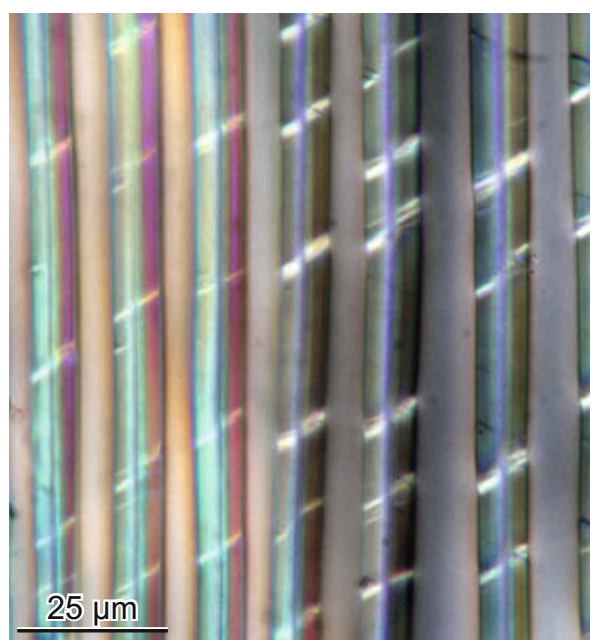

10.45 Cracks in axial tracheid walls of Picea abies under polarized light.

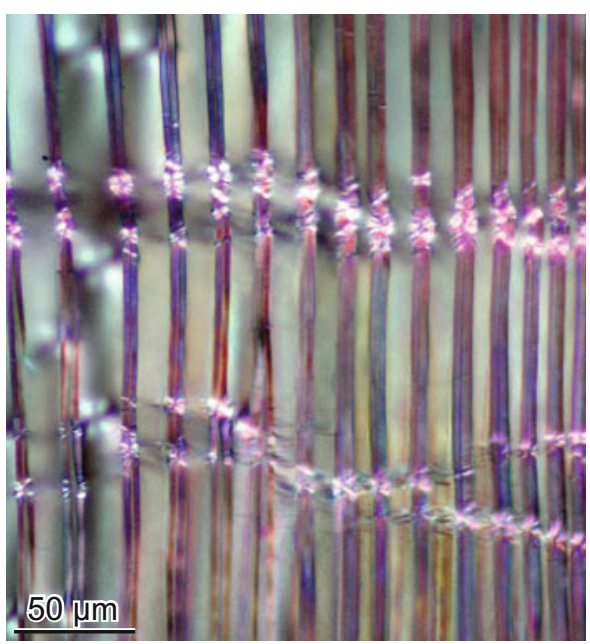

10.46 Zone of crushed tracheid walls in Picea abies under polarized light. 


\subsection{Effect of multi-annual environmental changes}

\subsubsection{Abrupt growth changes}

Abrupt growth changes are the result of long-lasting environmental changes. A long-term reduction in growth can be the consequence of crown damage by repeated insect defoliation, environmental pollution, pruning, a change in water availability or increased competition. Sudden increased growth can be the consequence of improved light conditions, e.g. after thinning, or improved hydrological conditions. Abrupt growth changes are rarely permanent. They can in extreme cases lead to the death of individuals, however, in most cases they are reversible. Their causes can only be evaluated in relation to observations or measurements of environmental conditions.

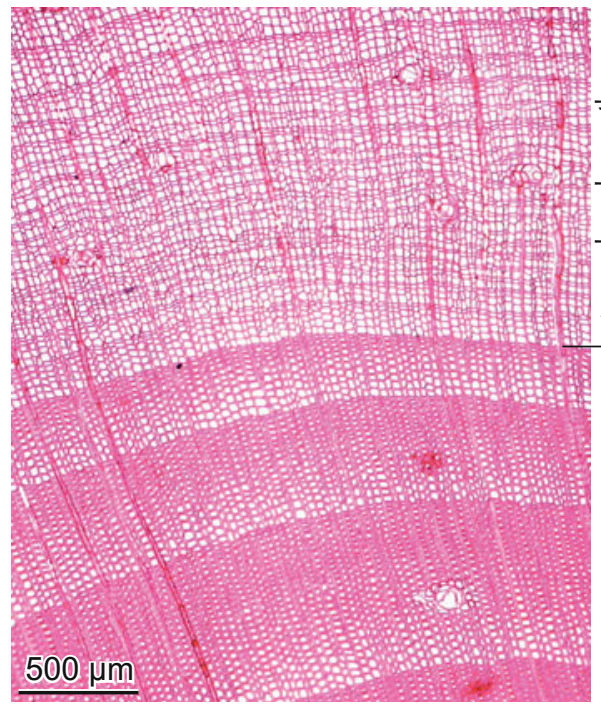

10.47 Growth reduction in the conifer Pinus mugo after crown damage by a rock slide.

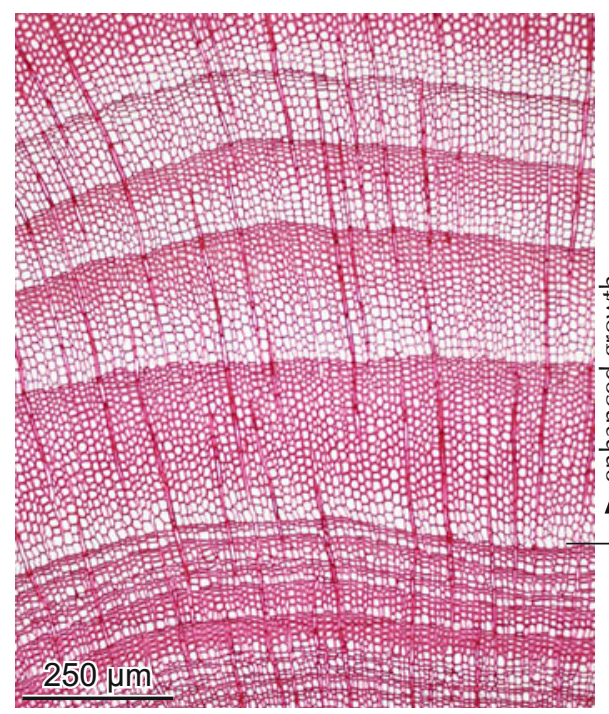

10.50 Enhanced growth in the boreal conifer Larix dahurica, its cause is unknown.
Abrupt negative growth changes

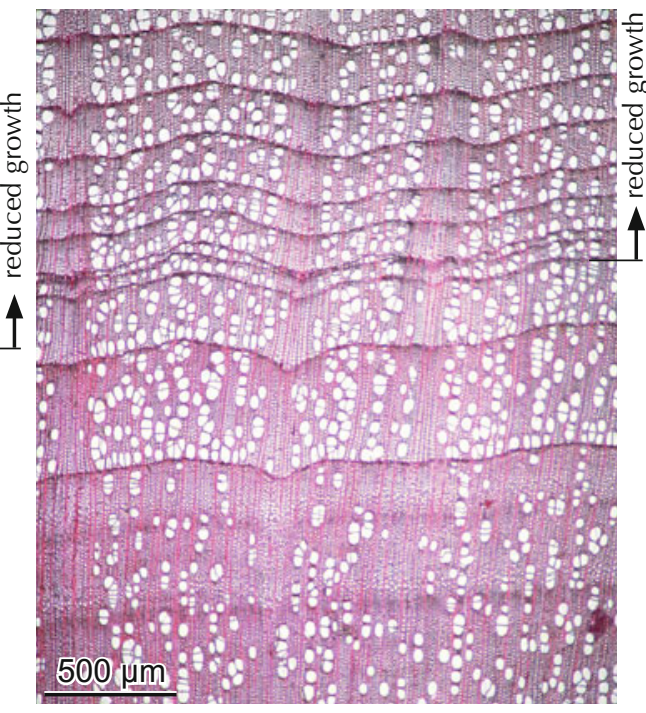

10.48 Growth reduction in the deciduous Alnus glutinosa after root damage during a landslide.

\section{Abrupt positive growth changes}

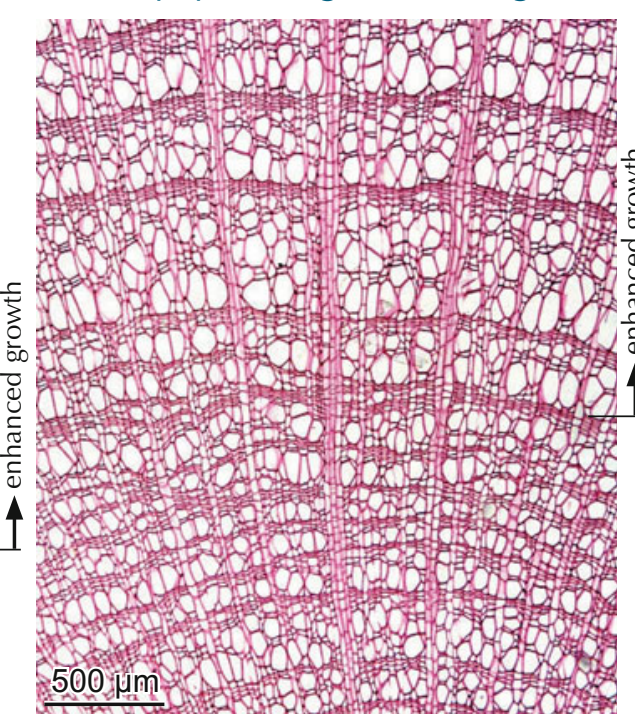

10.51 Enhanced growth in the prostrate mountain dwarf shrub Arctostaphylos rubra, its cause is unknown.

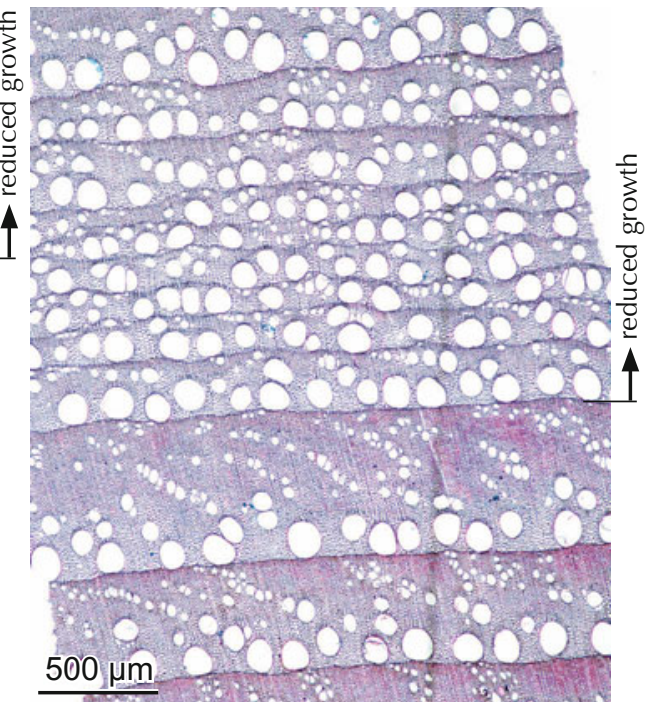

10.49 Growth reduction of the deciduous Castanea sativa after crown damage by the chestnut blight fungus (Cryphonectria parasitica).

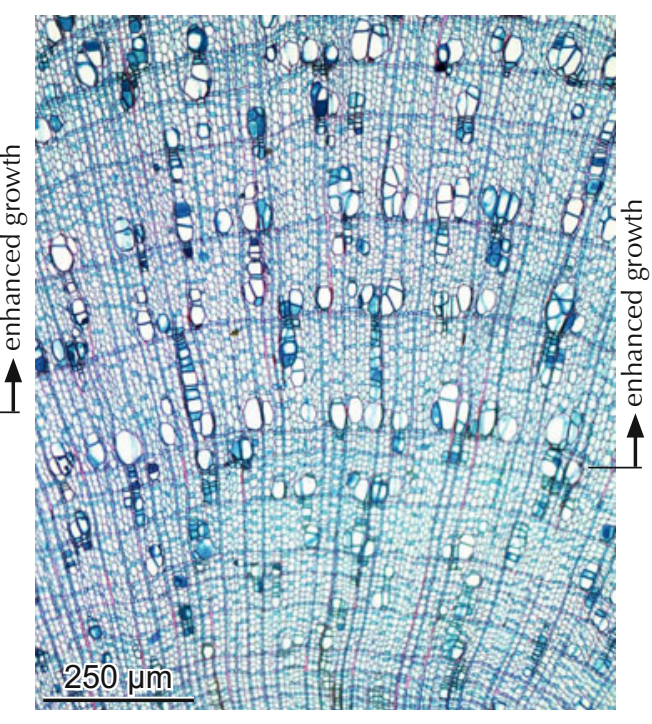

10.52 Enhanced growth in the prostrate arctic shrub Betula nana, its cause is unknown. 


\subsubsection{Structural changes}

Discussed here is the anatomical structure of changes in cell type, cell size, cell-wall density and cell orientation after root exposure in conifers and deciduous trees. Structural changes are the result of positional changes within the plant body, of extensive plant destruction, or long-term environmental changes, e.g. by root exposure, stem cutting and extreme suppression of individuals. This can only be ecologically explained in the context of external observation.

Root exposures are expressed by changes of tracheid diameters, fiber dimension, fiber-wall thickness, vessel distribution patterns, tyloses, ray width and ring distinctness.
Resprouting stumps after they have been cut indicate a reorganization of tissues. After removal of the crown, conifers and deciduous plants reduce radial growth, change fiber directions and reduce ray height. Conifers reduce latewood zones and tracheid walls, deciduous trees reduce vessel frequency and diameters. These reactions are an expression of dramatic physiological changes. Instead of using their own photosynthetic resources plants after crown removal use resources of neighboring individuals through anastomosing roots.

Dying stems in beech cohorts lose their foliage. Due to reduced sap flow the proportion of water conduction to nutrient storage changes. The conducting area of vessels continuously reduces its capacity, while the amount of parenchymatous tissue (rays) increases. See also Gärtner 2003.

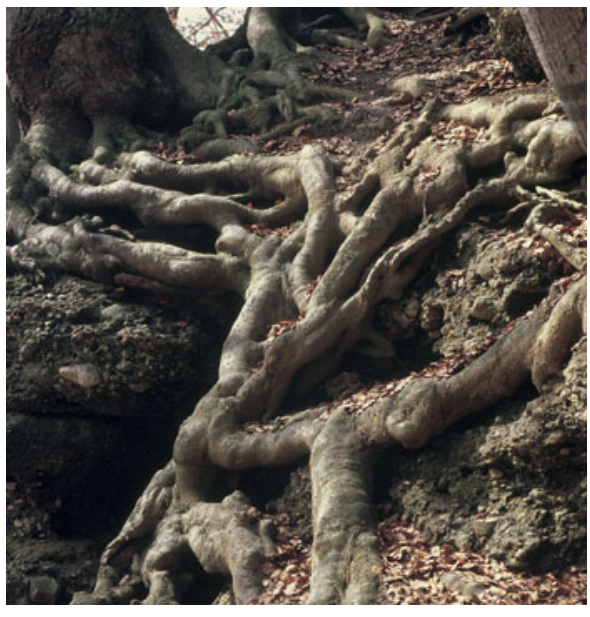

10.53 Exposed roots of Fagus sylvatica on a rock.

\section{Macroscopic view of exposed roots}

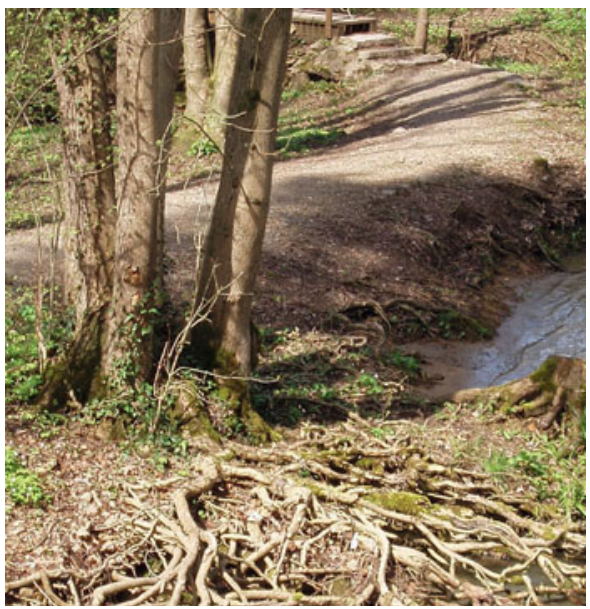

10.54 Exposed roots of Fraxinus excelsior at a river bank.

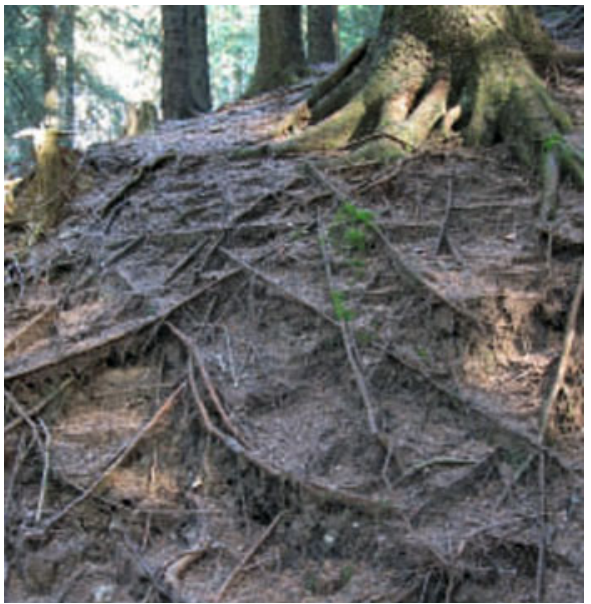

10.55 Exposed roots of Picea abies after an extremely intensive rainfall in the Swiss Alps.

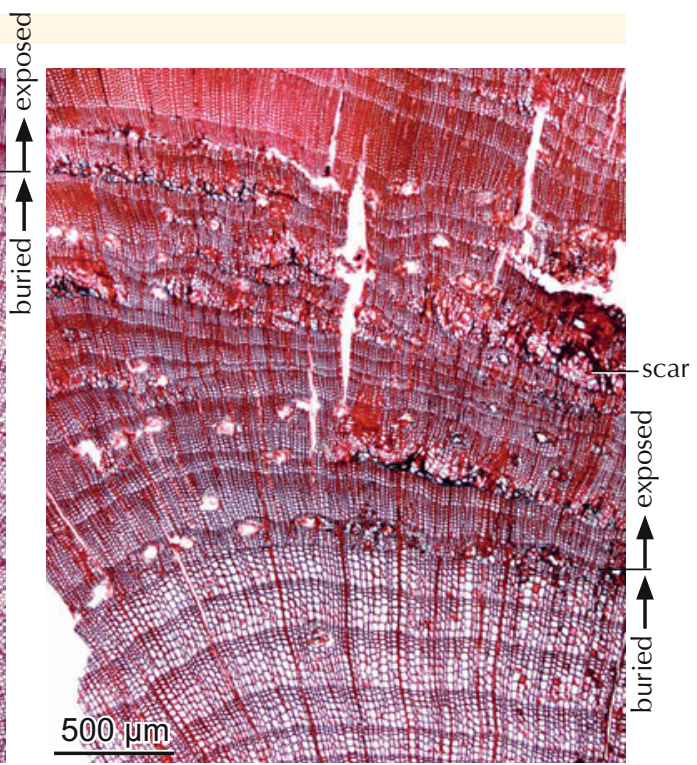

10.58 Root of Pinus sylvestris on a path. Exposure triggered changes in tracheid diameters and the formation of resin ducts. Scars in the exposed part of the root are a result of sustained injuries. 
Anatomical changes after root exposure in ring-porous deciduous trees

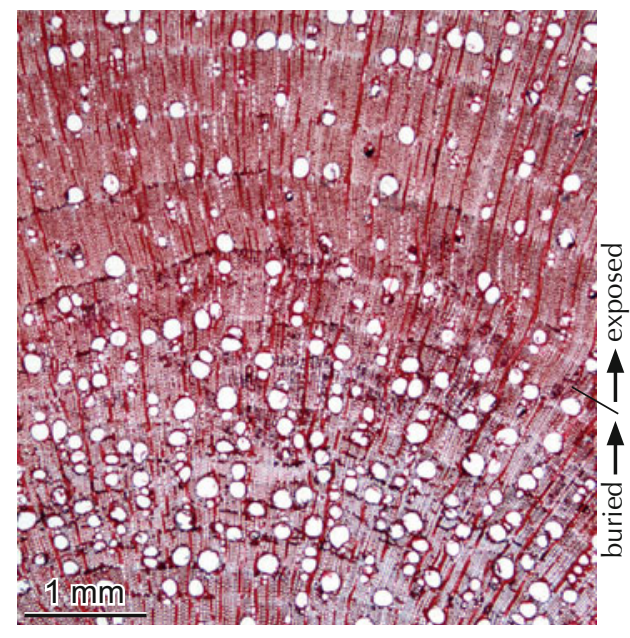

10.59 Root of Fraxinus excelsior on a river bank.

Cell walls of fibers are thicker, vessels are less

Anatomical changes after root exposure in diffuse-porous deciduous trees

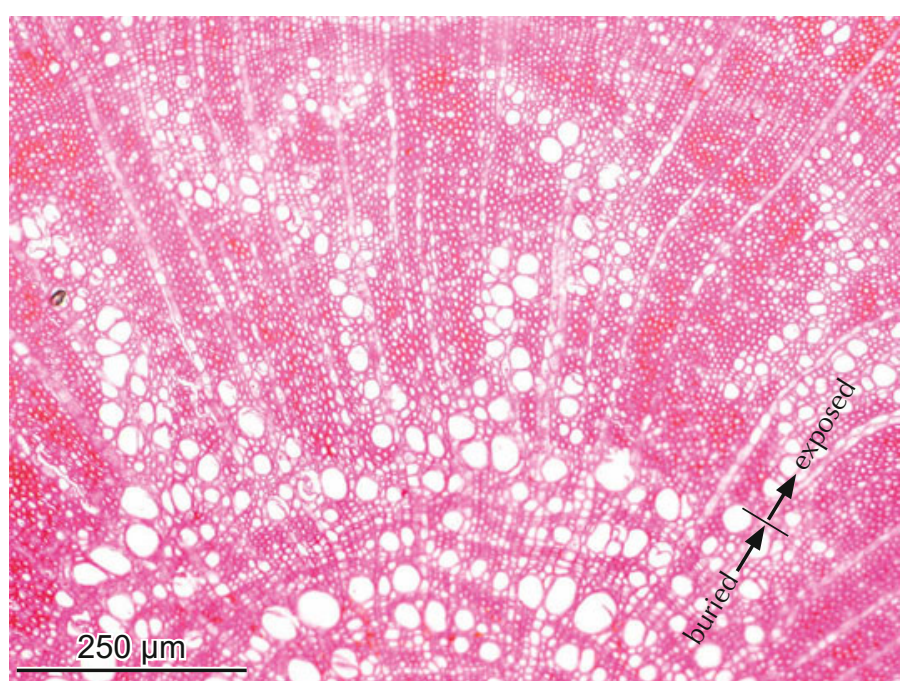

10.63 Root of Lycium chanar in a river bed. Ring width increases, vesse distribution patterns distinctly change, and vessel diameter is reduced after

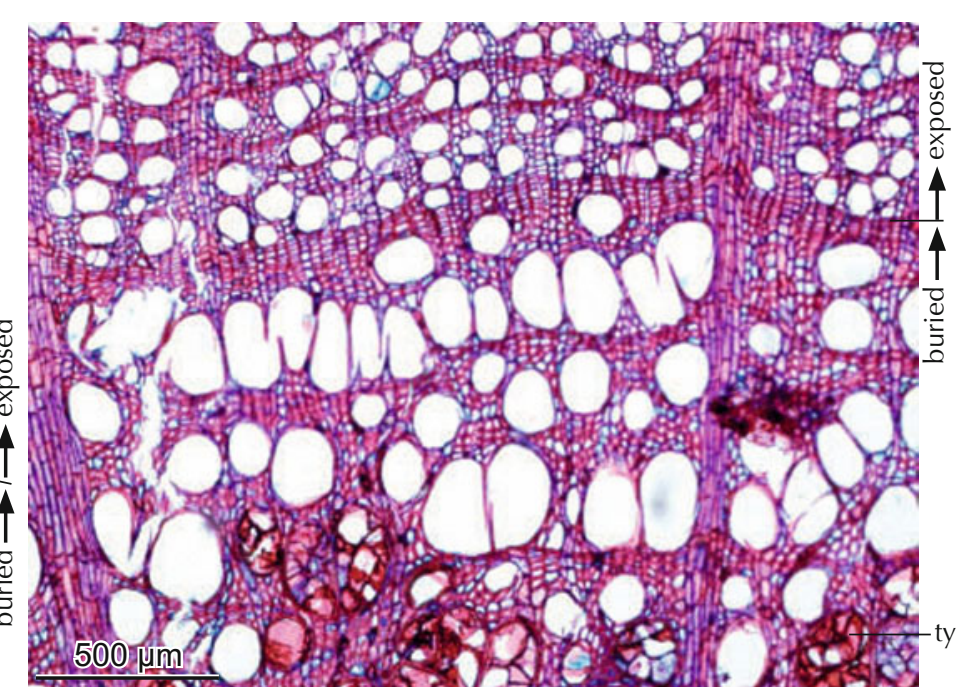



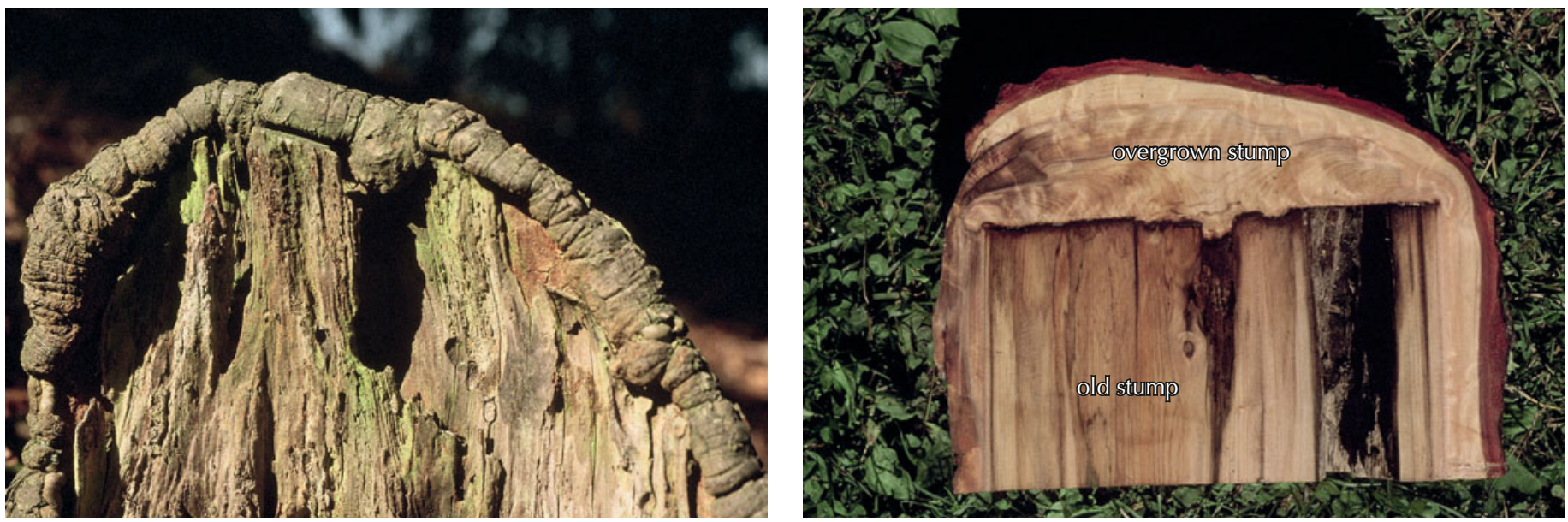

10.66 Decaying stump of Picea abies with a living external part.

10.67 Longitudinal section of a completely overgrown stump of Abies alba. The tracheids are axially oriented.
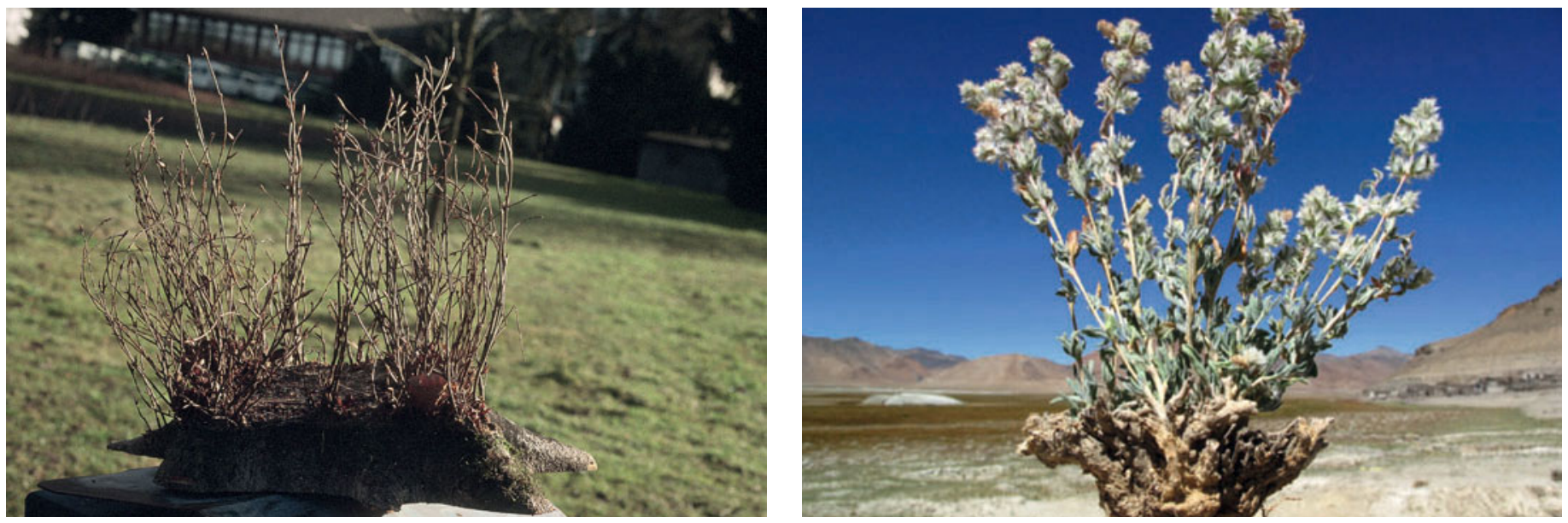

10.68 Decapitated Fagus sy/vatica with adventitious sprouts.

10.69 Intensively pollarded shrub of Krascheninnikovia ceratoides. The twigs are used for goat fodder in Ladakh, India.

Structural changes after decapitation in conifers

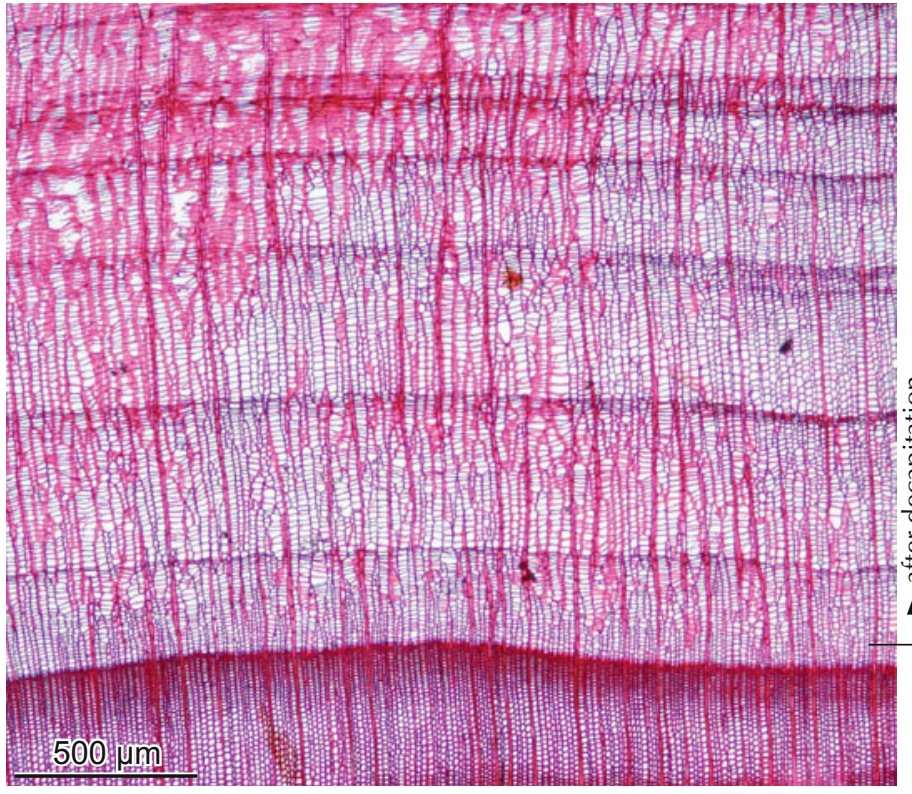

10.70 Reactions to decapitation in Thuja occidentalis are the reduction of radial growth, latewood formation and cell-wall thickness, and local changes in the direction of tracheids.

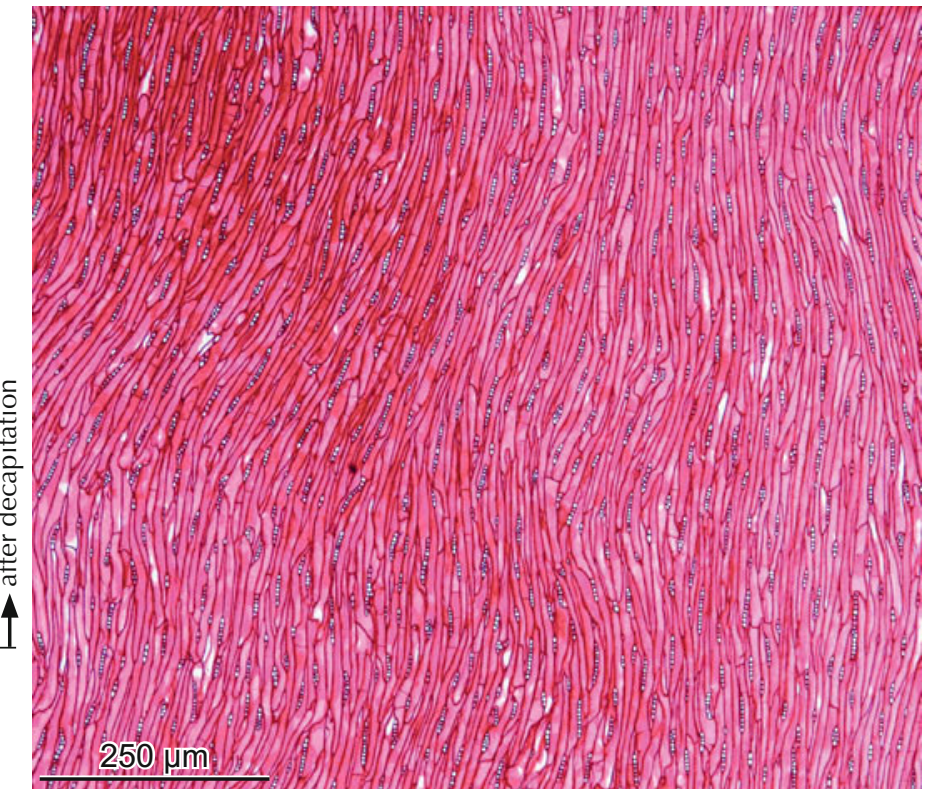

10.71 Wavy fiber direction after decapitation in Thuja occidentalis. 
Structural changes after decapitation in conifers traumatic resin ducts

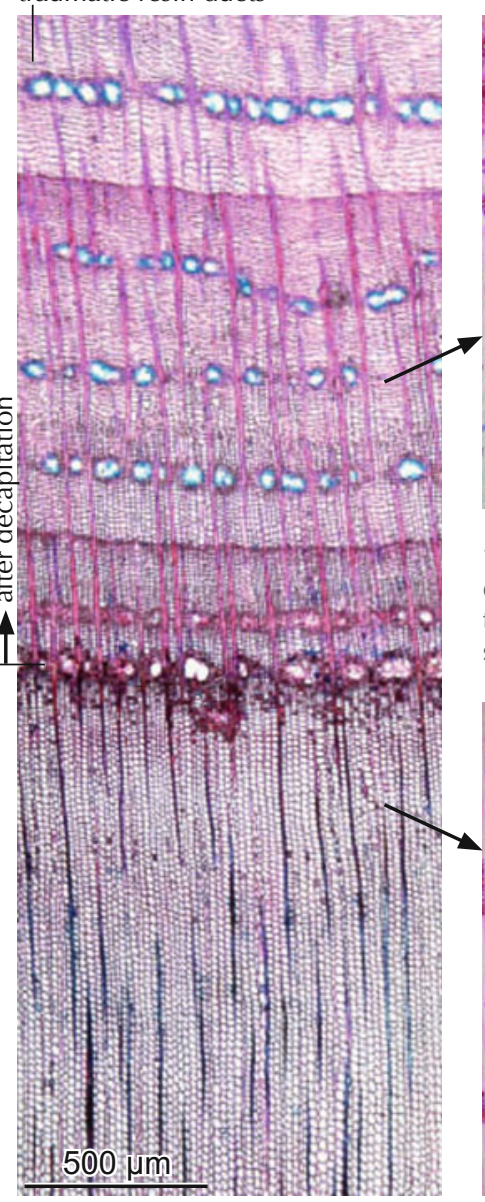

10.72 Reactions to decapitation in Picea abies are a reduction in radial growth, the formation of traumatic resin ducts, and a change in the direction of tracheids.

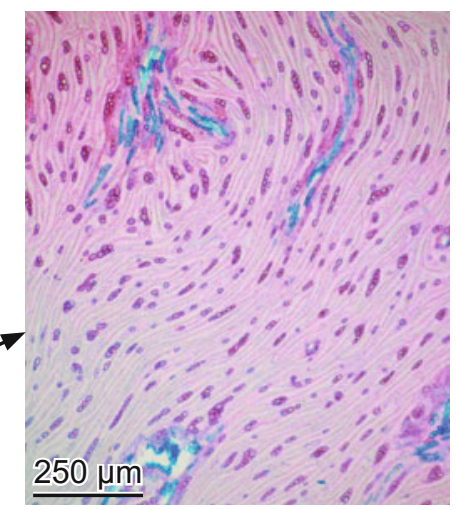

10.73 Structure in Picea abies after decapitation: Irregularly oriented tracheids and partially biseriate short rays with one to four cells.

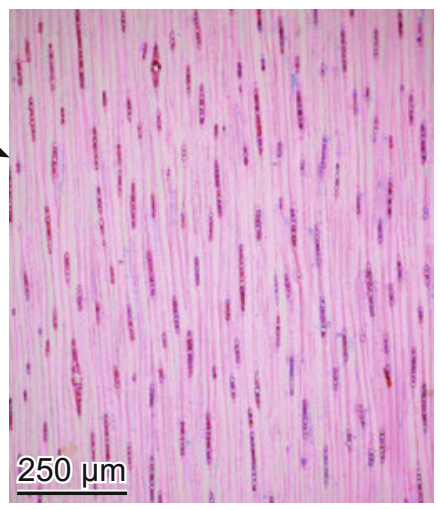

10.74 Structure in Picea abies before decapitation: Straight, axially oriented tracheids and exclusively uniseriate rays with four to ten cells.

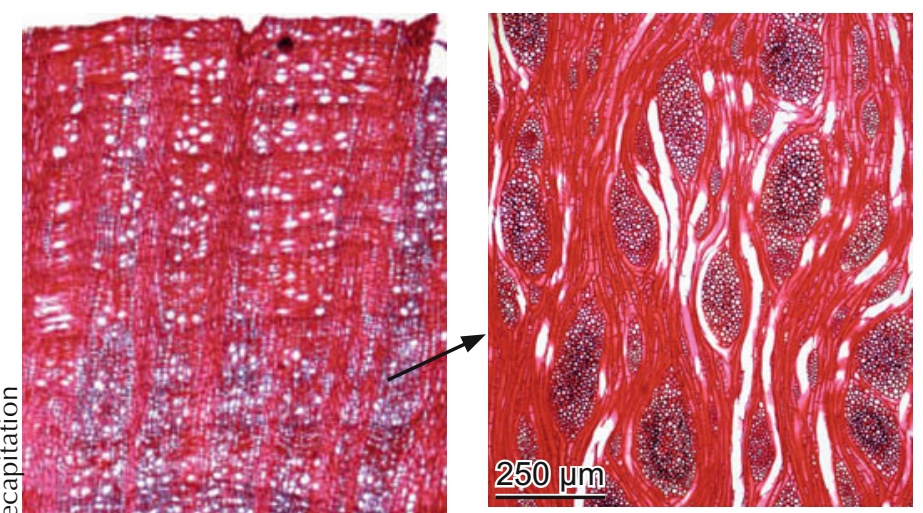

10.76 Structure in Fagus sylvatica after decapitation: Wavy axial tissues containing many very large, but short rays.

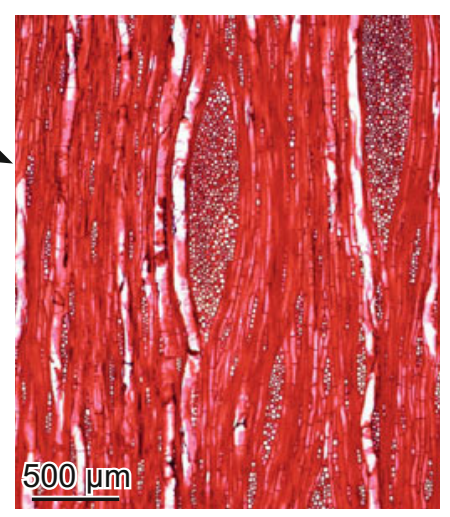

10.75 Reactions to decapitation in Fagus sylvatica are a reduction in radial growth, vessel frequency and diameter, an enlargement of rays and a change in fiber direction.
10.77 Structure in Fagus sylvatica before decapitation: Straight, axially oriented fibers and vessels, and slender small and large rays.

Structural changes in deciduous trees under extreme competition stress

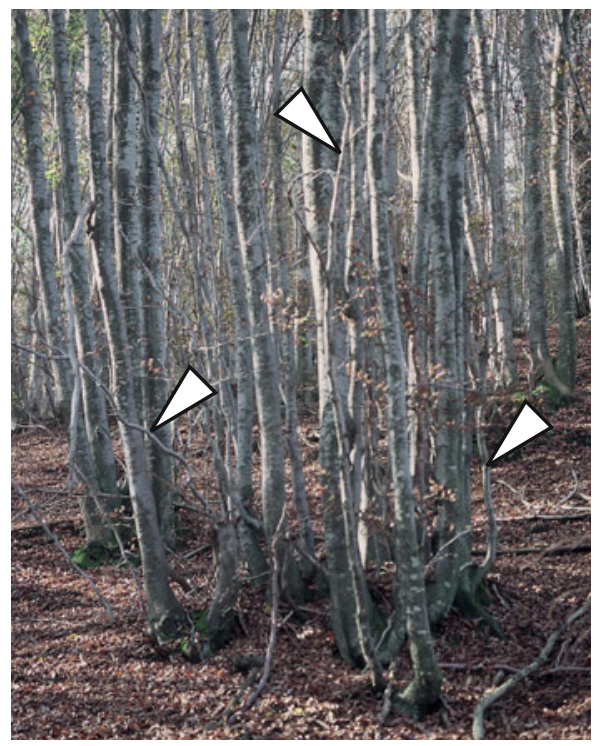

10.78 Dying suppressed individuals of Fagus sylvatica.

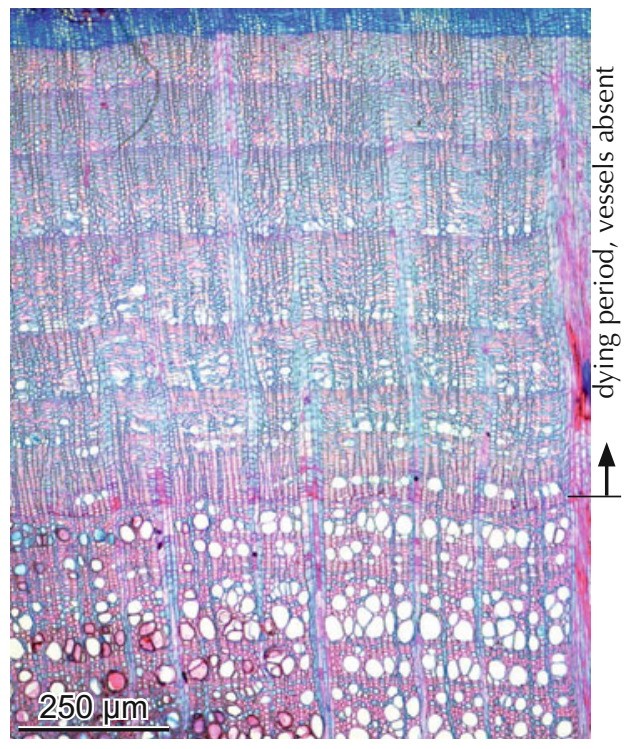

10.79 A continuous reduction in vessel frequency and diameter, and an enlargement in rays occurs after loss of foliage in Fagus sylvatica.

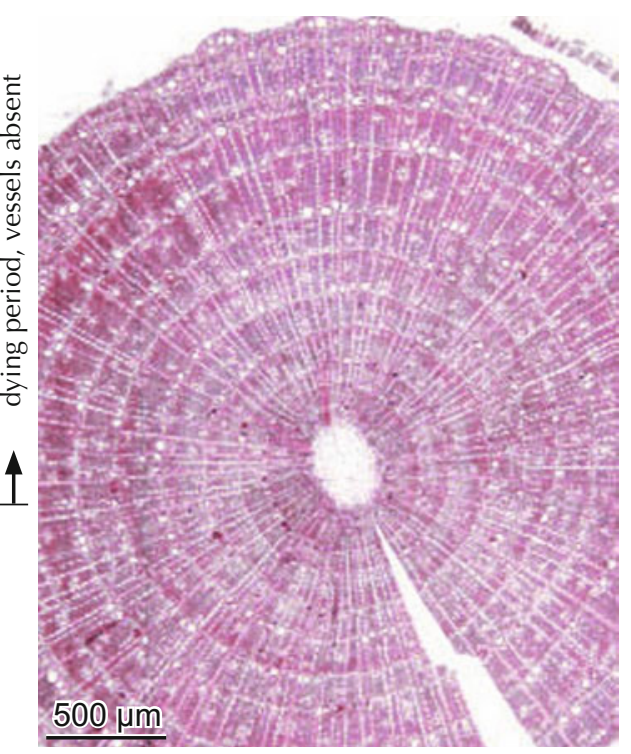

10.80 Twelve-year-old, $3 \mathrm{~cm}$-tall seedling of Fraxinus excelsior in a meadow. Grasses compete with it for light and resources, resulting in few, small vessels, uni- to biseriate rays and thin- to thick-walled fibers. 


\subsection{Eccentricity and irregular stem forms}

Changes in vertical position, irregularly applied tension or pressure, unfavorable growing conditions, or a genetic constitution can be expressed by eccentric growth in roots, stems and branches. Conifers generally form additional cells at the side of pressure, while deciduous plants form additional cells at the side of tension. The cambium is sensitive to short- or long-term changes. Each topological reaction is therefore reflected in a cross section.

In a cross section, circular annual rings indicate an upright, while oval rings indicate an oblique position. Growth reactions are indicators for extremely local changes within the plant. If a stem changes position the reaction is only expressed by eccentricity in this stem and not in any other plant parts.
Intra-annual dating of pressure or tension changes during the growing period is possible with some restrictions. If the cambium is not fully active or if hormonal influences are delayed, the anatomical reaction does not indicate the exact moment of the external mechanical influence. Any changes of balance during the dormant period are reflected in the next growing period, immediately in the early or in the late earlywood. Intraannual trophic changes are most reliable in fast-growing plants because many cambial cells are at disposition for reactions.

Eccentricity only indicates that an event took place that triggered a change in inclination. The exact cause can only be reconstructed through observation of the environmental conditions.

\section{Macroscopic aspect of trees with eccentric growth}

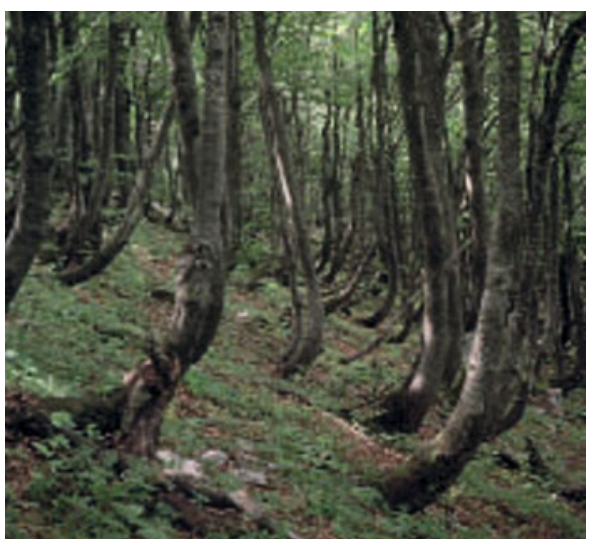

10.81 Snow creeping causes stems of Fagus sylvatica to grow with a curved stem basis.

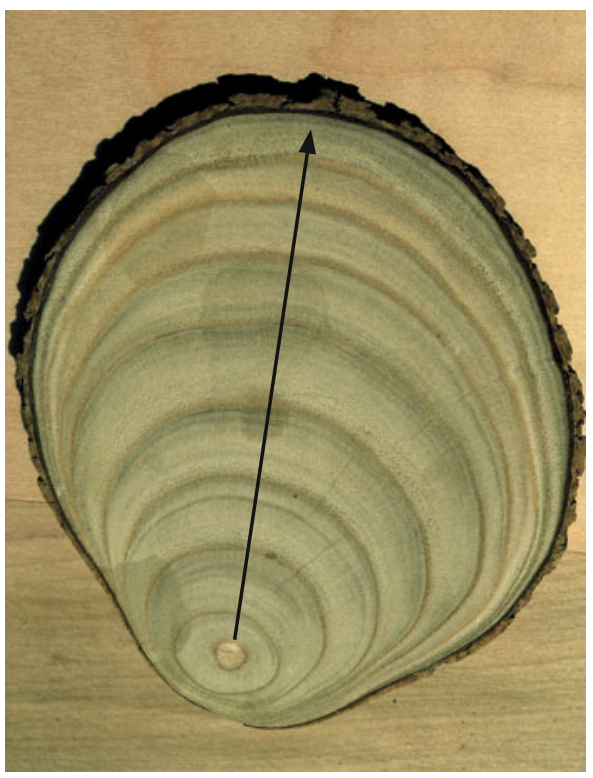

10.84 Leaning stem of the tree Rhus typhina, with an upright position of the shoot in the first year, leaning from the second year onwards. Accelerated growth occurs at the tension side.

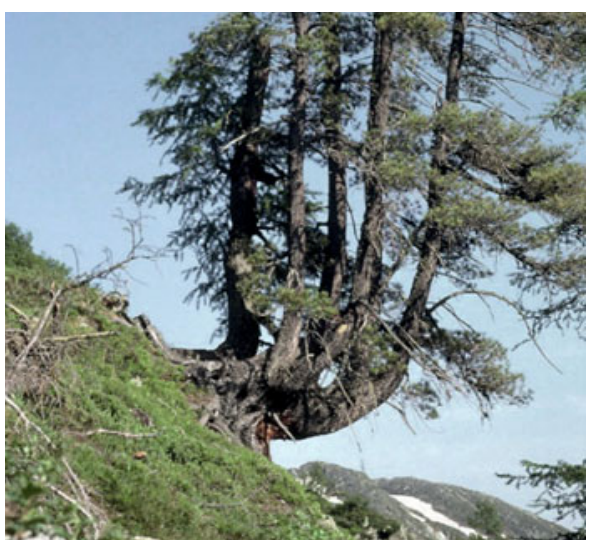

10.82 An avalanche bent these stems of Larix decidua. They regenerated in a vertical position.

\section{Reaction to a single event}

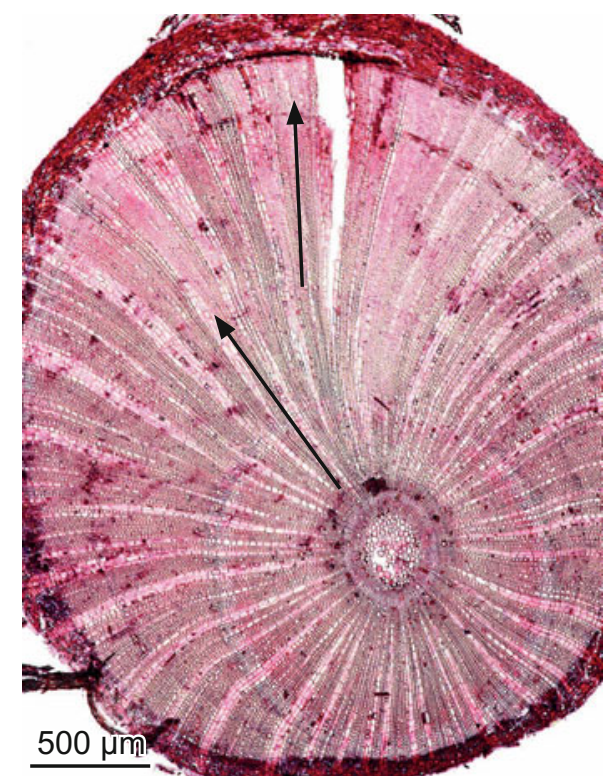

10.85 Leaning rhizome of the perennial herb Lythrum salicaria, with an upright position of the shoot in the first two years, leaning from the third year onwards.

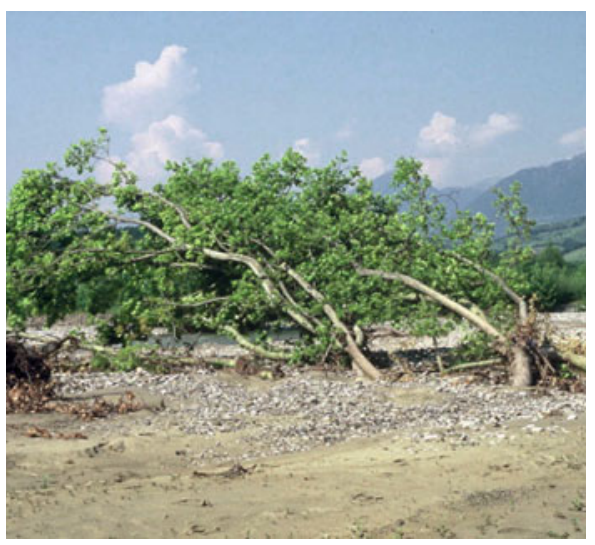

10.83 Leaning trees of Platanus occidentalis with eccentric stems after several flood events.

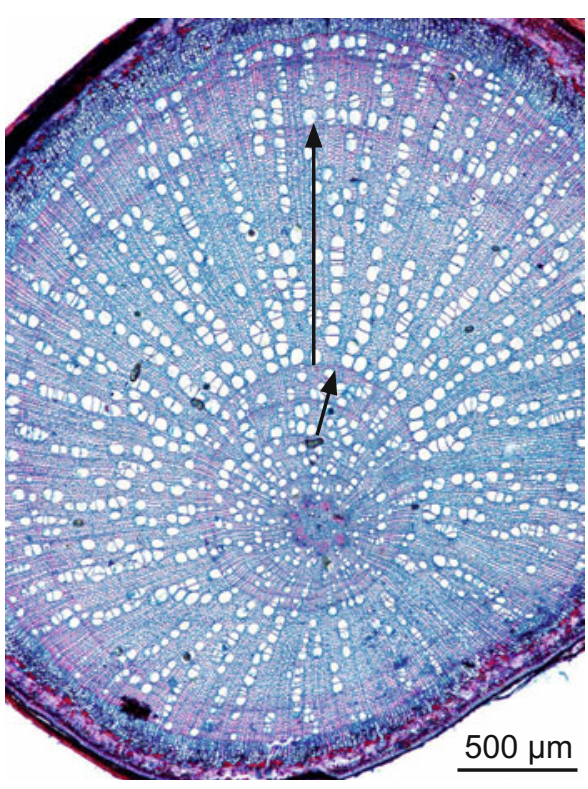

10.86 Changing inclination of a root of the shrub Corylus avellana. The root grew vertically in the first year and at an angle from the second year onwards. 


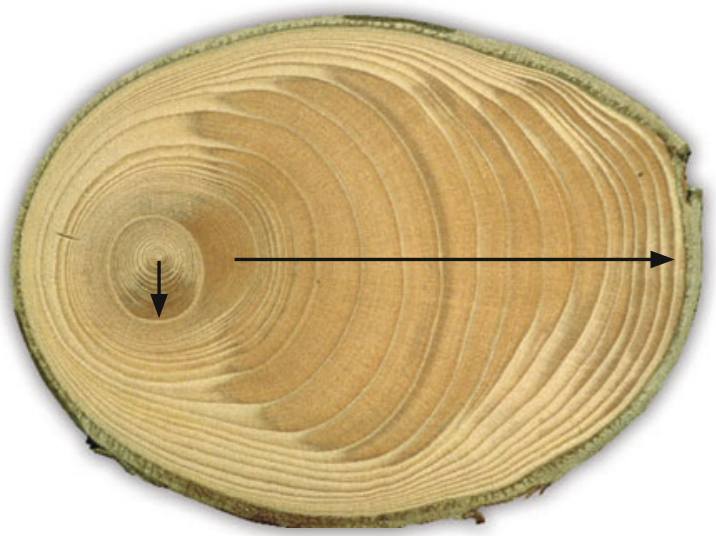

10.87 Changing inclinations of a stem of Picea abies in an avalanche track. The seedling grew upright in the first few years, then got hit and inclined twice.

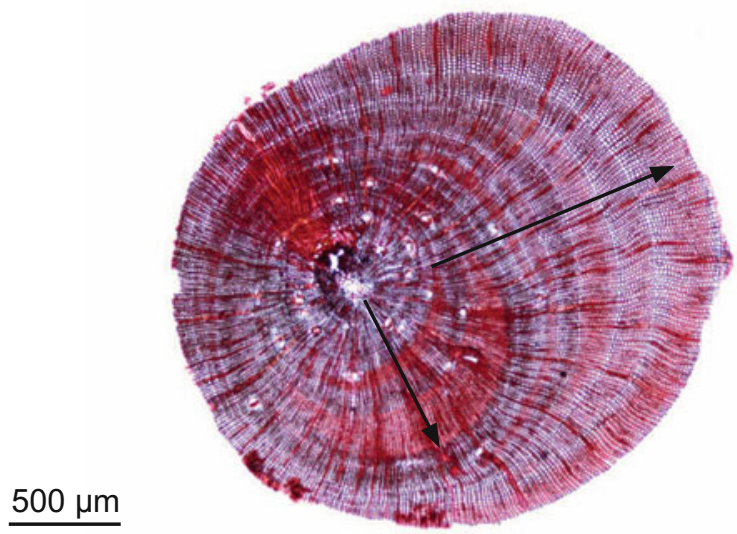

10.88 Changing inclination in a stem of Pinus mugo on an instable ground of a bog. The seedling grew upright in the first two years, after that moved twice.

Reaction to genetic constitution and mechanical events

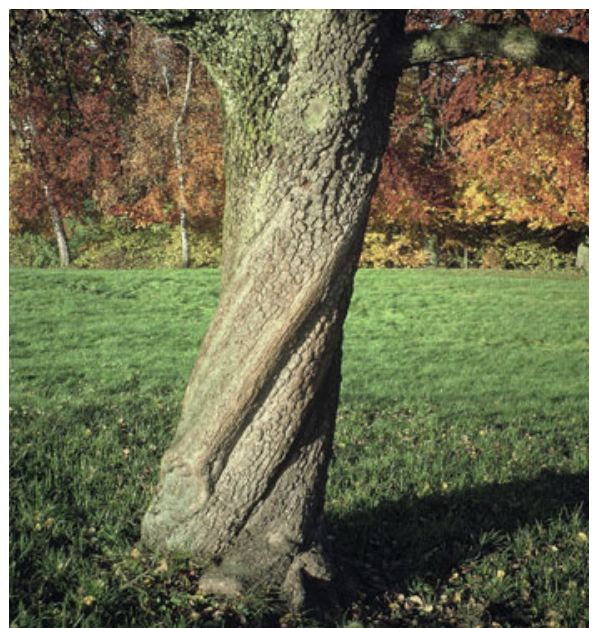

10.89 The fluted stem of a tree of Pyrus communis.

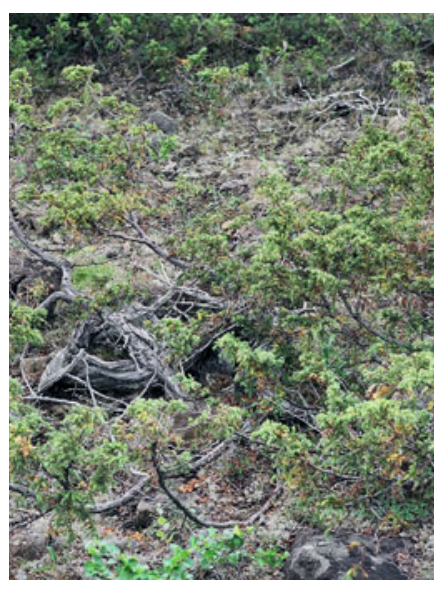

10.92 Prostrate conifer Juniperus sibirica on a rocky dry slope in the Polar Ural. Photo: S. Shyiatov.

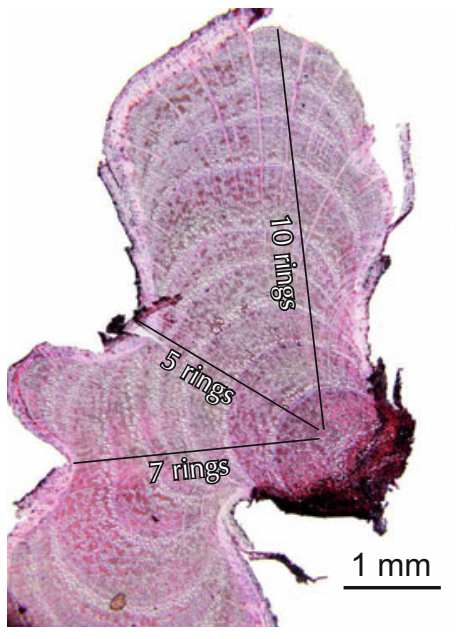

10.90 Eccentric fluted rhizome of the herb Hippocrepis comosa. The rhizome grew toward one side for five years, then various local cambial activities formed three lobes.

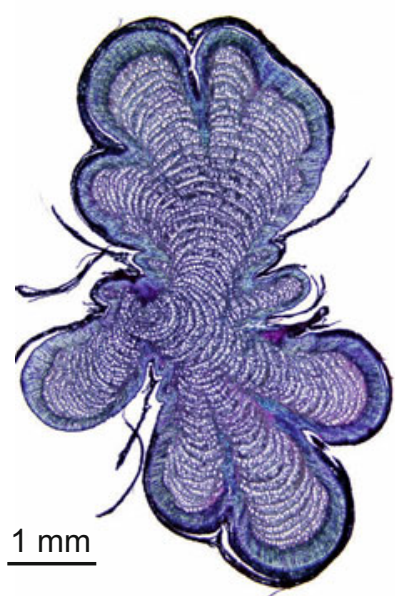

10.91 Eccentric fluted stem of the dwarf shrub Eriogonum jamesii. The shoot grew upright in the first five years, then various local cambial activities periodically formed lobes.
Reaction to unfavorable local growing conditions

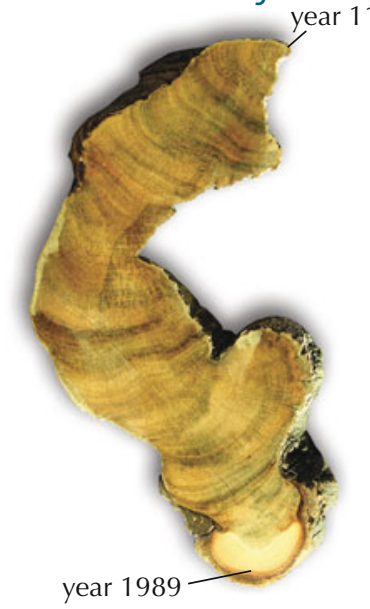

10.93 Very eccentric, horizontally growing stem of Juniperus sibirica. The cambium is only active towards the ground-facing side. Older stem sections are eroded. The ring sequence reflects cambial activity of 839 years.

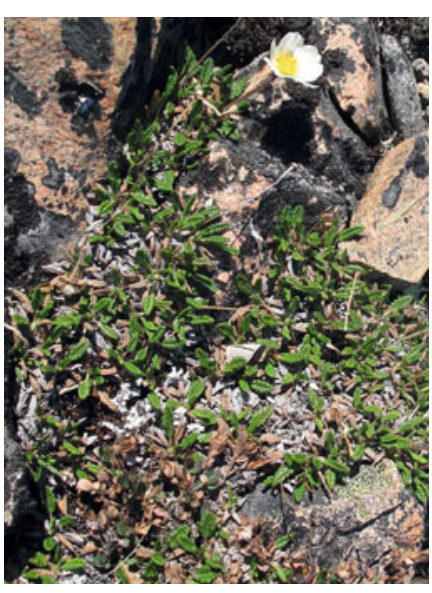

10.94 Prostrate dwarf shrub Dryas octopetala on a wind-swept, rocky slope in the high arctic of Greenland.

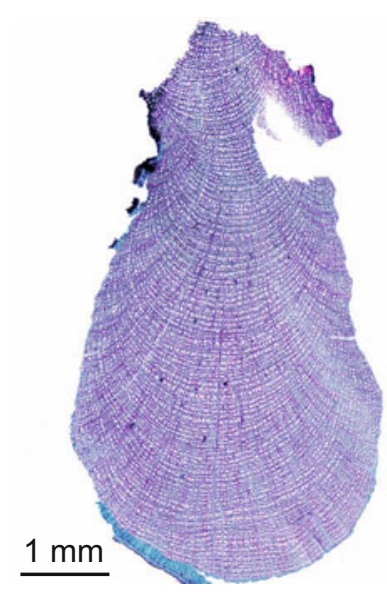

10.95 Extremely eccentric, horizontally growing, $20 \mathrm{~cm}$-long stem of Dryas octopetala. The cambium is only active towards the ground-facing side. The stem hasn't changed its position for 120 years. 


\subsection{Reaction wood - Reaction to mechanical stress}

The formation of reaction wood is a principal survival strategy of terrestrial plants. It is responsible for the formation of directed growth, and for regeneration after gravity-related deformations.

Reaction wood is defined (after Evert 2006) as "Wood with more or less distinctive anatomical characters, formed in parts of leaning or crooked stems and branches. Compression wood

\section{Compression wood}

- Occurs in all families and genera of conifers.

- Occurs at the compression side of leaning parts of trees and shrubs.

- Occurs in the xylem of stems, branches, twigs and roots.

- Occurs in tracheids, never in parenchyma.

- Secondary walls are high in lignin and low in cellulose. Tertiary walls are absent.

- Macro-fibrils are angled up to $45^{\circ}$ towards the axis of the tracheid. The angle of spiral thickenings increases with increasing intensity of the compression wood, e.g. in Taxus.

- Tracheids are round in circumference, with intercellulars between the tracheids.

- Branches are stiff, with a high resistance to compression and low flexibility.

- Longitudinal shrinking is high (up to $7 \%$ ). occurs in conifers at the compressed parts (e.g. lower side of branches) and tension wood in angiosperms at the tension side (e.g. upper side of branches)."

The presence of intensively lignified primary walls is common for compression wood and tension wood. Each living cell reacts independently from another to mechanical stress.

\section{Tension wood}

- Occurs in selected families and genera of dicotyledonous plants. It does not occur in hydrophytes.

- Occurs at the tension side of leaning parts of trees, shrubs and herbs.

- Occurs in the xylem and phloem of stems, branches and twigs, never in roots.

- Occurs in fibers and fiber tracheids, never in parenchyma.

- Secondary walls contain mostly gelatinous fibers (G-layer), which are low in lignin and high in cellulose.

- Macro-fibrils are oriented parallel to the axis of the fiber.

- Fibers are angular in circumference. Intercellulars are absent.

- Branches are flexible, with a high resistance to tension and high flexibility.

- Longitudinal shrinking is low (up to $1 \%$ ).

See also Gardiner et al. 2014, Ghislain \& Clair 2017 and Onaka 1949.

\section{Occurrence of compression wood and tension wood}

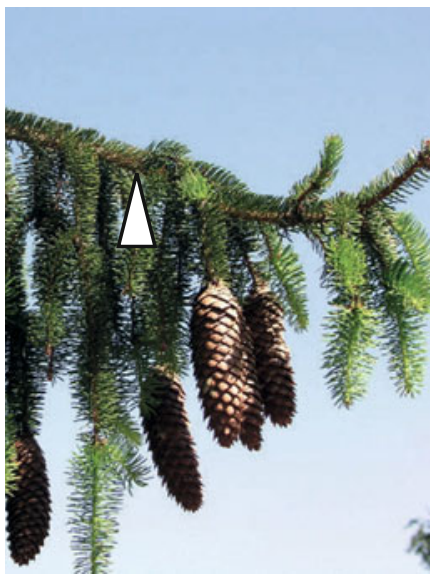

10.96 Branch and twigs of the conifer Picea abies. Compression wood occurs at the underside of branches.

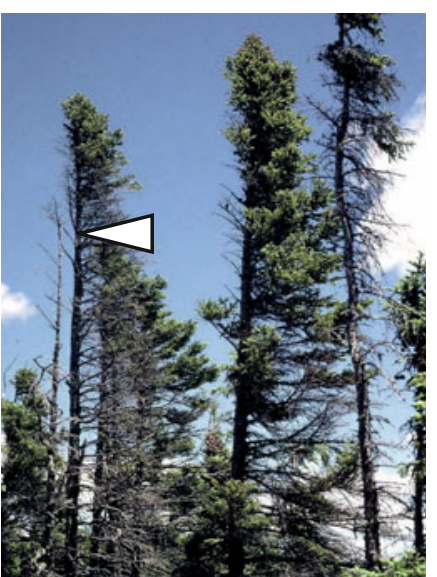

10.97 Wind-exposed trees of Picea engelmannii. Compression wood occurs at the lee side of the stems.

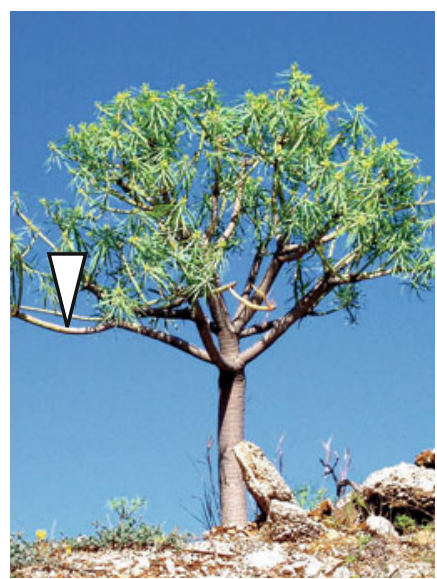

10.98 Small tree of the dicotyledonous Euphorbia balsamifera. Tension wood occurs at the upper side of the branches.

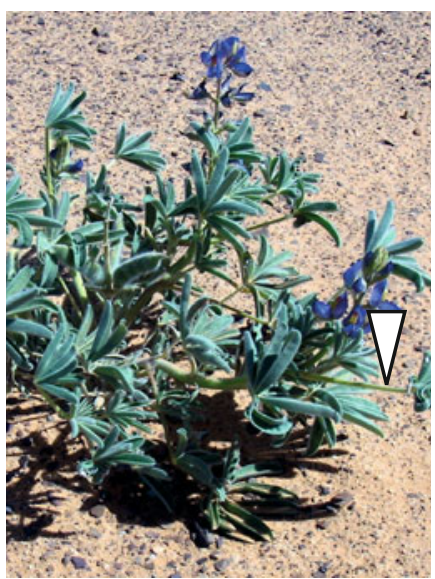

10.99 Dicotyledonous herb Lupinus sp. Tension wood occurs at the upper side of the branches. 


\subsubsection{Compression wood in conifers}

Compression wood appears on polished discs as dark brown zones, and in stained slides as intensively stained layers.

Directed reactions to gravity influences are obvious.

Macroscopic aspect

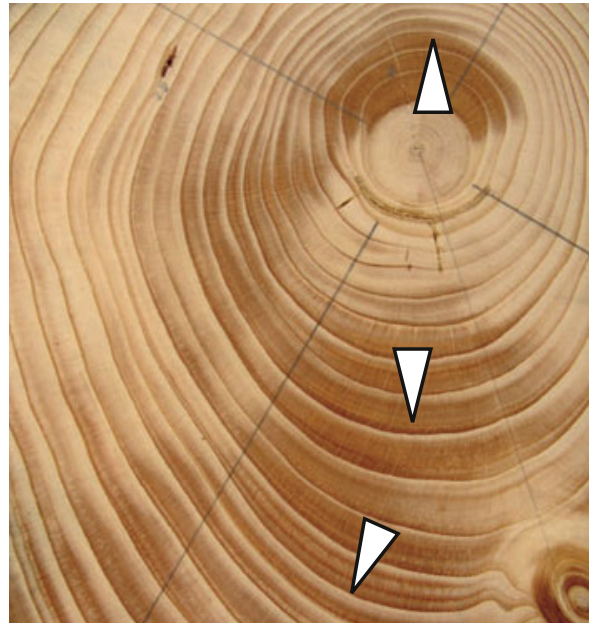

10.100 Polished disc of Picea abies. The dark zones represent compression wood. Its position indicates the influence of gravity (arrows).

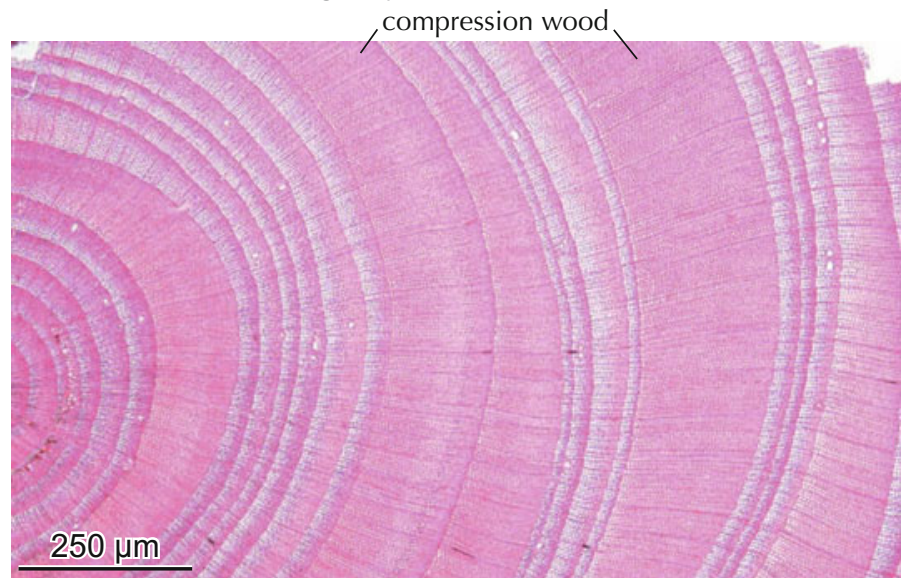

10.103 Thick-walled round latewood tracheids with intercellulars in a leaning small Picea abies tree.

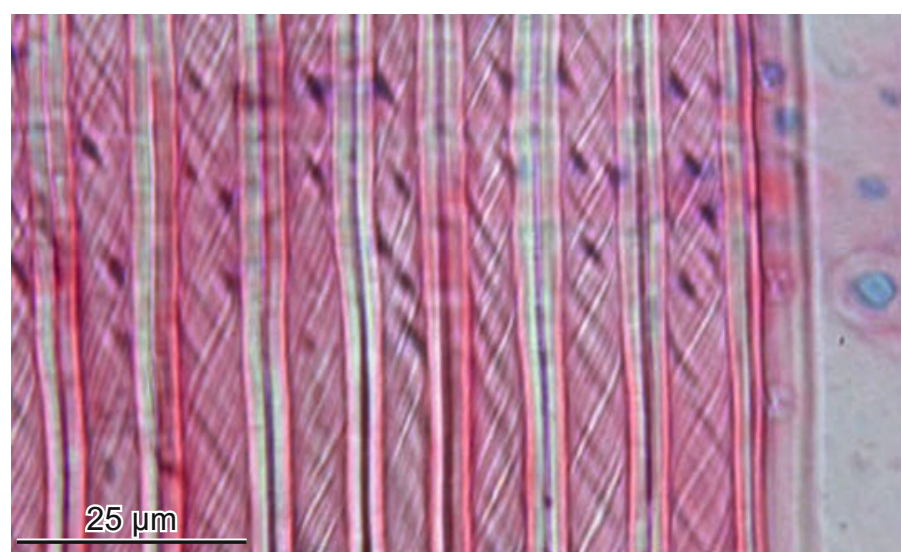

10.105 Longitudinal spiral-like cracks in latewood tracheids walls indicate macro-fibrils in the compression wood of Picea abies.
Microscopic aspect

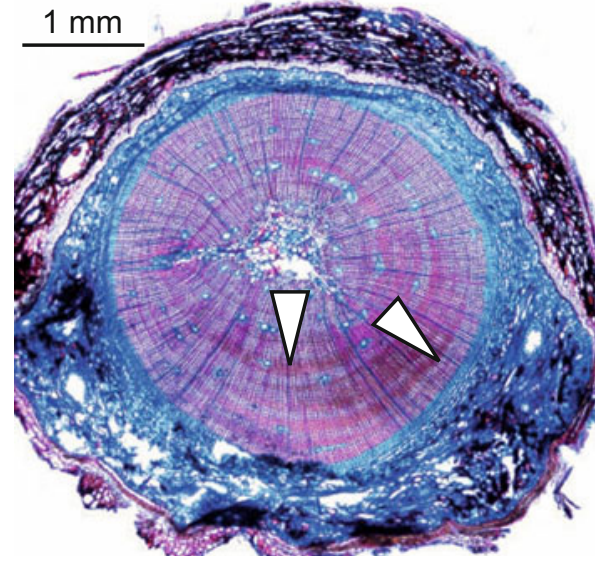

10.101 Compression wood in a twig of Pinus sylvestris.

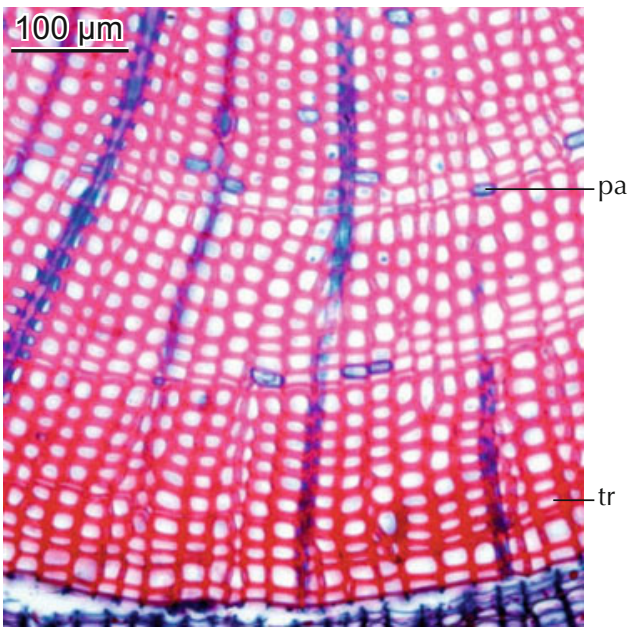

10.102 Compression wood in a twig of Taxus baccata. Only tracheids form compression wood. Axia parenchyma cells and rays are not responsive. tertiary wall

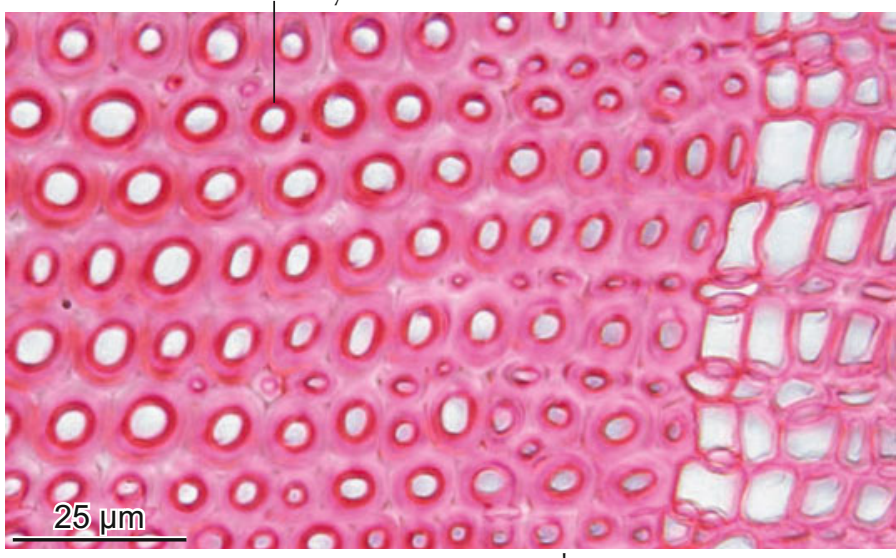

Iw

10.104 Round, thick-walled latewood tracheids with large, distinct tertiary walls in Pinus mugo.

right-turning horizontal

left-turning

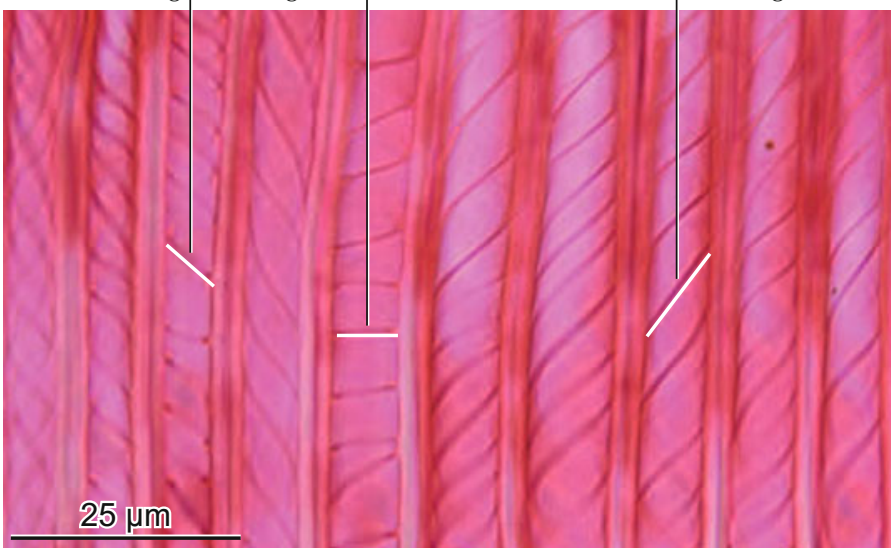

10.106 Changing direction in the angle of helical thickenings in Taxus baccata indicates various gravitational influences. Some helical thickenings in tracheids are left-turning, and some are right-turning. 


\subsubsection{Tension wood in angiosperms}

Tension wood is difficult to recognize on polished wood discs. Macroscopically it appears on planed longitudinal sections as a felt-textured surface. The chemical composition and the position of gelatinous fibers within plants differ. Tension wood primarily occurs on the tension side in the xylem of angiosperm trees, shrubs and herbs, but also in the cortex and the phloem of angiosperm herbs (e.g. in Euphorbia sp.), shrubs (e.g. Daphne sp.) and trees (e.g. Broussonetia papyrifera) and in gymnosperms (e.g. Gnetum gnemon). The presence of lignified primary walls is common for gelatinous fibers in the xylem. The anatomical and chemical composition of tension wood varies, which is shown by differences in acceptance of Astrablue/Safranin stain. The function of gelatinous fibers probably varies between different types. Their occurrence in species with extremely different positions within the phylogenetic tree leads to the assumption that gelatinous fibers, at least those in the cortex, are of polyphyletic origin.

\section{Macroscopic aspect}

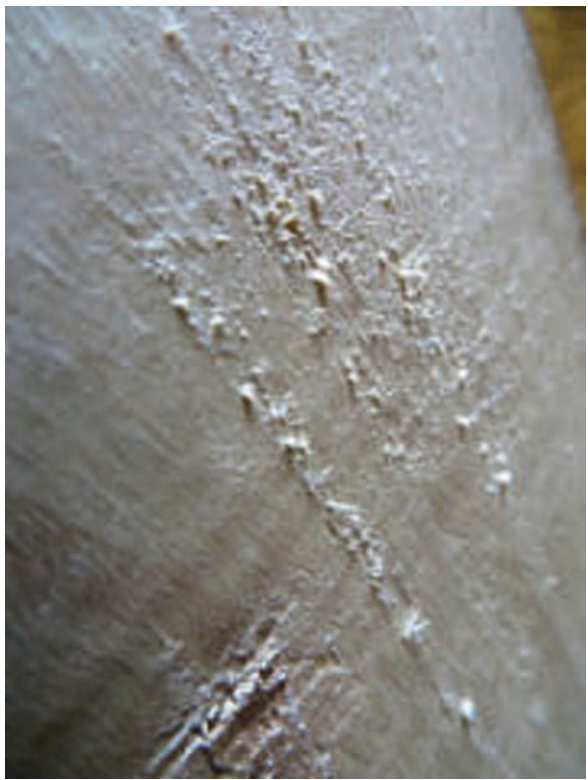

10.107 Planed board of a Populus sp. The feltlike surface is characteristic for tension wood. Photo: A. Crivellaro.

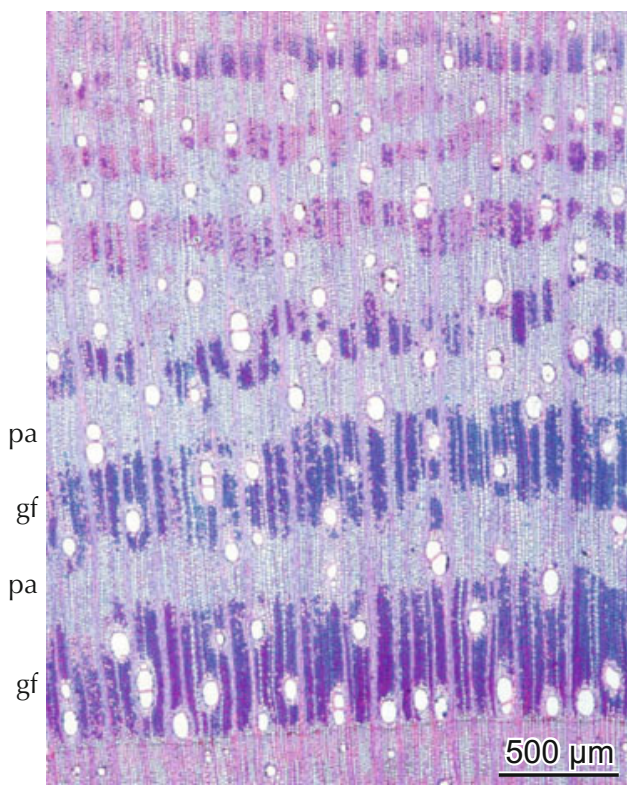

10.110 Stem of Ficus carica with tangential bands of different intensities of tension wood (violet) in the earlywood.

Microscopic aspect - Location within the xylem and bark

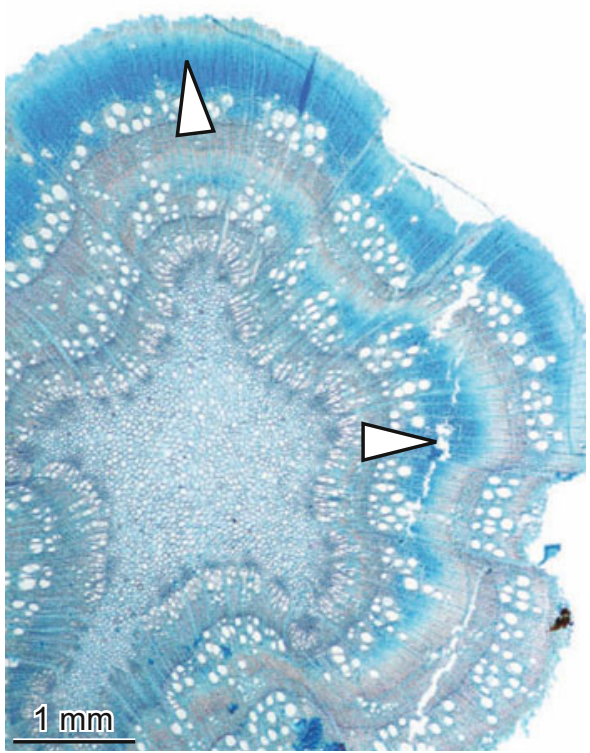

10.108 Twig with tension wood (blue) in the latewood of the second and third ring in a cross section of Quercus robur.

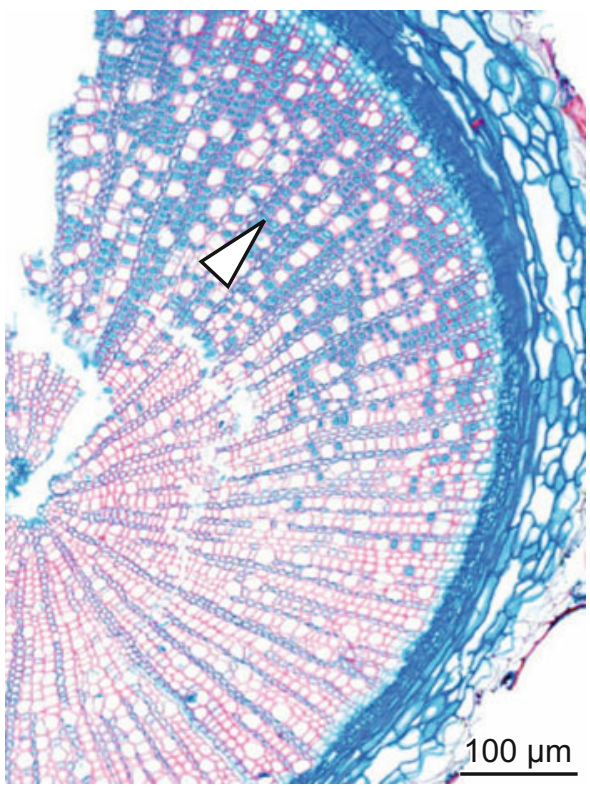

10.111 Shoot of Linum bienne with tension wood (blue) in the whole ring of the annual plant.

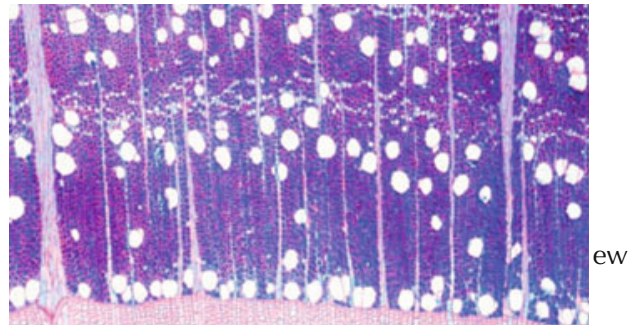

Iw

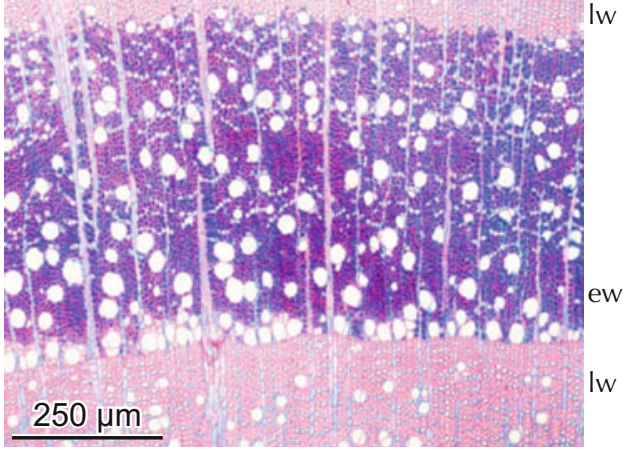

10.109 Stem of Fagus sylvatica with tension wood (violet) in the earlywood.

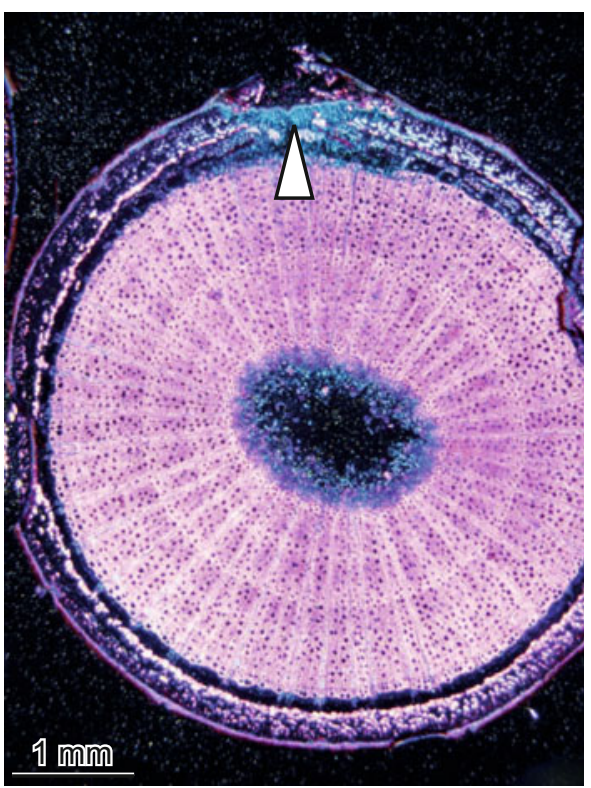

10.112 Tension wood in the bark of the Gnetaceae Gnetum gnemon, polarized light. 
Gelatinous fibers in the xylem
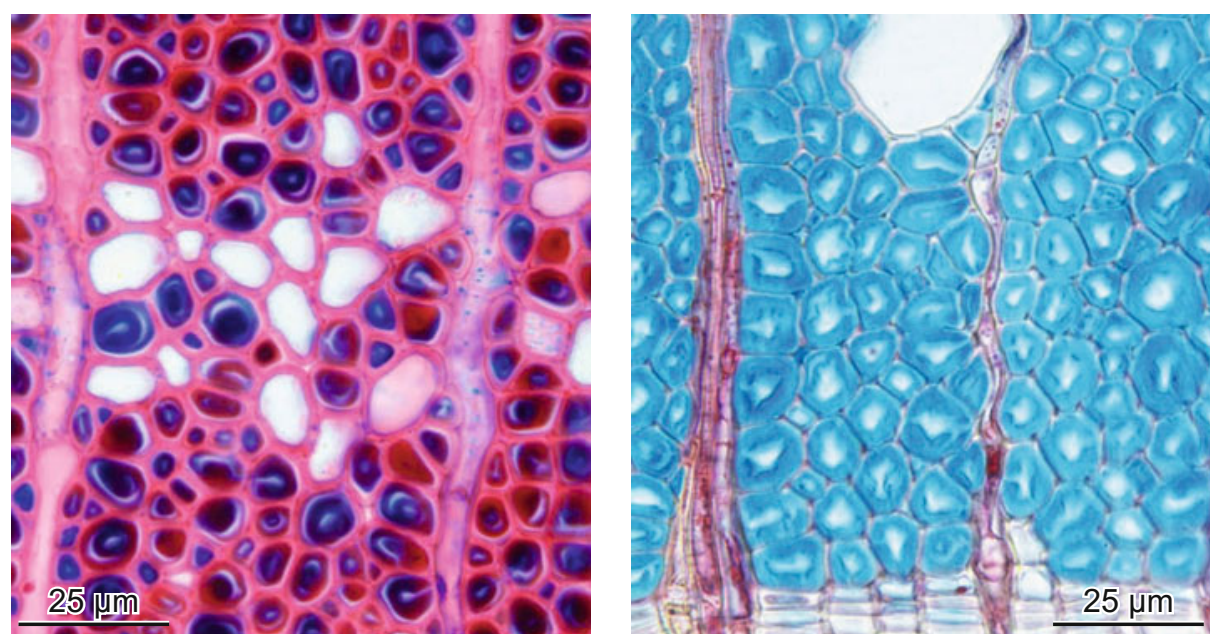

10.113 Dark-blue- to red-stained secondary walls of the tree Fagus sy/vatica, Fagaceae.

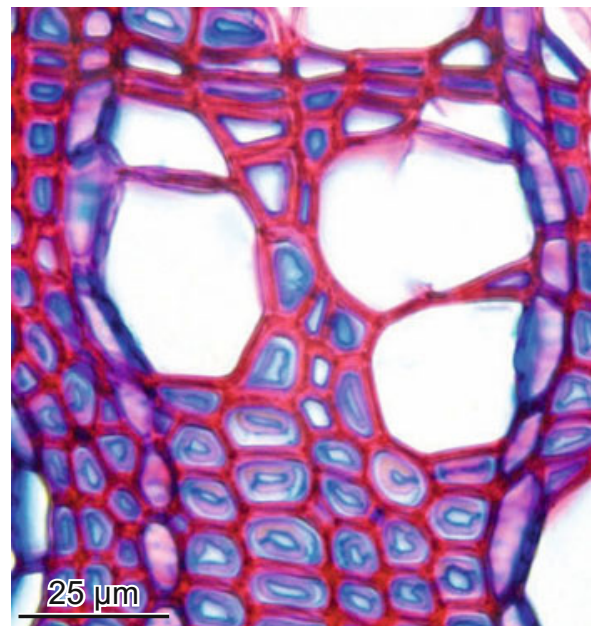

10.116 Pink-stained secondary walls and bluestained tertiary walls in the alpine prostrate dwarf shrub Salix retusa, Salicaceae.

10.114 Light-blue-stained secondary walls of the tree Betula pendula, Betulaceae.

10.117 Red- to dark-blue-stained secondary and tertiary walls in Sorbus aucuparia, Rosaceae. Tension wood is hardly expressed.

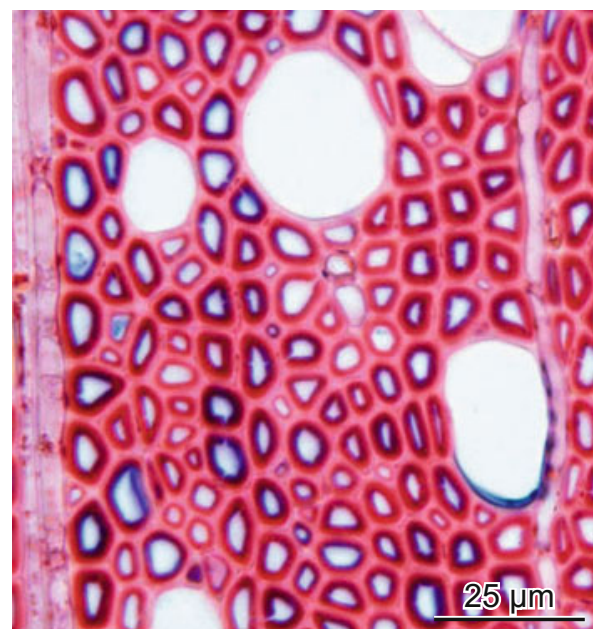

Gelatinous fibers in the cortex

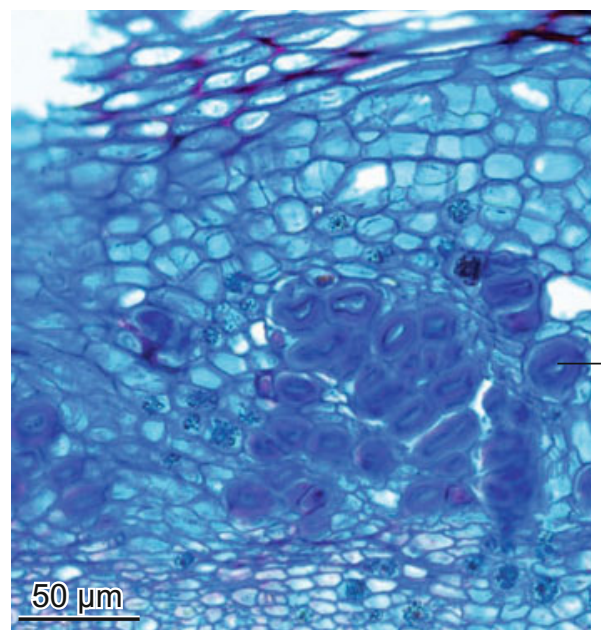

10.119 Dark-blue-stained gelatinous fibers in Urtica dioica, Urticaceae. These fibers were used for textiles.

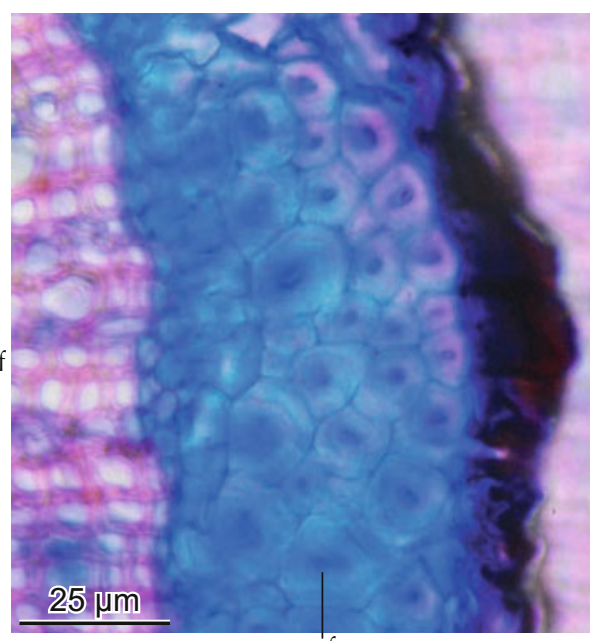

g

10.120 Blue-stained gelatinous fibers in Linum usitatissimum, Linaceae. These fibers are used for textiles (linen).

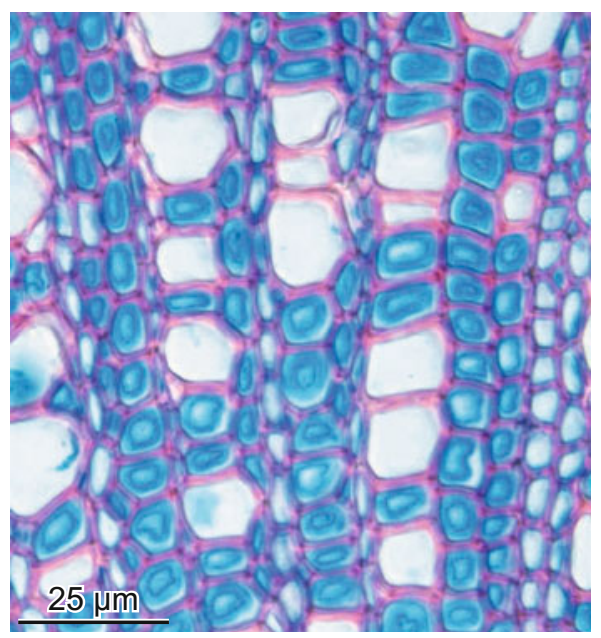

10.115 Light-blue-stained secondary walls of the annual herb Linum bienne, Linaceae.

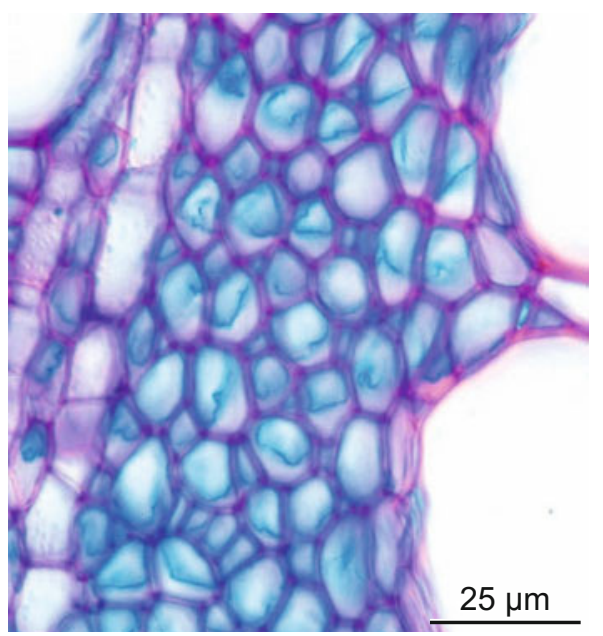

10.118 Doubtful tension wood. The fibers with thin blue secondary or tertiary walls are located at the tension side of the annual herb Cannabis sativa, Cannabaceae.

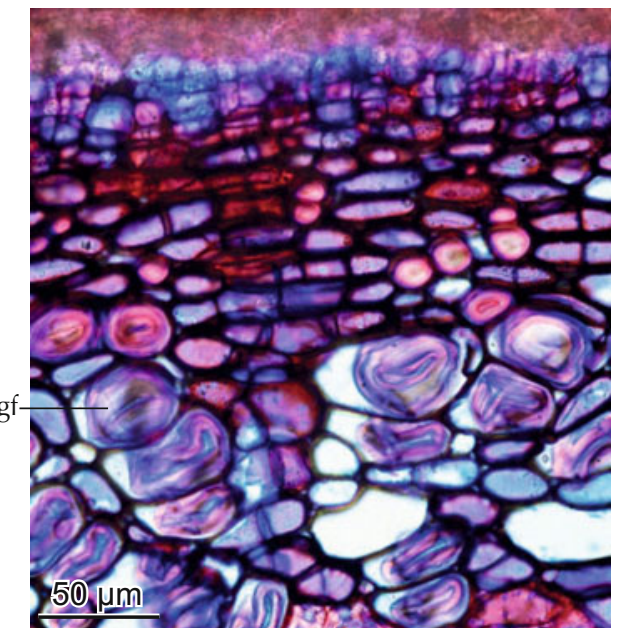

10.121 Pink-stained gelatinous fibers in Gnetum gnemon, Gnetaceae. These fibers are used for strings of musical instruments. 


\subsection{Cell collapse and lateral ray compression}

Cell collapse occurs in the xylem, the phloem, the cortex and the phellem. As soon as the turgor in thin-walled cells exceptionally decreases, the negative pressure makes cells collapse.

Cell collapse in the xylem is the first step of a chain reaction. Direct mechanical damage, e.g. by hail stones or woodpeckers, primarily causes cell damage which induces callus formation. Physiological imbalances between transpiration and available water resources can cause negative pressure in water conductive areas. Therefore thin-walled, unlignified vessels, tracheids or fibers can collapse. This occurs e.g. after browsing, pollarding, heavy frost damage in the leaf area, or extreme summer droughts.

Cell collapse in the phloem is a normal, ontogenetic phenomenon for many species. As soon as sieve elements are no longer turgescent, they collapse. The occurrence of collapsed sieve elements is an indication for a non-conductive phloem. Periodic collapse of tangential bands of sieve tubes leads to a radial contraction and, in consequence, to bent rays. Cork cells in the phellem mostly collapse soon after their formation.

The course of a ray in the xylem is influenced by the pressure in vessels. Vessel development normally has the highest priority within the xylem formation. Due to high pressure in vessels, adjoining rays may change their course. They get compressed, but do not collapse.

Subfossil and fossil wood is often deformed, e.g. by heavy ice or sediment loads. The weakest components of the xylem-mostly earlywood tracheids-collapse. Anaerobically degraded wet wood from archaeological sites shrinks dramatically, which is microscopically expressed by deformed, compressed cells.

Macroscopic phenomena causing cell collapse

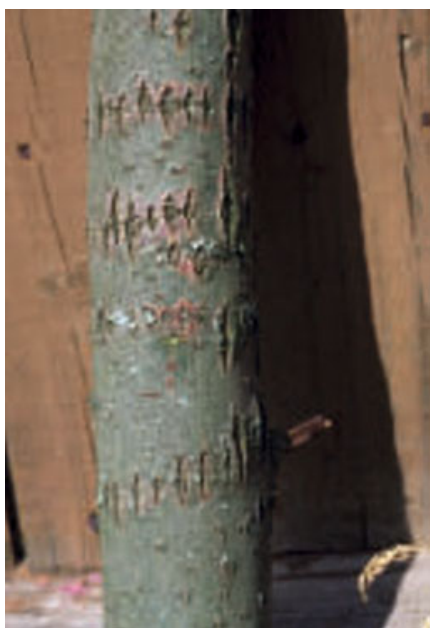

10.122 Woodpecker marks on a Salix sp.

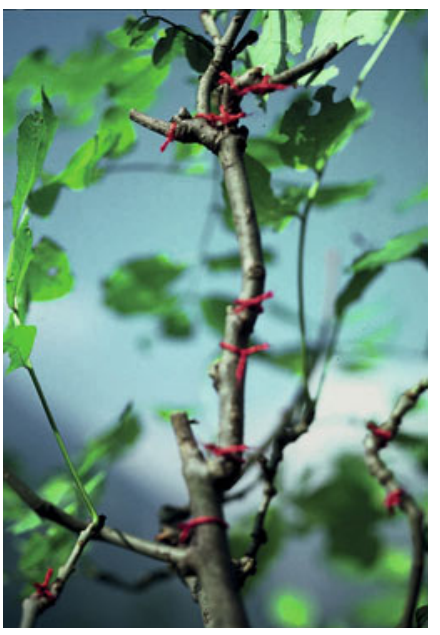

10.123 Browsed Fraxinus sp.

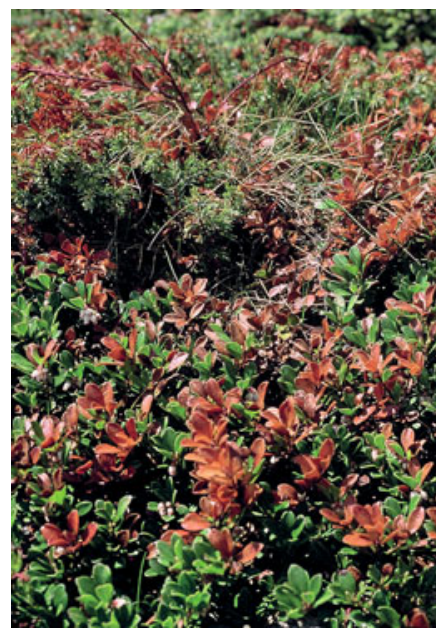

10.124 Frost damage on the dwarf shrub Arctostaphylos uva-ursi.

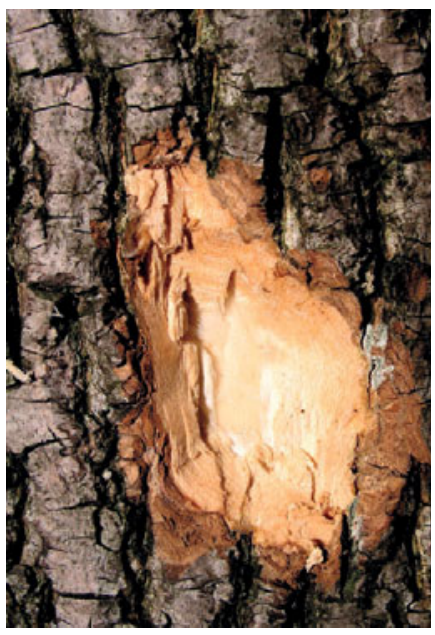

10.125 Wounded bark of an old Salix sp.

Cell collapse in the xylem

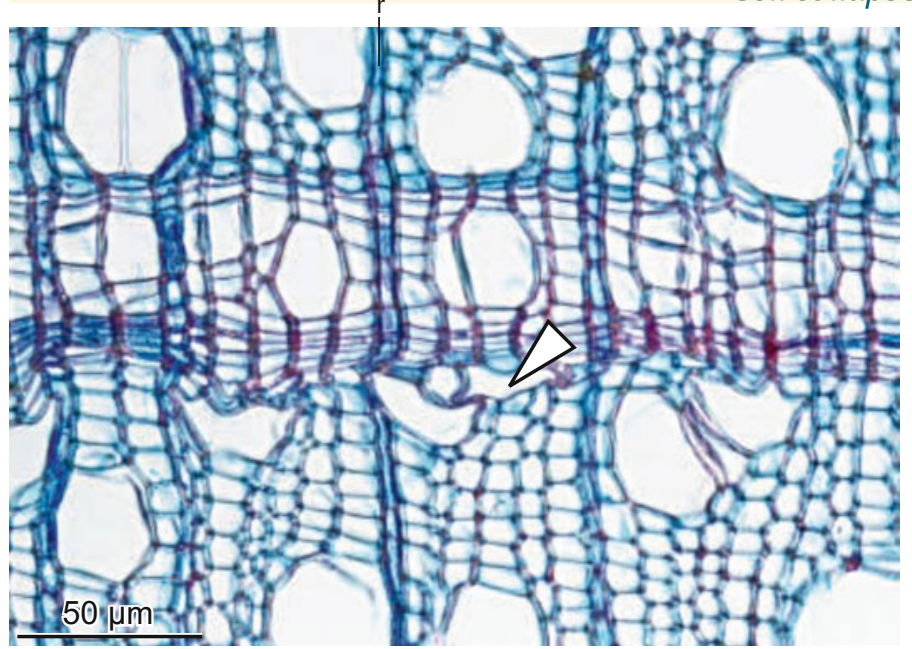

10.126 Collapsed vessels in the alpine Salix glaucosericea after a heavy late frost.

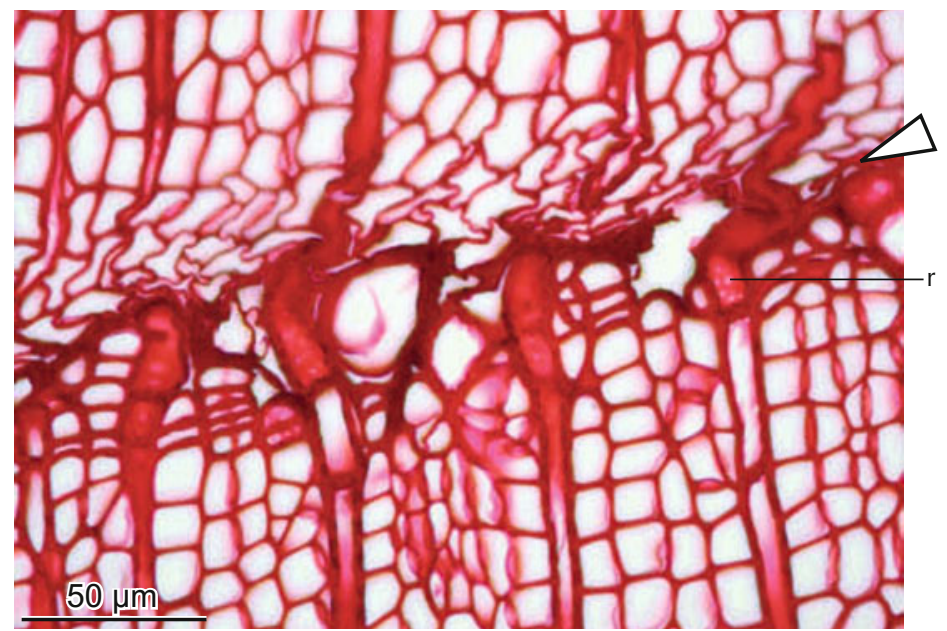

10.127 Collapsed tracheids and bent rays in Larix sibirica after a heavy late frost. 
Cell collapse and cell deformation in the phloem

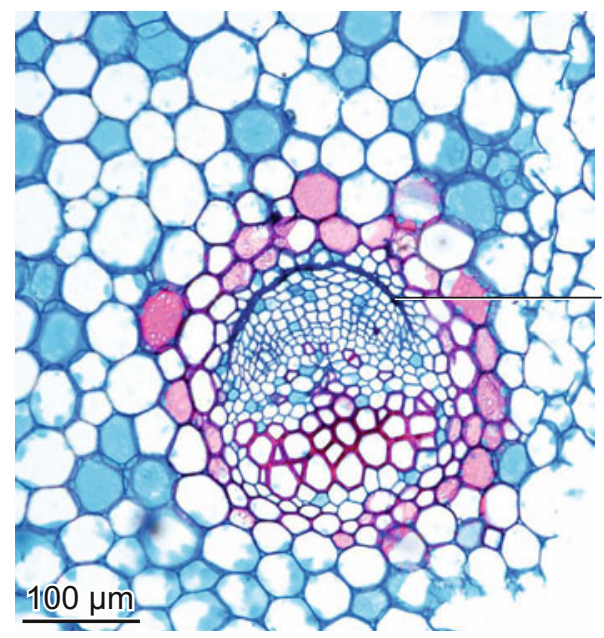

10.128 Collapsed and compressed sieve elethe petiole of Cycas revoluta.

Cork cell collapse in the phellem

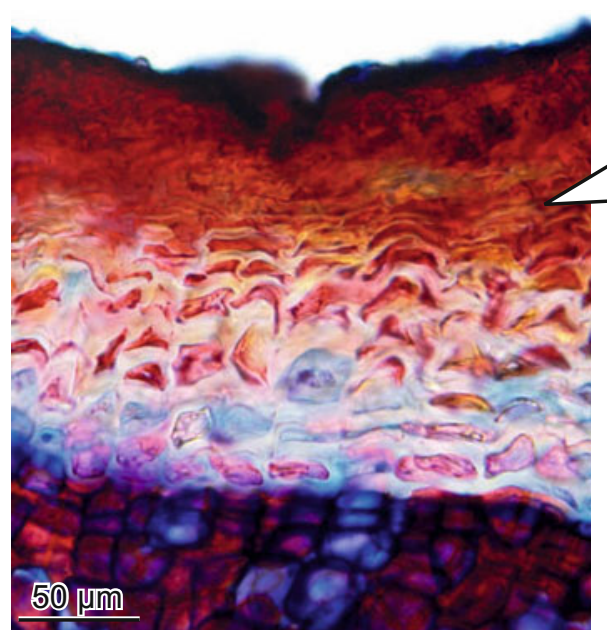

10.131 Collapsed dead cork cells in the phellem

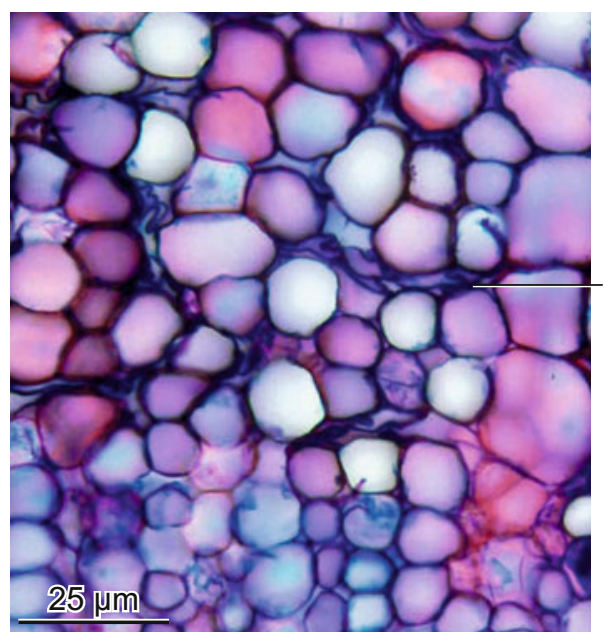

10.129 Collapsed sieve elements between parentree Schinus molle.

Lateral compression of rays

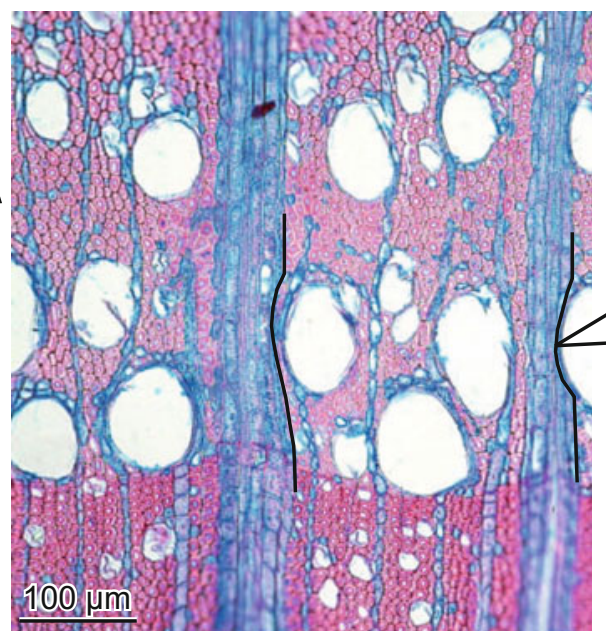

10.132 Living rays, bent in the area of large ves-

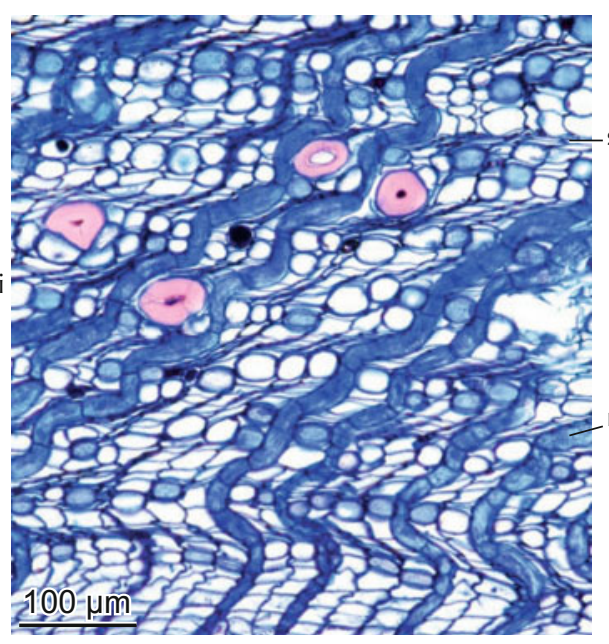

10.130 Compressed and deformed tangentially conifer Larix decidua.

Macroscopic aspect of subfossil wood

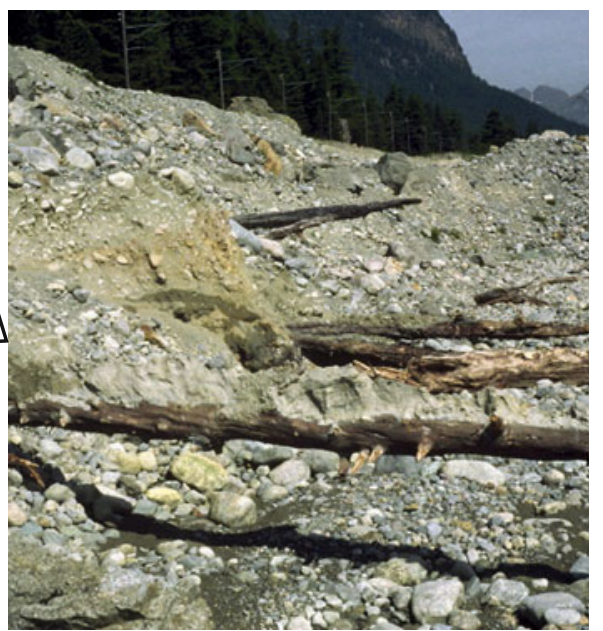

10.133 Subfossil stems in Quaternary river sedi ments of the Alps.

Microscopic aspect of subfossil and fossil wood

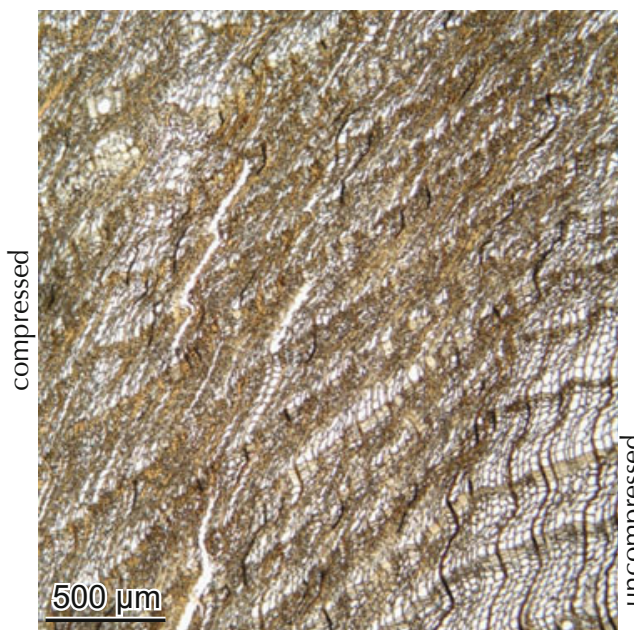

10.134 Compressed xylem of a stem of Larix

decidua in a glacier moraine.

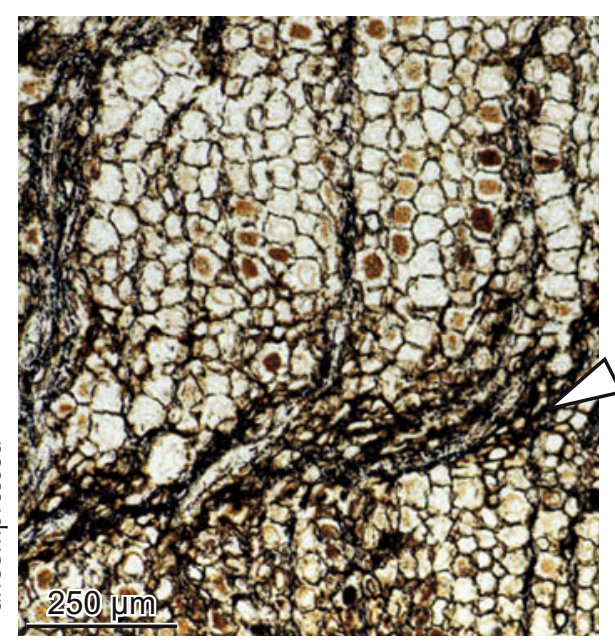

ous petrified wood of Dadoxylon sp.

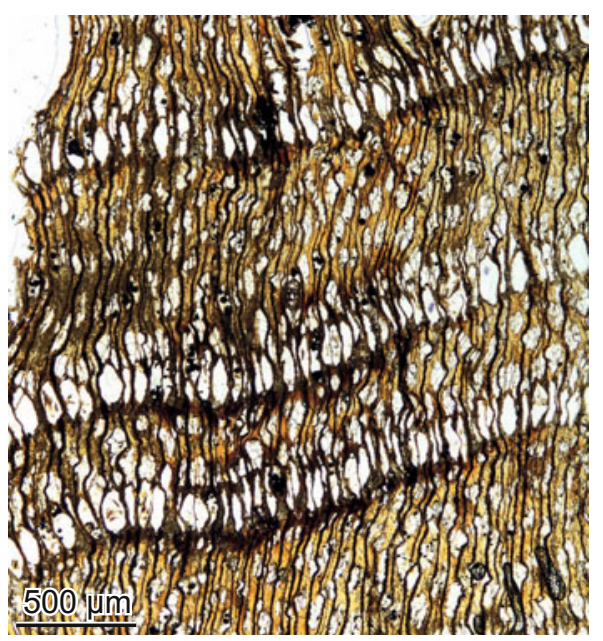

10.136 Laterally compressed xylem in the Neo-

drated wood of Fraxinus excelsior. 


\subsection{Cambial wounding - Callus formation, overgrowing of wounds}

All plants with secondary growth have been confronted with cambial wounding by mechanical, environmental, biological or pathogenic causes for more than 300 million years. Repair mechanisms have therefore been developed to isolate the living tissues from destruents and pathogens. Wounds can be caused mechanically by environmental factors, such as hail, lightening, storms, fire, rock fall, floods, avalanches, ice plates, pruning or decapitation, and-human-induced-by grafting. Many wounds are biologically induced by animals, such as insects, birds, herbivores, rodents, and many others. Pathogenic infestations can also cause cambial reactions, e.g. mistletoes, witches' brooms, fungi, or cancerous agents.

If meristematic cells are affected, a reaction chain starts. The first anatomically visible step is the formation of a chemical and mechanical protective zone, called barrier zone. Chemical boundaries compartmentalize parts of stems adapted to their anatomical structure (Shigo 1989; see also Chapter 12.4). All cell elements can be plugged with phenols, and vessels with tyloses. Protective reactions are weak along the stem axis, but intense in radial and tangential directions. In a second step, callus tissue formed. Living meristematic and parenchymatic cells produce undifferentiated cells. The further wound occlusion process is characterized by accelerated growth, the transformation of undifferentiated callus cells to original xylem and phloem cells, and the reorganization of the cell structure corresponding to the stem axis.

Monocotyledonous plants are not able to close wounds. The excretion of phenolic slime, and the formation of tyloses and suberin layers around wounds protect the culms of bamboo against decay (Liese \& Köhl 2015).

\section{Macroscopic aspect of scars}

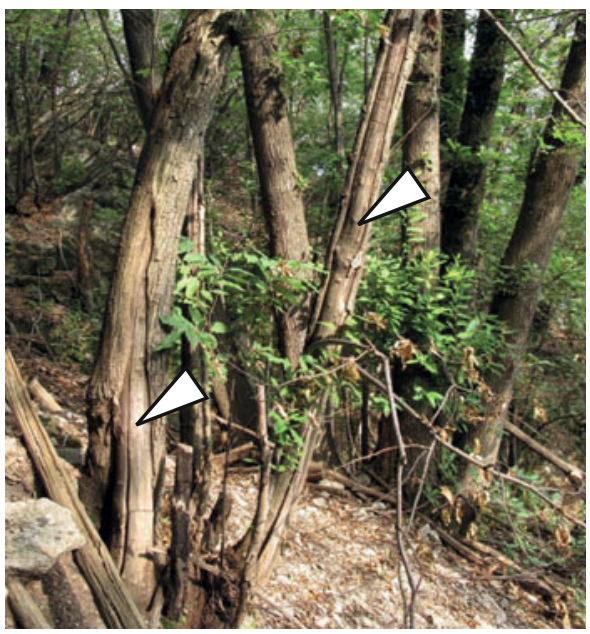

10.137 Fire scars on Castanea sativa.

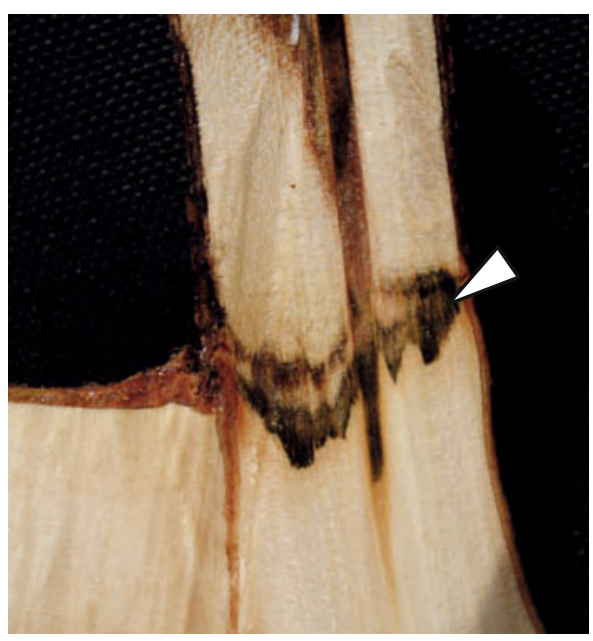

10.140 Barrier zone at the base of a dead branch of Acer pseudoplatanus.

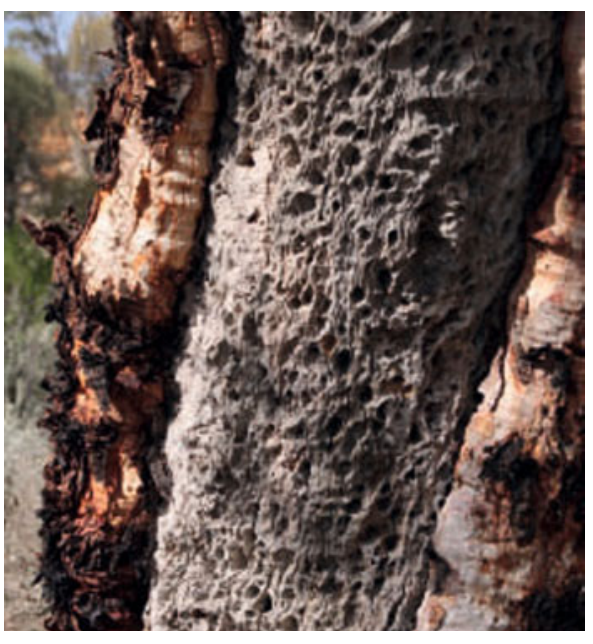

10.138 Open scar on a stem of Eucalyptus capillosa.

\section{Barrier zones}

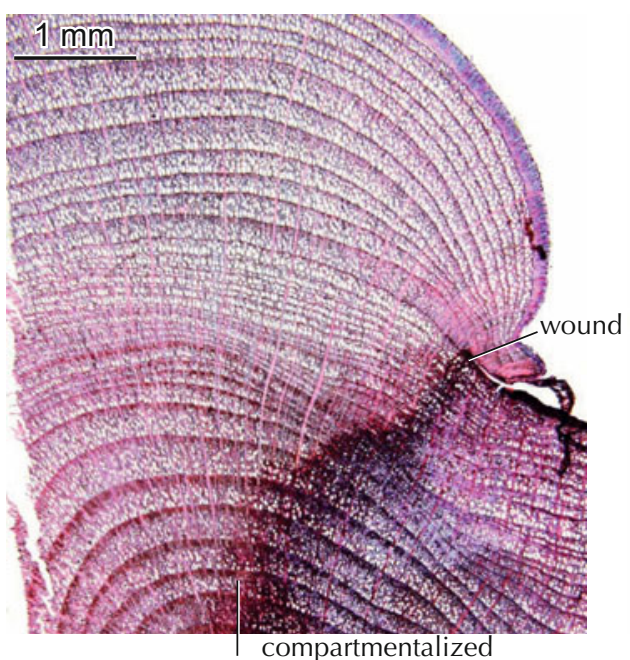

10.141 Compartmentalized zone of a mechanical wound in the dwarf shrub Arctostaphylos uva-ursi.

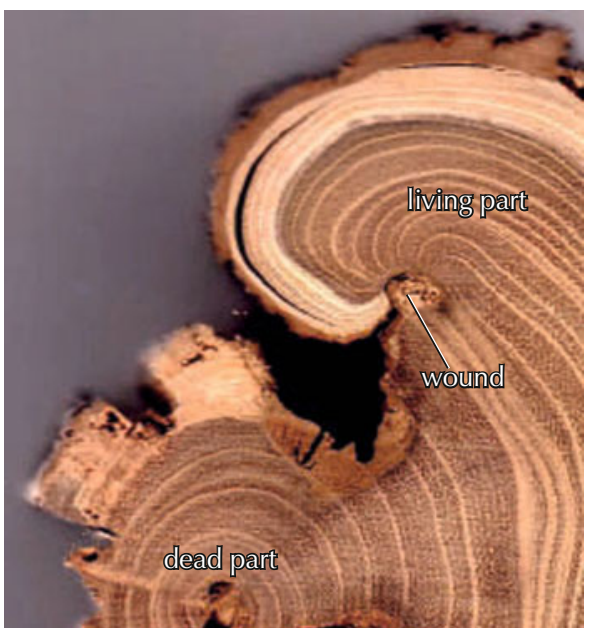

10.139 Surviving callus after fire on a stem of Robinia pseudoacacia.

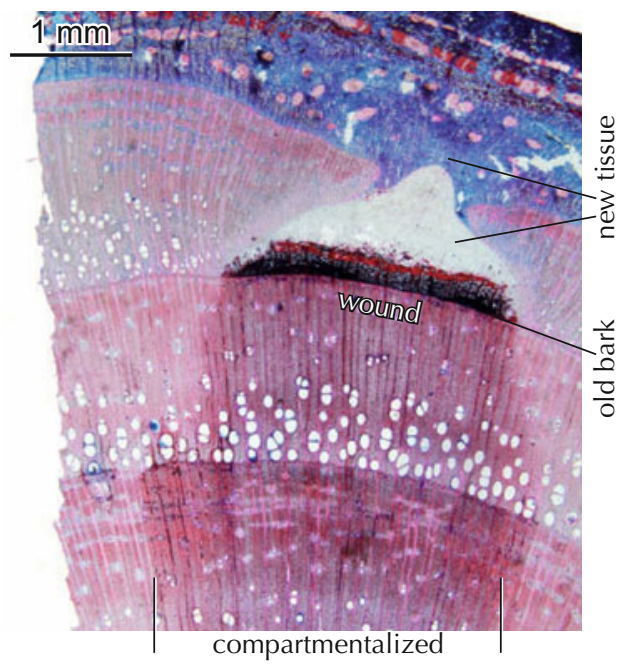

10.142 Compartmentalized and overgrown zone of a mechanical wound in the tree Fraxinus excelsior. 


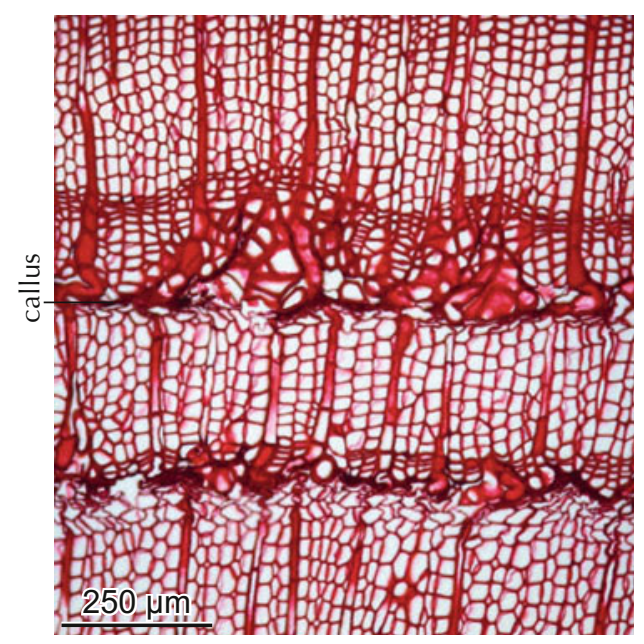

10.143 Frost rings with callus cells in Larix decidua.

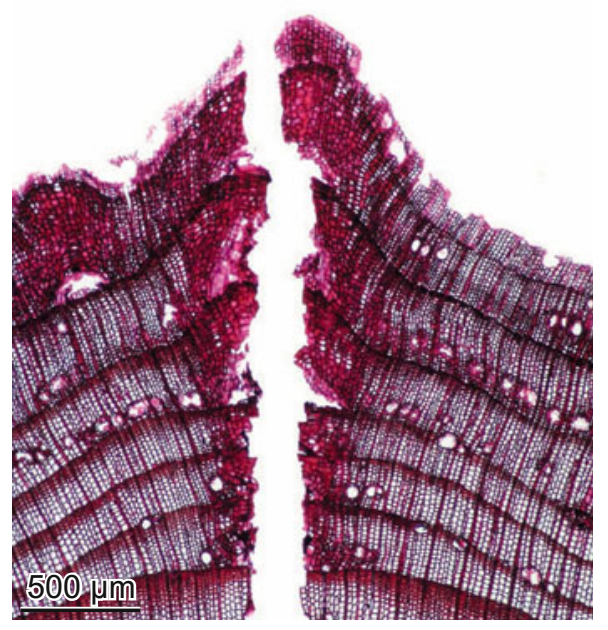

10.144 Frost crack with lateral callus cells in Larix decidua.

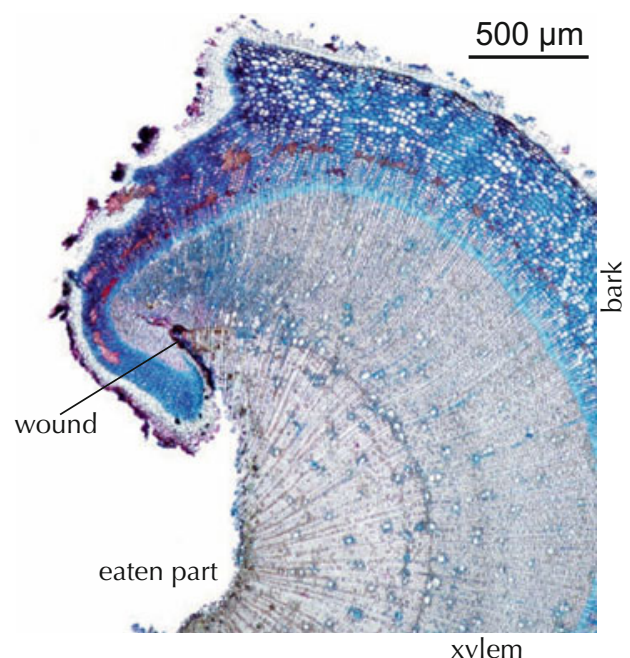

10.145 Scar from a rodent on a shoot of Fraxinus excelsior.
Open scar

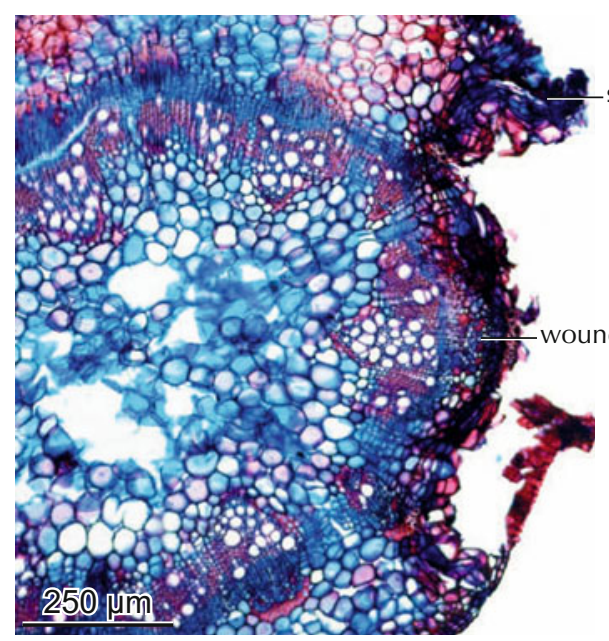

10.146 Scar on an annual stem of the $2 \mathrm{~cm}$-tall herb Knorringia pamirica.
Overgrown scars

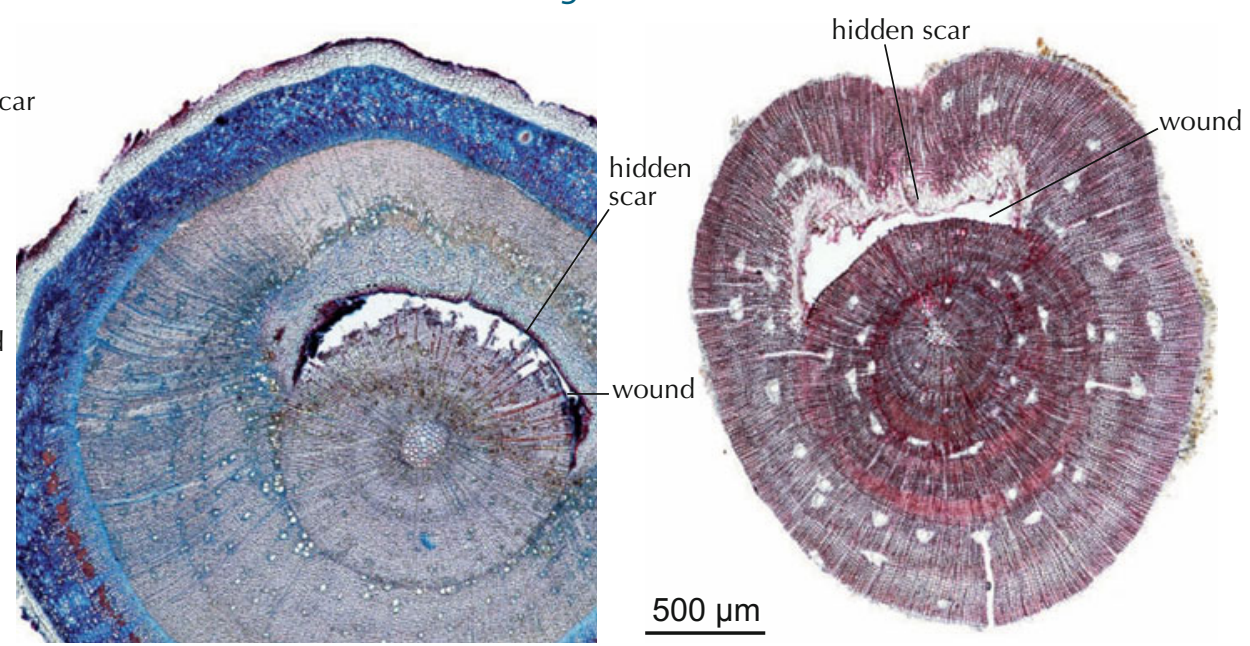

10.147 Completely healed wound with a hidden scar on a $10 \mathrm{~cm}$-tall seedling of Fraxinus excelsior.
10.148 Completely healed hail wound with a hidden scar on a small branch of Pinus mugo.

Reorientation of the axial fiber structure in an overgrowing scar

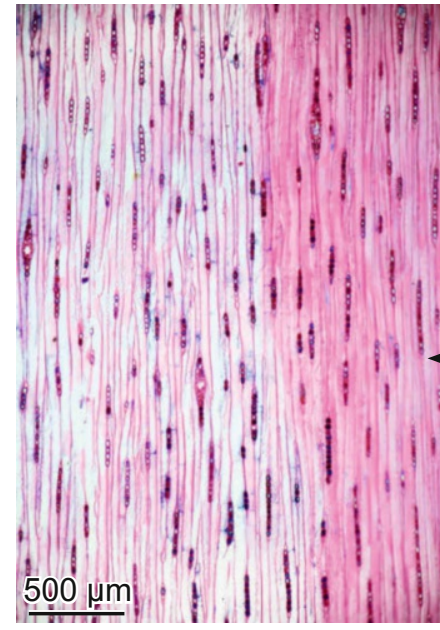

10.149 Axial parallel fiber and ray structure on the inside of the scar.

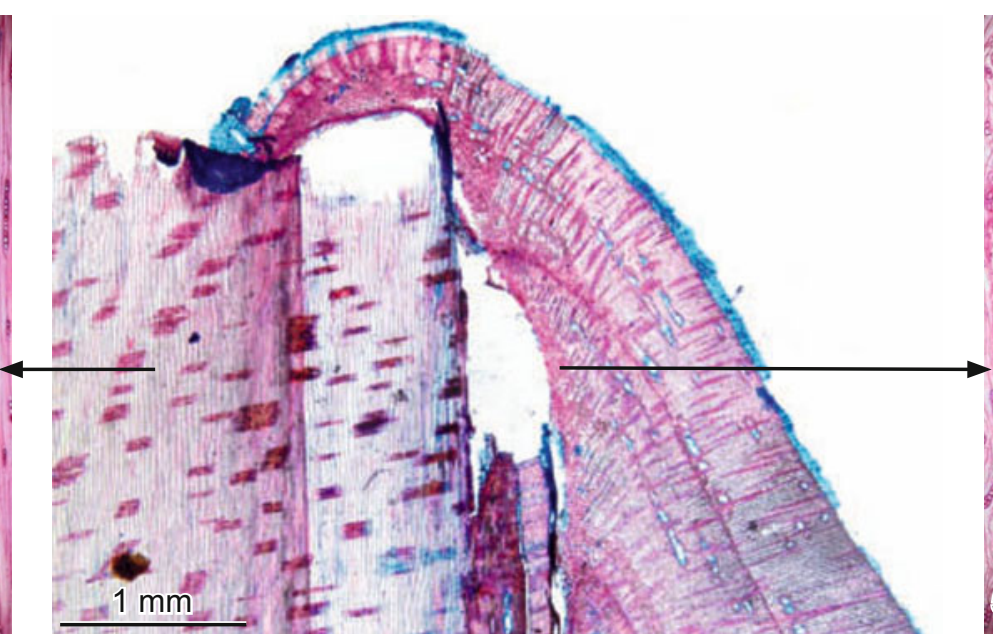

10.150 Scar on a broken stem of Picea abies.

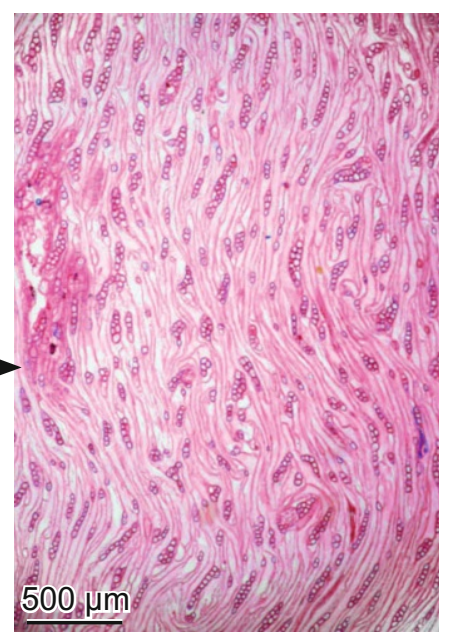

10.151 Chaotic fiber and ray structure on the outside of the scar. 


\subsection{Prevention of wounds}

Ontogentic processes in plants have the potential to create wounds. Obvious are scars created by dropping buds, leaves, twigs, fruits and rhizoids. Plants prevent wounds by the formation of periderms, especially phellem (cork), before the potential wound is exposed to destruents (see also Chapter 6.1.3).

Stem expansions created by radial growth cause tangential tension in the bark. Before bark cracks, living parenchymatic cells react with accelerated cell-wall growth and cell division, the phloem and cortex therefore dilate. Parallel to the expansion, phellem layers seal the endangered zone with cork (see also Chapter 6.2.1). Many small plants never form complete stems, they keep the form of vascular bundles for many years, however, they are linked by inter-fascicular cambia. Stem or root segregation is a widespread phenomenon in many taxonomic units, and in many biomes. A few examples may illustrate this here. Plant stems reorganize themselves by forming new phloem or periderm belts around a part of the xylem. Stems of many alpine cushion plants segregate near the soil surface. In consequence, living parenchyma cells change their physiological mode and form phloem, and partially phellem, all around the partial stems. The cactus Carnegia gigantea in American deserts has a full stem at the base, but a circle of single stems inside the cortex. A few species within the family of Primulaceae form little stems within a cortex without cambium.

Pathogenic organisms are able to penetrate meristems. Hosts and parasites live in a symbiosis. Hosts react to parasites, e.g. mistletoes, with accelerated growth without obvious structural disturbances.

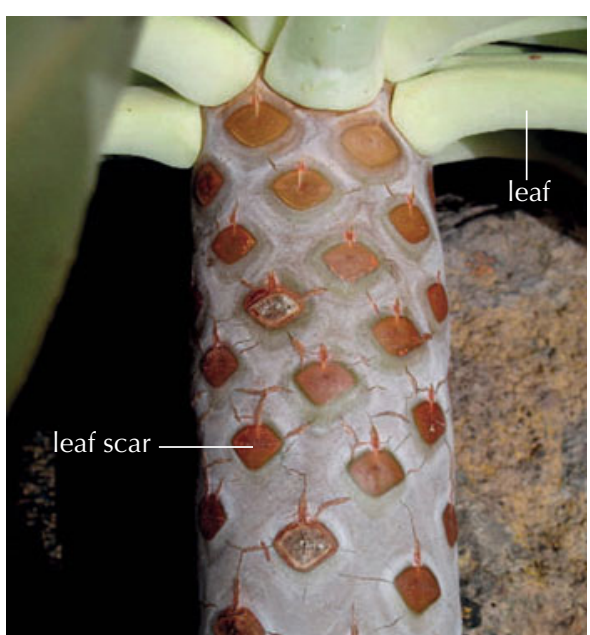

10.152 Leaf scars on a stem of the succulent Aeonium arboretum. Brown spots represent cork layers.

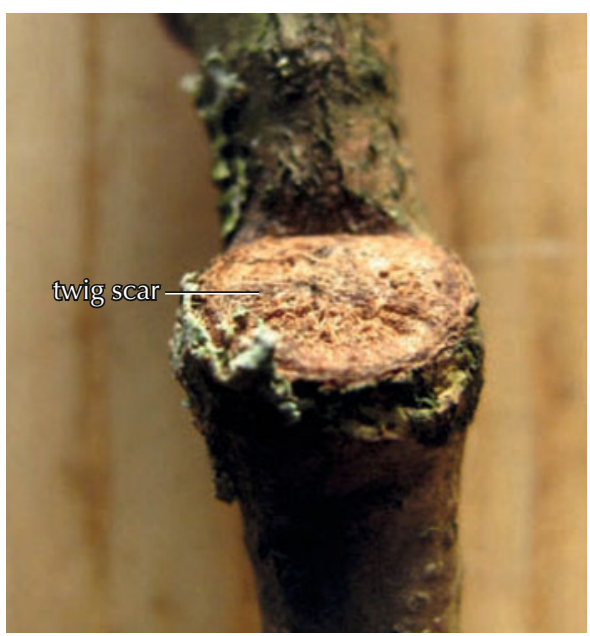

10.155 Macroscopic aspect of the scar of a shed twig in Quercus robur.

\section{Leaf scars}

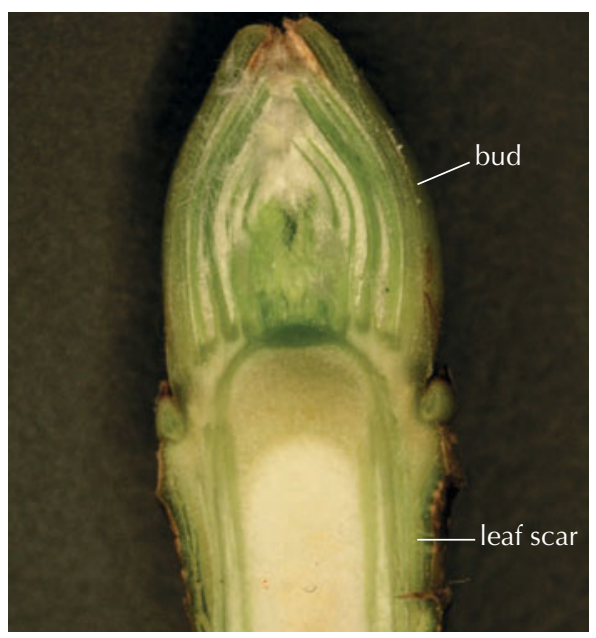

10.153 Macroscopic aspect of leaf scars on a long shoot of a twig of Acer pseudoplatanus.

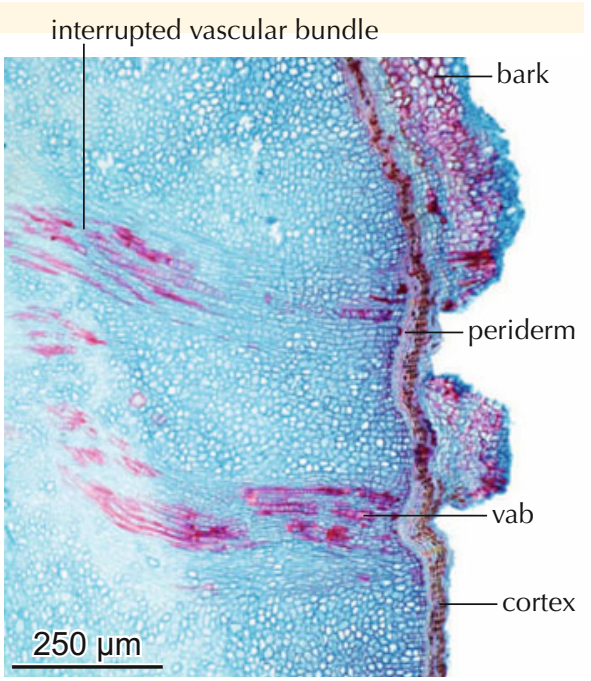

10.154 Microscopic aspect of leaf scars on a shoot of Castanea sativa.

\section{Twig abscission}

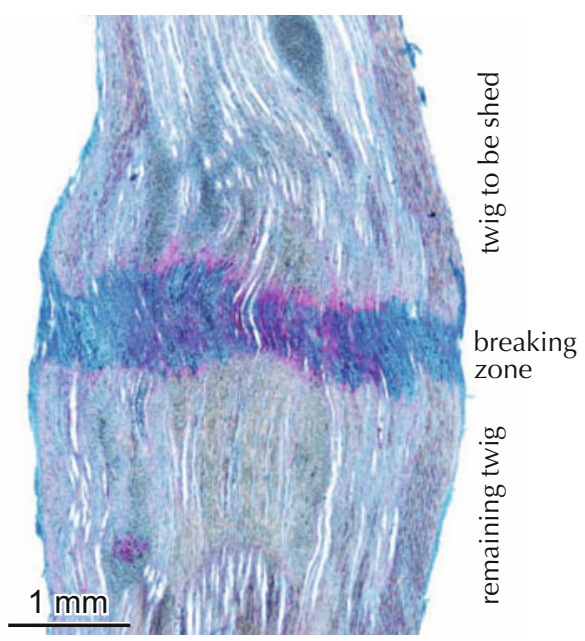

10.156 Longitudinal section trough a breaking zone of a twig of Quercus robur.

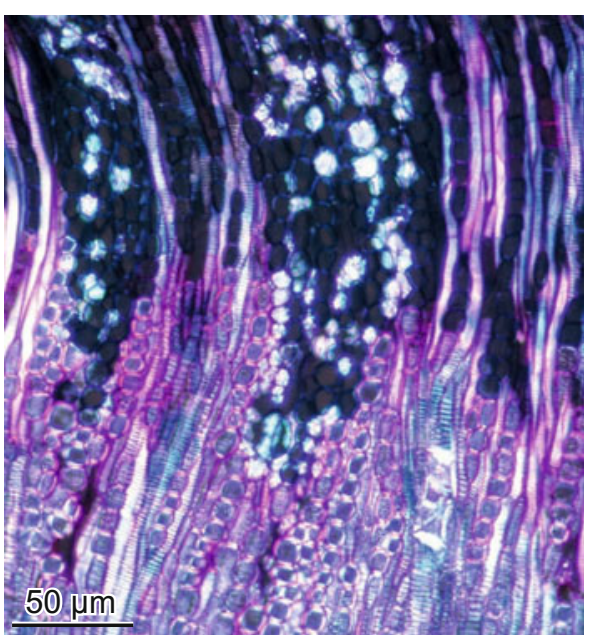

10.157 Microscopic detail of the breaking zone of a twig of Quercus robur, ploarized light. Crystal druses are characteristic. 
Fruit abscission

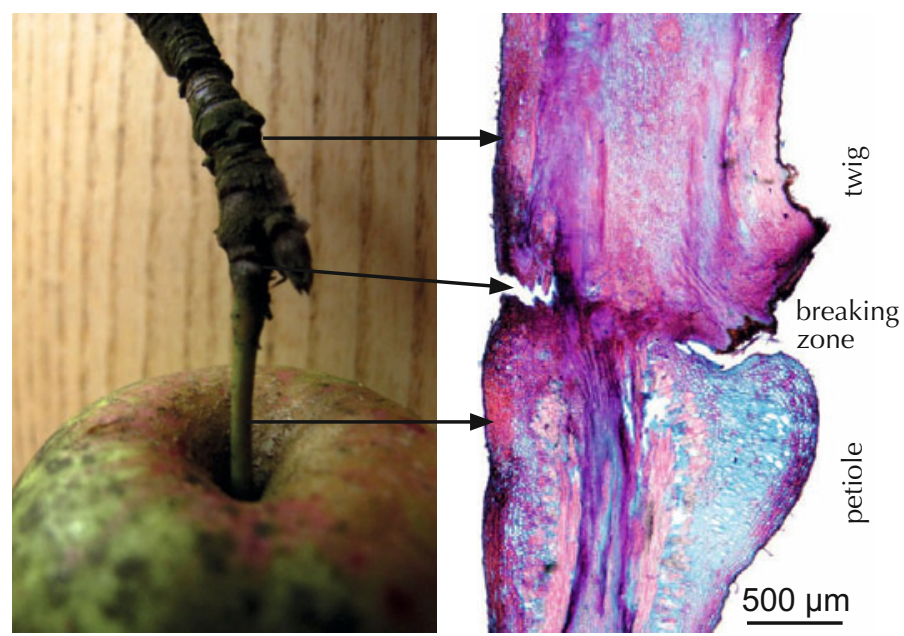

10.158 Apple (Malus sylvestris) with petiole on a twig before shedding.
10.159 Microscopic aspect of the abscission zone between petiole and twig in Malus sylvestris.

\section{Rhizoid abscission}

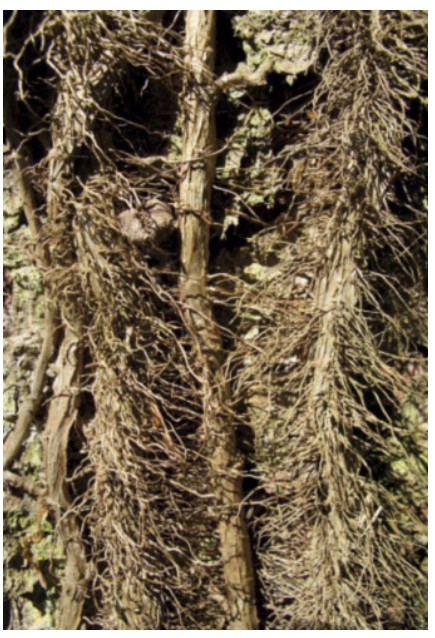

10.160 Dead rhizoids on the stem of the climber Hedera helix.

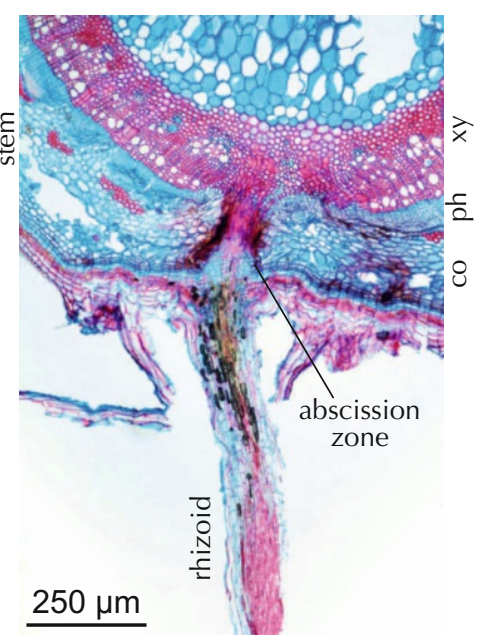

10.161 Interrupted connection between the stem and a rhizoid in Hedera helix.

Stem thickening and prevention of cracks in living stem parts

sclerenchyma

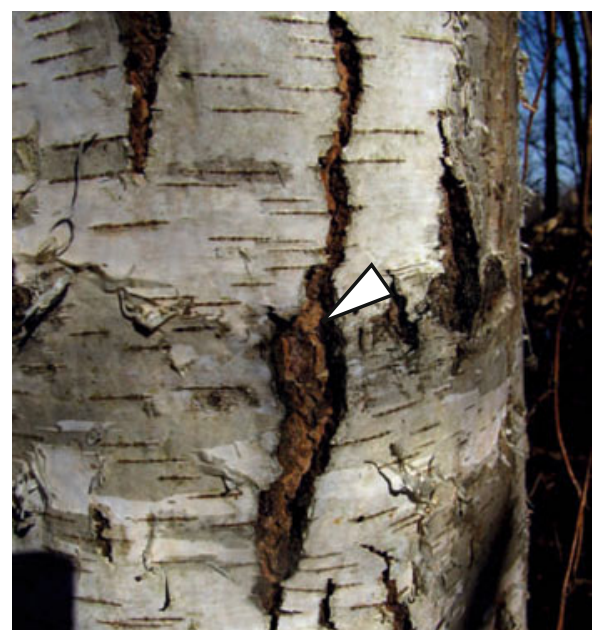

10.162 Longitudinal crack in the bark of Betula pendula.

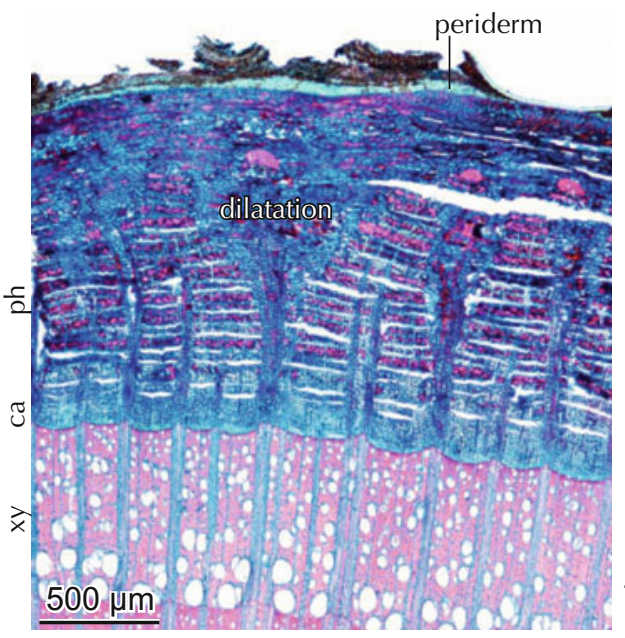

10.163 Phloem enlargement by dilation and formation of phellem in Rosa elliptica.

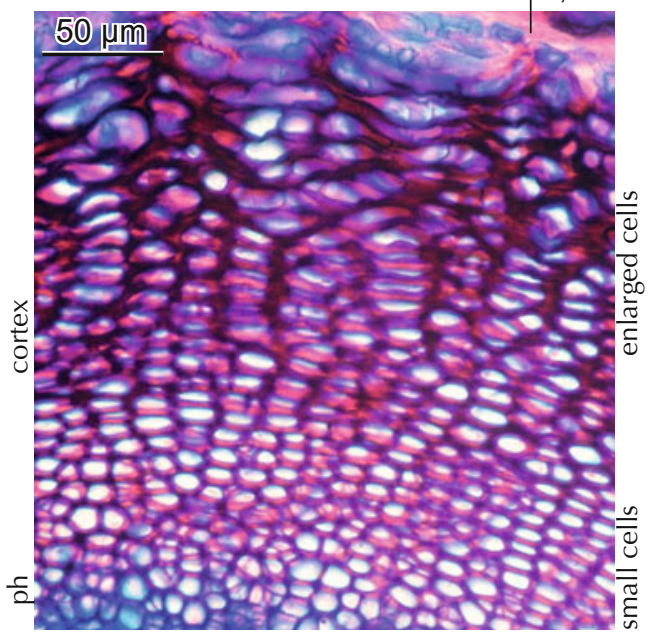

10.164 Cortex enlargement by cell wall growth, and reinforcement by sclerenchymatic tissues in the alpine herb Androsace villosa.

Initial stages of stem segregation in herbs

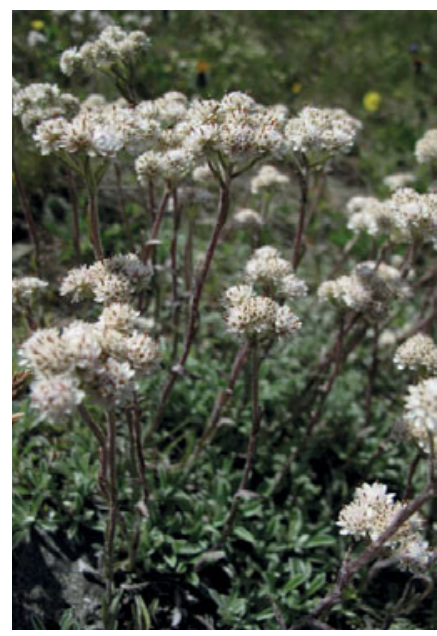

10.165 Alpine herb Antennaria dioica.

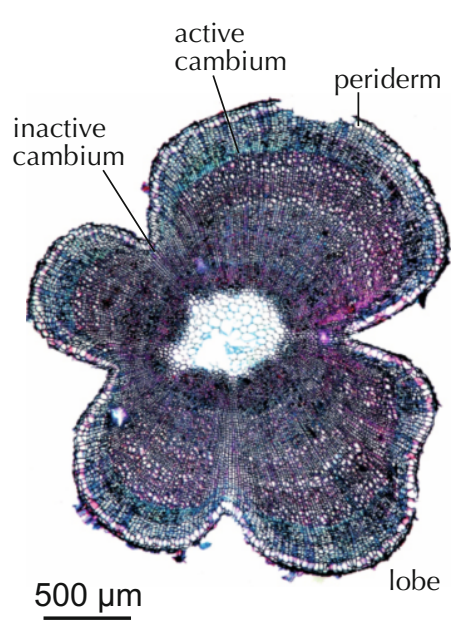

10.166 Formation of lobes is the first stage of stem segregation, Antennaria dioica.

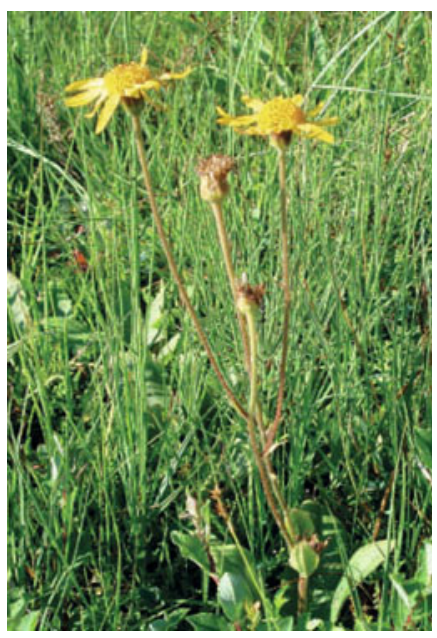

10.167 Alpine herb Arnica angustifolia.

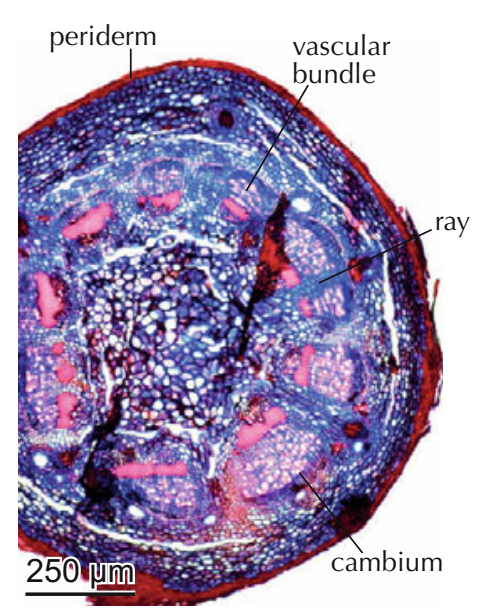

10.168 Vascular bundles in the rhizome of Arnica angustifolia represent incompletely segregated stems. 
Segregated stems of herbs

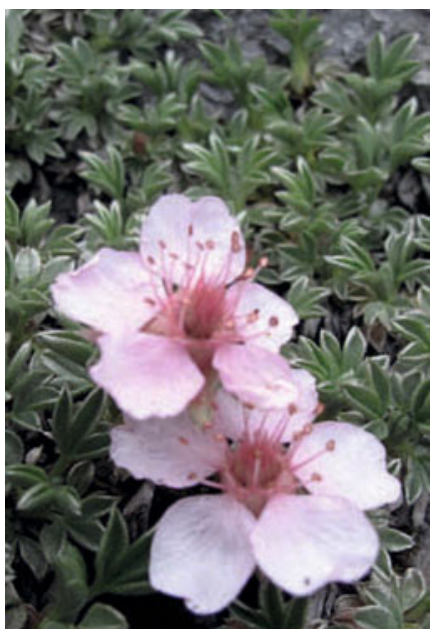

10.169 Alpine herb Potentilla nitida.

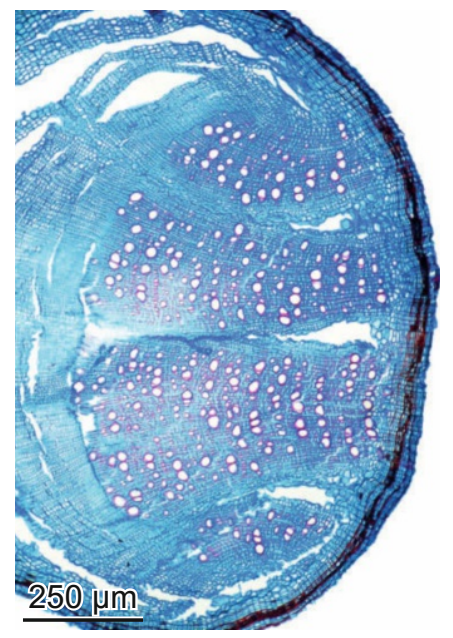

10.170 Microscopic aspect of a segregated rhizome of Potentilla nitida, completely surrounded by a periderm.
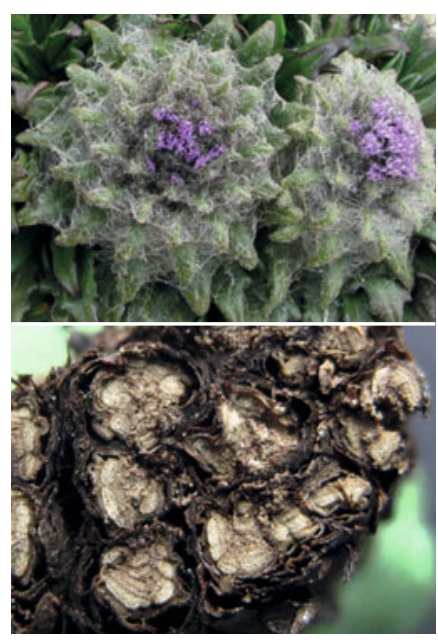

10.171 Top: Alpine cushion plant Saussurea hypsipeta. Bottom: Segregated stems of Saussurea glanduligera. Material: J. Dolezal.

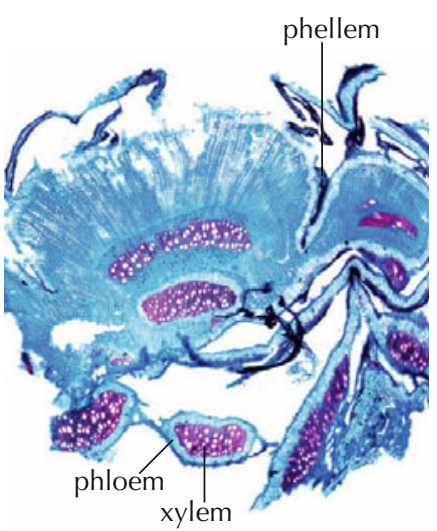

$500 \mu \mathrm{m}$

10.172 Microscopic aspect of a segregated stem of Saussurea andryaloides. Material: J. Dolezal.

Segregated stem of a cactus

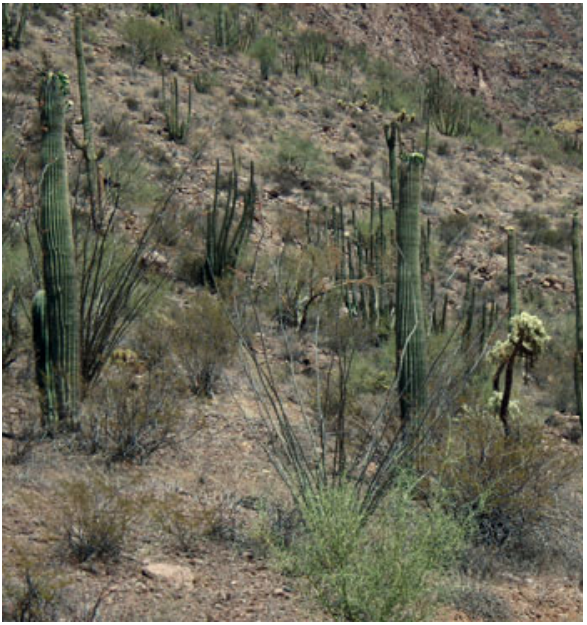

10.173 Carnegia gigantea in a desert in northern Mexico.

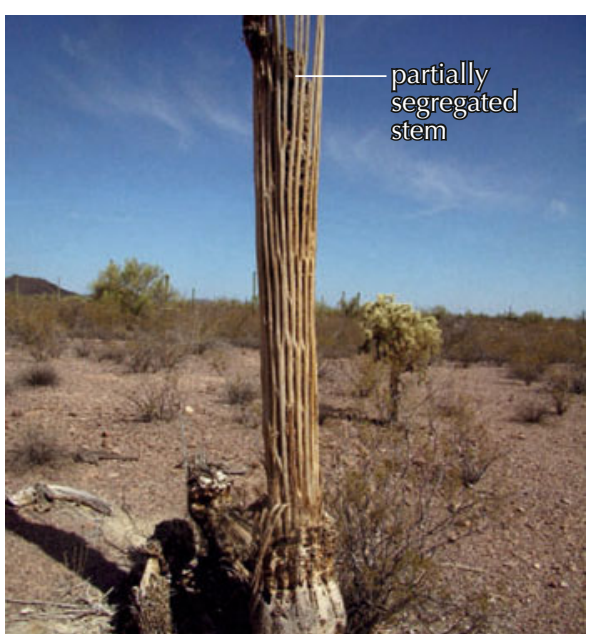

10.174 Macroscopic aspect of a segregated stem of Carnegia gigantea. The cortex is rotten.

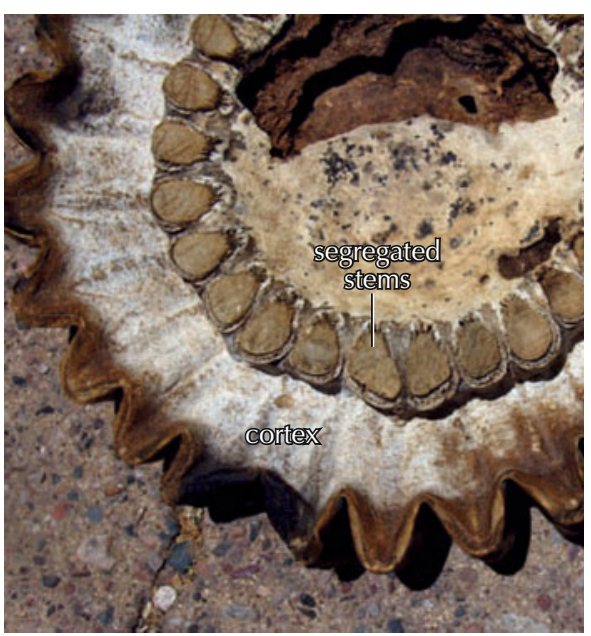

10.175 Macroscopic aspect of a cross section of a segregated stem of Carnegia gigantea.

Suppression of a rejection reaction between host and parasite haustorium

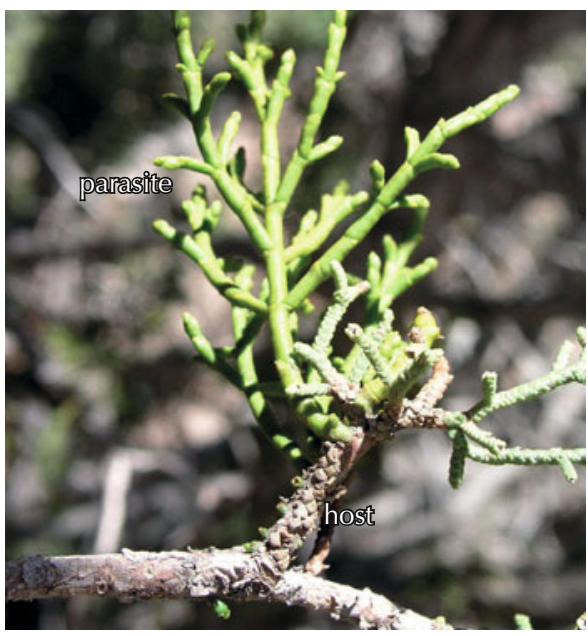

10.176 Semiparasite Phoradendron sp. on the conifer Juniperus sp.

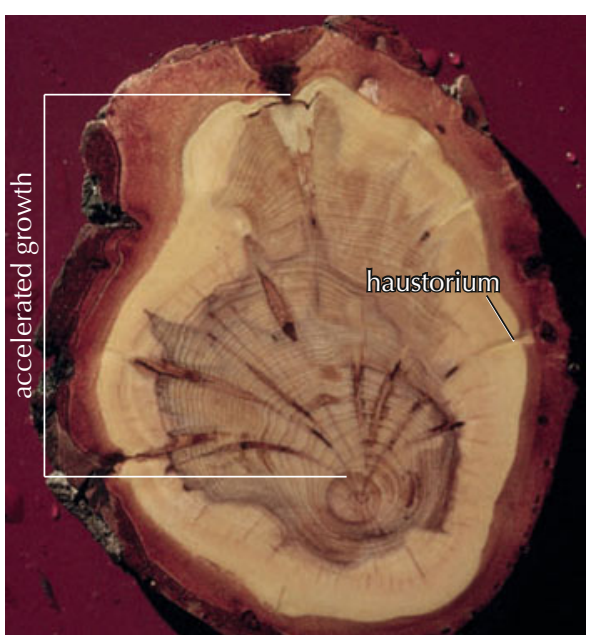

10.177 Macroscopic aspect of mistletoe haustoria (Viscum album) in a stem of Abies alba.

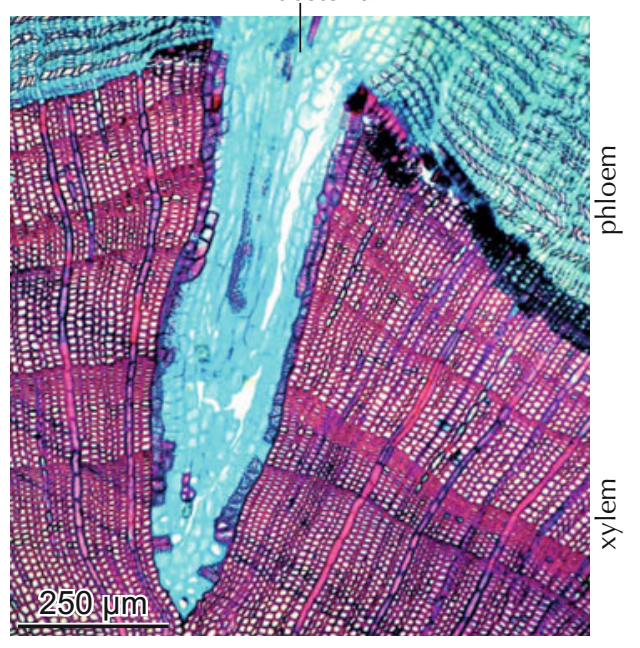

10.178 Microscopic aspect of a haustorium of Phoradendron sp. in the stem of Juniperus sp. Callus tissues are absent. 


\subsection{Resin and gum ducts}

Resin ducts are part of the defense system of some plants (see also Chapter 4.12), and secrete resin and gums in the living parts of roots, stems, twigs and needles. Resin canals are axially and radially linked and form a network. The occurrence and distribution of resin ducts in conifers is primarily related to taxonomy. In some genera, e.g. Pinus and Picea, resin ducts occur in the bark and the xylem. In other species, resin ducts occur only in the bark, and in some they are completely absent.
The frequency of resin ducts in conifers is related to stress, and increases with higher stress levels. If stress occurs mechanically in the cambial region, e.g. after woodpecker attacks, or through intensive fungal infections or insect infestations, tangential rows of ducts in the xylem and phloem make intra-annual dating of the event possible. If stresses occur in the crown, e.g. by defoliators, the frequency of resin ducts is increased, but the diffuse distribution of ducts make intra-annual dating impossible. Tangential rows of resin ducts after wounding indicate sporadic long-term reactions.

\section{Conifers with resin ducts}

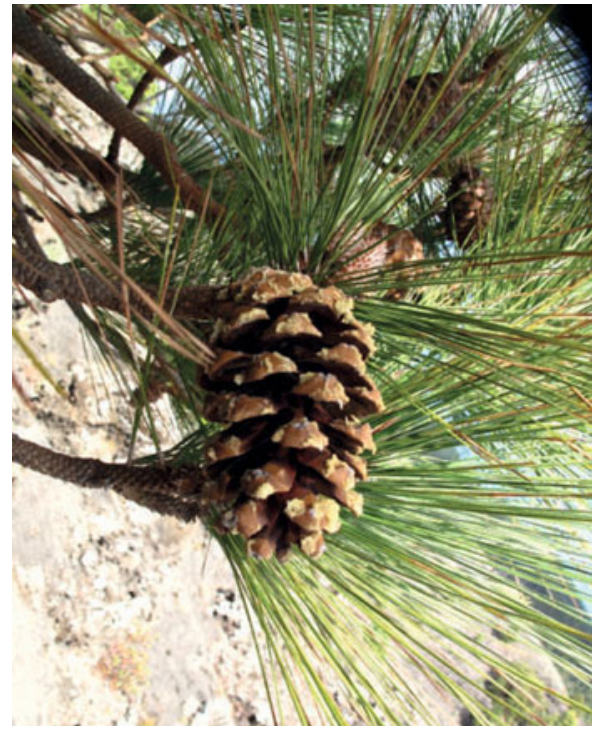

10.179 Pinus canariensis with many resin ducts.

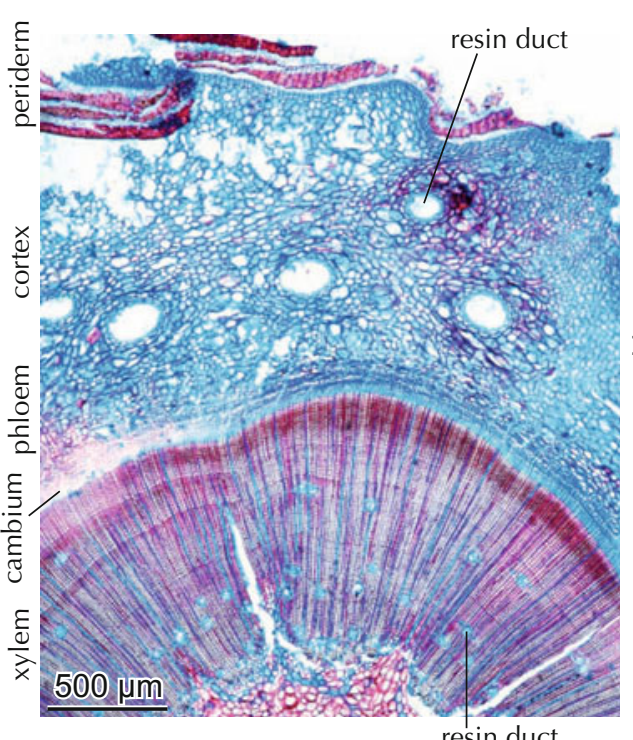

resin duct

10.182 Pinus ponderosa with resin ducts in the xylem and the cortex.

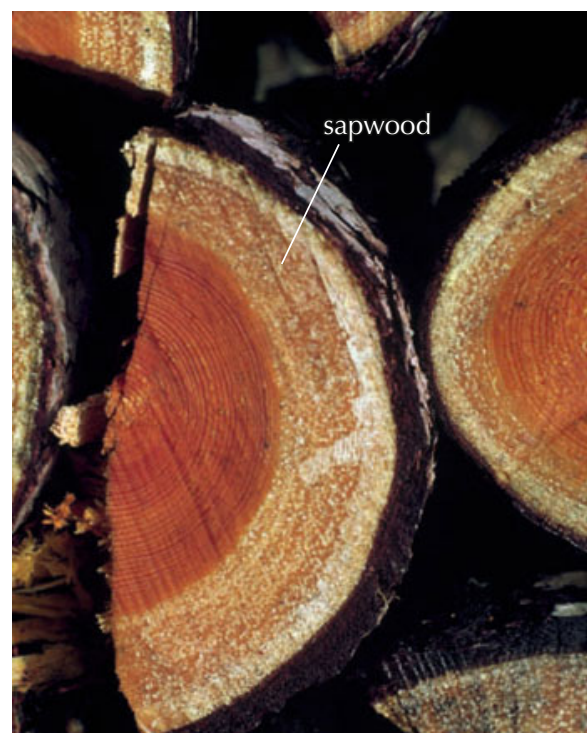

10.180 Sapwood of Pinus sylvestris with living resin ducts.

\section{Taxonomic significance of resin ducts}

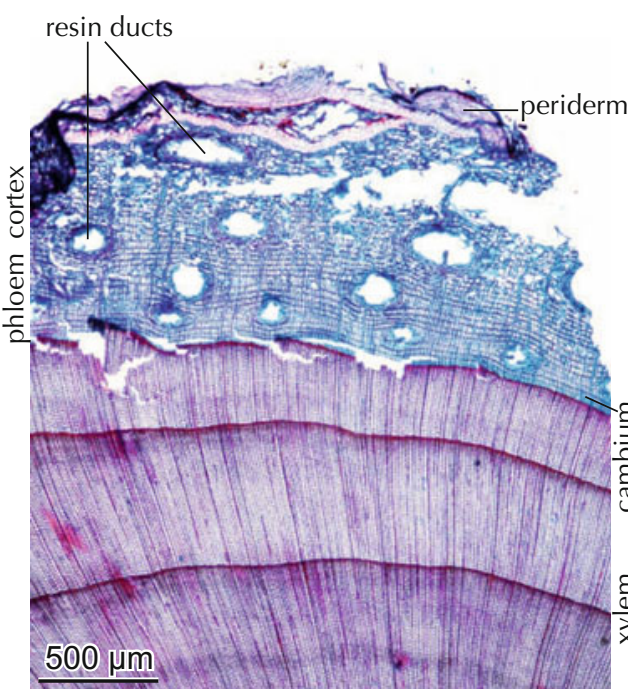

10.183 Microbiota decussata with resin ducts in the phloem and the cortex, but no ducts in the xylem.

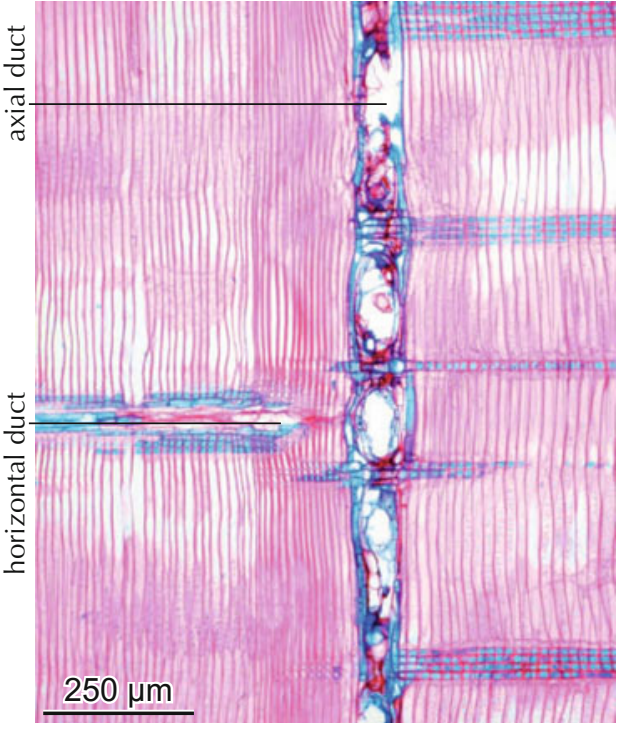

10.181 Longitudinal section of the intraxylary network of resin ducts in Pinus sylvestris.

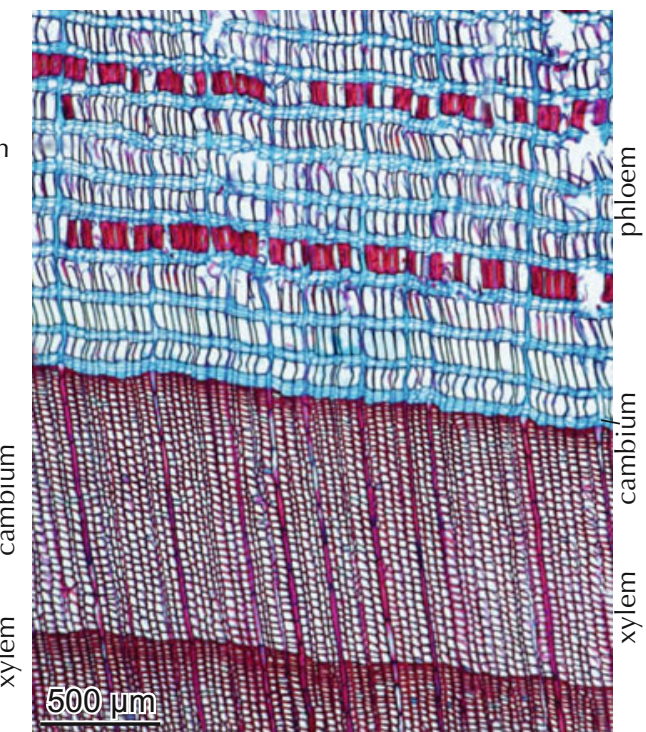

10.184 Pilgerodendron uviferum without resin ducts. 


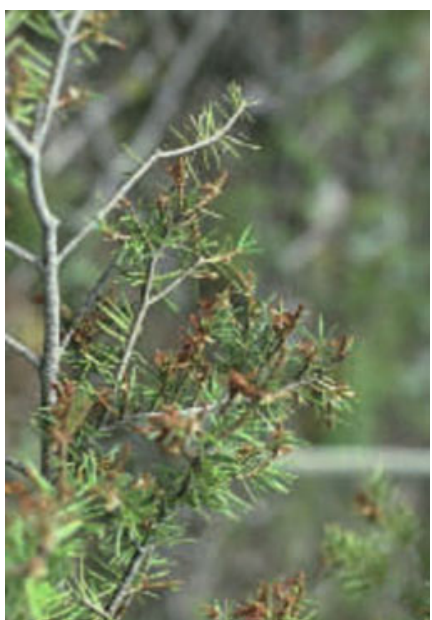

10.185 Spruce bud worm (Choristoneura fumiferana) infestation on Picea engelmannii.

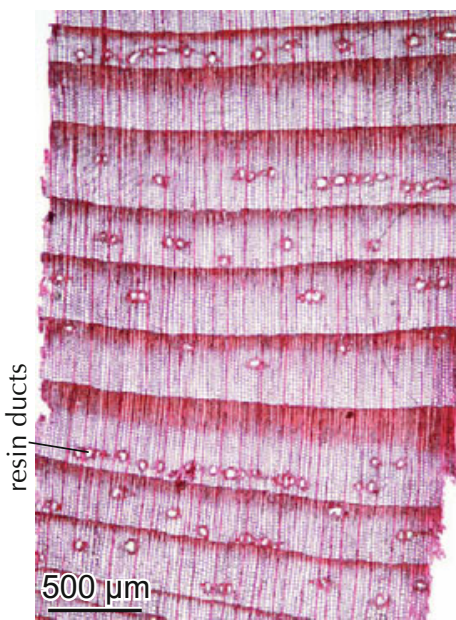

10.186 The frequency of resin ducts is extremely high for Pseudotsuga menziesii.

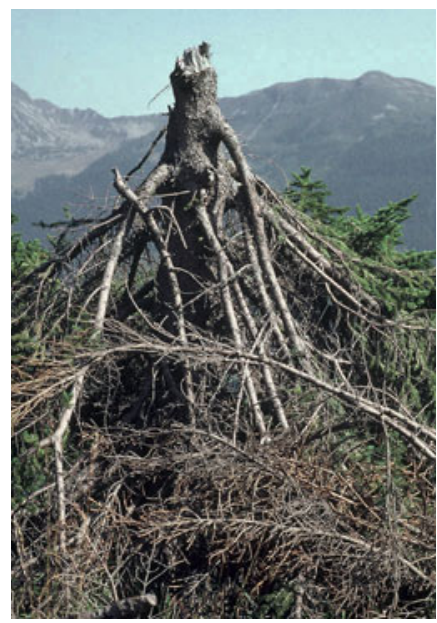

10.187 Windbreak on Picea abies.

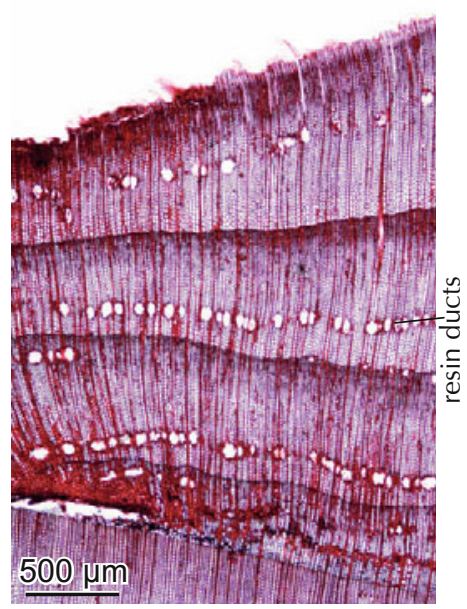

10.188 Scar on Picea abies with periodic formation of traumatic resin ducts.

Short-term reaction to woodpecker attacks

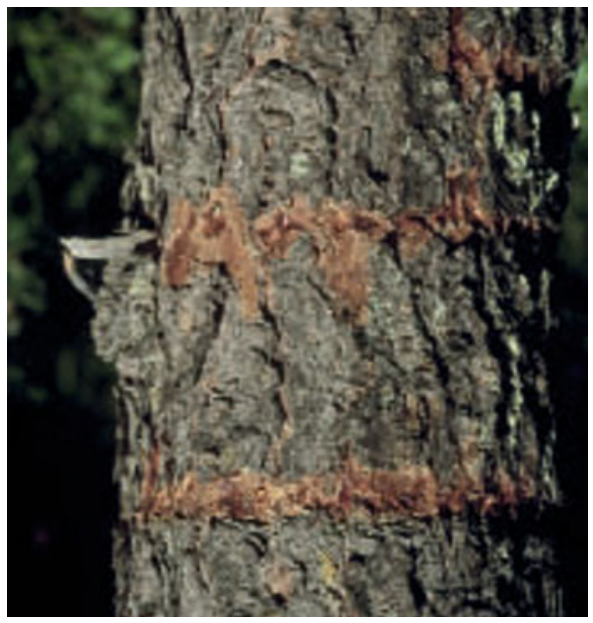

10.189 Woodpecker scars on a stem of Pinus mugo.

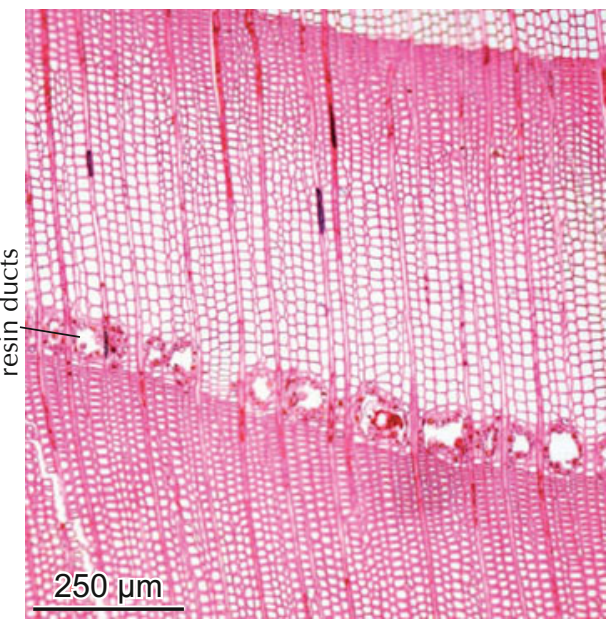

10.190 Traumatic resin ducts in the xylem of Abies alba. The damage occurred in the dormant period or just at the beginning of the growing season. Firs do not normally form resin ducts in the xylem.
Reactions to fungal attacks

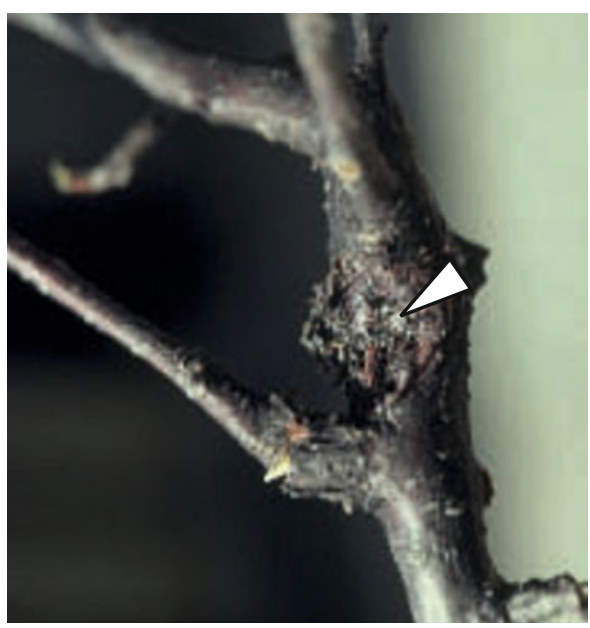

10.192 Scar caused by the fungus Monilia sp. on a twig of Prunus armeniaca. The fungus attacks the cambium, initiating scars and dieback of twigs.

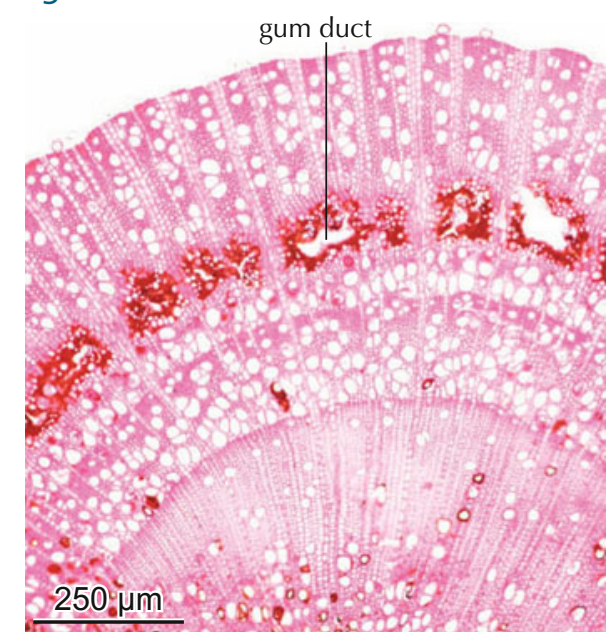

10.193 Tangential, traumatic gum ducts in the xylem of Prunus cerasus. The fungal attack occurred in early summer, just after earlywood formation.

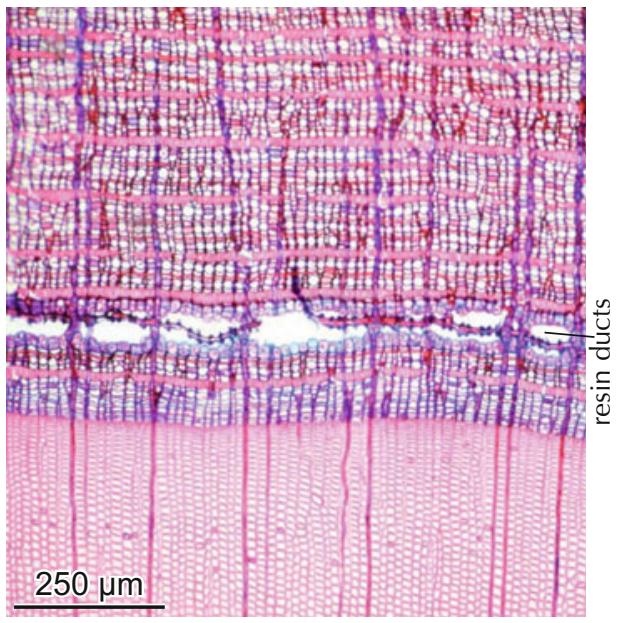

10.191 Traumatic resin ducts in the phloem of luniperus oxycedrus, caused by a bird attack.

Unknown cause

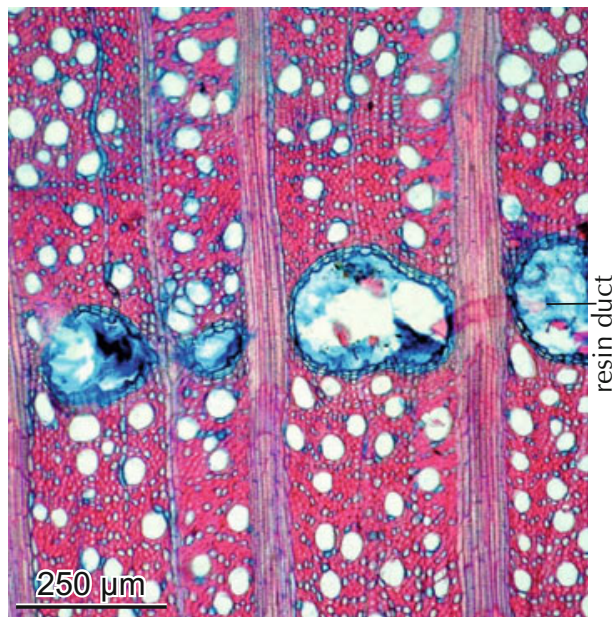

10.194 An unknown attack triggered traumatic ducts in the xylem of Elaeagnus pungens. 
Open Access This chapter is licensed under the terms of the Creative Commons Attribution 4.0 International License (http://creativecommons.org/licenses/by/4.0/), which permits use, sharing, adaptation, distribution and reproduction in any medium or format, as long as you give appropriate credit to the original author(s) and the source, provide a link to the Creative Commons license and indicate if changes were made.

The images or other third party material in this chapter are included in the chapter's Creative Commons license, unless indicated otherwise in a credit line to the material. If material is not included in the chapter's Creative Commons license and your intended use is not permitted by statutory regulation or exceeds the permitted use, you will need to obtain permission directly from the copyright holder. 